BNL 50715
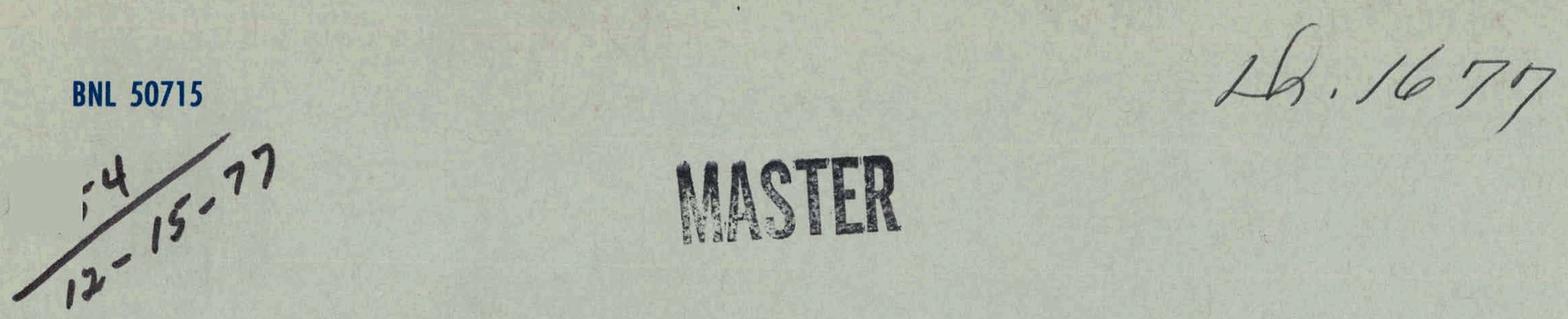

\title{
PHOTOCHEMISTRY RELEVANT TO NUCLEAR WASTE SEPARATIONS A FEASIBILITY STUDY
}

\author{
TOM GANGWER
}

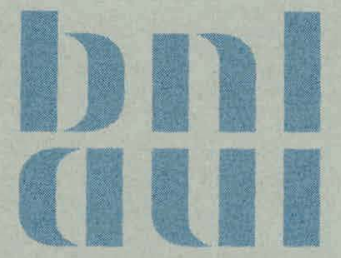

BROOKHAVEN NATIONAL LABORATORY ASSOCIATED UNIVERSITIES, INC. UNDER CONTRACT NO. EY-76-C-02-0016 WITH THE UNITED STATES DEPARTMENT OF ENERGY 


\section{DISCLAIMER}

This report was prepared as an account of work sponsored by an agency of the United States Government. Neither the United States Government nor any agency Thereof, nor any of their employees, makes any warranty, express or implied, or assumes any legal liability or responsibility for the accuracy, completeness, or usefulness of any information, apparatus, product, or process disclosed, or represents that its use would not infringe privately owned rights. Reference herein to any specific commercial product, process, or service by trade name, trademark, manufacturer, or otherwise does not necessarily constitute or imply its endorsement, recommendation, or favoring by the United States Government or any agency thereof. The views and opinions of authors expressed herein do not necessarily state or reflect those of the United States Government or any agency thereof. 


\section{DISCLAIMER}

Portions of this document may be illegible in electronic image products. Images are produced from the best available original document. 


\title{
PHOTOCHEMISTRY RELEVANT TO NUCLEAR WASTE SEPARATIONS A FEASIBILITY STUDY
}

\author{
TOM GANGWER
}

This work was funded by the National Science Foundation (NSF) and supported, in part, by the United States Department of Energy

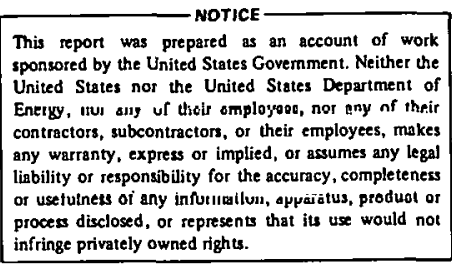

BROOKHAVEN NATIONAL LABORATORY UPTON, NEW YORK 11973 


\section{NO'I'LE}

This report was prepared as an account of work sponsored by the Uniter States Government. Neither the United States nor the United States Department of Energy (UUE), nor the National Science Foundation (NSF), nor any of their employees, nor

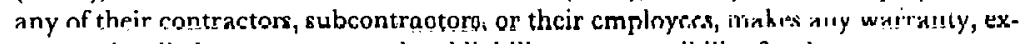
press or implied, or assumes any. legal liability or responsibility for the accuracy, completeness or usefulness of any information, apparatus, product or process disclosed, or represents that its use would not infringe privately owned rights.

Printed in the United States of $\Lambda$ mcrica

$$
\text { Avaailable from }
$$

National Technical Information Service

U.S. Department of Commerce

5285 Port Royal Road

Springfield, VA 22161

Price: Printed Copy $\$ 7.25$; Microfiche $\$ 3.00$

October 1977

240 copies 


\section{CONTENTS}

Abstract

$\begin{array}{ll}1.0 & \text { Introduction }\end{array}$

2.0 Photochemistry 1

2.1 Uranium Photochemistry 5

2.1.1 Photochemistry of the Uranyl Ion Using Alcohols 6

2.1.2 Photochemistry of the Uranyl Ion Using Carboxylic Acids

2.1.3 Photochemistry of the Uranyl Ion Using Other

Organic Solutes

2.1.4 Photochemistry of the Uranyl Ion Using Inorganic

Solutes

2.2 Neptunium Photochemistry $\quad 34$

$\begin{array}{lll}2.3 & \text { Plutonium Photochemistry } & 43\end{array}$

2.4 Fission Product Photochemistry 51

2.5 Nitric Acid Photochemistry 55

2.6 Excited State Quenching 56

2.7 Effects of Radiation on Photochemical and Thermochemical $\begin{array}{ll}\text { Yields } & 61\end{array}$

3.0 Nuclear Waste Processing $\quad 65$

3.1 Composition of Reprocessing Solutions 66

$\begin{array}{lll}3.2 & \text { Purex Chem1stry } & 69\end{array}$

$\begin{array}{lll}4.0 & \text { Specliuscopy } & 72\end{array}$

4.1 Photochemical Spectral Region. 73

4.2 Preliminary Considerations and Simplifications $\quad 74$ 
4.3 Thermochemistry Relevant to Spectroscopy

4.4 Solution Spectra of Ions Absorbing in the Photochemical $\begin{array}{ll}\text { Spectral Region } & 78\end{array}$

4.4.1 Solvent-Related Absorptions $\quad 79$

4.4.2 Solute Ion Absorptions $\quad 82$

4.5 Spectral Windows 112

4.5.1 The Uranyl Window 115

4.5.2 The Plutonium Windows $\quad 119$

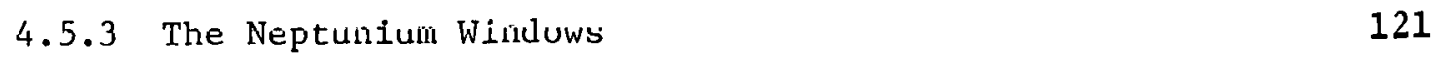

4.5.4 The Americium Window 122

4.5.5 The Curium Windows 123

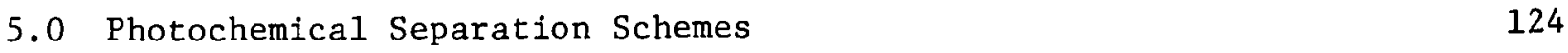

6.0 Conclusions and Future Research 131

References 133 


\section{Abstract}

The feasibility of photochemically fractionating the actinides in nuclear waste processing is evaluated on a preliminary basis. The data indicate that there are potentially useful photoredox reactions. However, there is a serious lack of data on photochemical parameters for the solution conditions existing in nuclear waste processing. The problem areas relevant to photochemical processing are identified. The experimental areas that must be investigated in order to further evaluate the photochemistry are defined. A research and development program is outlined to determine whether these photochemical reactions can be successfully modified and adapted to a functional actinide fractionating process. 


\subsection{INTRODUCTION}

The objective of the present report is to evaluate the potential utility of photochemistry in fractionating the actinides from nuclear waste processing streams -- a possibility not considered in previous nuclear waste processing schemes.

The 1iterature of photochemistry has been reviewed, and the data found relevant to the present study are presented in section 2 .

This evaluation deals with the processing of spent fuel rods from nuclear power reactors. The Purex process (see section 3), is used as a model system. The complex Purex solutions represent the extreme in photochemical limitations. It is hoped that this "worst case" approach will identify all the important photochemical parameters and lead to a critical evaluation of the feasibility of photochemically processing nuclear wastes. Consideration of photochemical applications for less complex nuclear waste processing systems should be a direct spinoff of this study. The parameters that must be characterized before the feasibility of photochemical processing can be evaluated are discussed in section 4 .

Potential photochemical processing schemes are discussed in section 5. The conclusions of this study and areas of future research are the subjects of section 6 .

\subsection{PHOTOCHEMISTRY}

The photochemistry of the actinides has been studied since the $1830^{\prime} s, 1-29$ with the bulk of the work being done on uranium ion systems. The photochemical behavior of the uranium systems serves as a basis on which the neptunium 30,31 and plutonium ${ }^{24,32-36}$ systems can be compared and correlated and, it is hoped, their photochemistry predicted. As discussed in section 2.3, one such exten- 
sion of the uranium photochemistry to the plutonium system has been experimentally successful.

In the majority of studies the exciting light source was polychromatic, with no light filtering. Note that utilization of the entire spectrum of the exciting lamp is not required to carry out a given photochemical reaction. For a given actinide ion the wavelength and spectral width of the exciting light required to produce the excited state that undergoes the desired photochemical reaction wil1 be determined by the electronic absorption spectrum of the groundto-excited reactive state transition and the absorptions of any interfering solution components. This is one of the major advantages of a separation scheme based on photochemical reactions; in a multicomponent mixture a given component can be selectively excited and will then react with a given solute to the exclusion of all other components. A condition on this photoselectivity is that any other component absorbing at the wavelength of interest should not undergo interfering photochemistry. Another is that any interfering absorption should not be strong enough to prevent significant excitation of the desired actinide. This problem is nontrivial for the Purex solutions and 1s discussed In some deta11 in section 4.

Since the rates and yields for the photochemical reactions are a function of several solution parameters, such as $\mathrm{pH}$, light intensity, and solution composition, the data in the tables and figures presented below are useful only for rough, relative comparisons.. Only the general trends in rate or yield for a given change in reaction conditions are of value because the photochemistry presented covers a diverse range of solution parameters.

Because the solution conditions found in the Purex process are not duplicated in the literature, the photochemistry of the actinides under Purex 
process conditions must be studied to determine their photochemical behavior. The main point of the following results is that the existing literature does suggest that certain photochemical redox reactions may be of value in the separation of the actinides and should be studied further.

The photochemistry of metal complexes can be divided into three general categories: photosubstitution, photoredox, and photosensitization reactions. Excitation of a ligand-field electronic state of a heavy metal ion tends to give heterolytic photosubstitution reactions in which a species in solution replaces a ligand in the metal complex coordination sphere. Charge-transfer excited states in which the electron is transferred to orbitals on the metal tend to give redox decomposition in which the metal is reduced and either a ligand or a solvent is oxidized. Excitation of charge-transfer states in which the electron is transferred to solvent-related orbitals tends to give oxidation of the metal or complex as a unit, accompanied by either reduction of the solvent or production of a solvated electron. ${ }^{37,38}$ The photosensitization process involves transfer of the excited metal complex energy to a solute which subsequently undergoes decomposition.

The actinide photochemistry will be covered first (sections 2.1 to 2.3). The actinide photochemistry systems display both photoredox and photosensitization reactions. Photosensitization chemistry is not of interest here since it does not lead to any net change in the metal complex. The chemical processes of concern here are the redox reactions that an actinide ion undergoes following its electronic excitation by light, hv:

$$
\mathrm{A}^{\mathrm{n}+} \stackrel{\mathrm{h \nu}}{\longrightarrow}\left(\mathrm{A}^{\mathrm{n+}}\right)^{*},
$$




$$
\left(\mathrm{A}^{\mathrm{n}+}\right)^{*}+\mathrm{R} \longrightarrow \mathrm{A}^{\mathrm{m}+}+\text { products, }
$$

where $\mathrm{A}^{\mathrm{n}+}$ represents a particular actinide valence state, $\left(\mathrm{A}^{\mathrm{n}+}\right)^{*}$ is the electronically excited actinide ion, and $\mathrm{R}$ is a solute that undergoes a photoredox reaction with $\left(\mathrm{A}^{\mathrm{n}+}\right)^{*}$ to form $A$ in a different valence state $A^{\mathrm{m}+}$ and photochemical products. The parameter used to specify the fraction of excited molecules undergoing a given photochemical process is the quantum yield, $\phi$. In terms of the above reaction scheme the photochemical quantum yield can be defined as

$$
\phi=\frac{\text { Number of mulecules of } A^{\text {ilt }} \text { fonmed }}{\text { Number of excited molecules }\left(A^{n+}\right)^{*} \text { formed }} .
$$

The fission product ions show all three photochemical processes. $37-42$ The general photochemistry of the fission product photoredox and photosubstitution reactions is discussed in section 2.4 .

The photodecomposition of the nitrate ion in aqueous nitric acid solutions is presented in section 2.5. The nitrite ion photogenerated in such systems offers a potentially useful photochemical source of this reductant, which is required in the Purex process. ${ }^{43-50}$

The excited actinide ion $\left(\mathrm{A}^{\mathrm{n}}\right)^{*}$ can undergo a number of processes that compete with the desired photochemical step. These processes can be classified as radiative (e.g., fluorescence, phosphorescence) or nonradiative (e.g., chemistry, quenching, internal conversion, intersystem crossing). The main competitor for the actinide photochemistry is the quenching of the excited ion $\left(A^{n+}\right)^{*}$, which leads to no net chemical change in $A^{n+}$. The extent to which the $\left(A^{n+}\right)^{*}$ species undergoes quenching will have a directly affect the photochemical yields. 
A discussion of actinide excited-state quenching and its role in evaluating possible photochemical separation schemes $21,25-29,51$ is given in section 2.6.

Section 2.7 , is a discussion of the effect of radiation-produced excited states and radiation-initiated thermochemistry on product yields. $52-58$

\subsection{Uranium Photochemistry}

Although the literature on uranium photochemistry is extensive, ${ }^{1-29}$ most of the data are 15 to 20 years old and contain difficulties and contradictions that call for new studies. One source of problems in the early studies was the failure to regulate the oxygen content of the solutions. Despite these limitations, there is sufficient evidence in several photoredox reaction systems to indicate that potentially useful photochemical reactions for separation of the actinides exist. The uranium reactions should be studied and utilized as model systems, since the photochemical data for these reactions are much more extensive than those for the other actinides and are experimentally much easier to handle (i.e., no radiation hazard).

For present purposes the known photochemical reactions are classified according to type of reactive solute added. The four general types of solute that undergo photochemical redox reactions with excited uranium complexes in aqueous solutions are alcohols, carboxylic acids, miscellaneous organics, and miscellaneous inorganics. At present the literature does not contain sufficient data to determine whether differences in uranyl photochemistry occur for a given solute in various mineral acid solutions. Similarly, the influence of complexation on the photochemistry of the uranium ions by various ions has not been sufficiently studied. These two areas should be experimentally investigated to determine optimum solution conditons for efficient photochemical partitioning. The solution conditions are discussed in general in terms of acidity. 
Uranium photochemistry is covered extensively in two reviews. ${ }^{1,2}$ Unless noted otherwise, the chemistry discussed below was obtained from literature cited in these reviews and will therefore not be specifically referenced.

In the majority of the studies reported, the photochemical reaction mixtures were checked for thermochemical reactivity by placing the mixtures in the dark for several days. Results indicated that thermochemical complications were either minimal or nonexistent for these photolabile mixtures.

2.1.1 Photochemistry of the Uranyl Ion Using Alcohols. In acid solution the excitation of the uranyl ion in the presence of alcohols leads to the photoreduction

$$
\mathrm{U}(\mathrm{VI}) \underset{\mathrm{RCH}_{2} \mathrm{OH} / \mathrm{H}^{+}}{\rightarrow} \mathrm{U(IV)}
$$

Reaction 1)

where $h \nu$ is generally the entire spectrum of the excitation source. The rate of deexcitation of the uranyl fluorescing species by alcohol was found to correlate with the U(IV) quantum yield. This collisional deexcitation process was thus found to be a photochemical reduction. The photoreduction of U(VI) to $U(I V)$ is thought to proceed through the unstable $U(V)$ oxidation state in which $\mathrm{U}(\mathrm{IV})$ is generated from the disproportionation of $U(V)$. The polarity of the substituent on the alcohol was found to be more important in determining the rate of photoreduction than steric effects, with primary attack occurring at the carbonhydrogen bond of the hydroxylated carbon. Table 2.1 gives some photoreduction rate constants for various uranyl-alcohol systems determined in a laser flash photolysis study. ${ }^{2}$

I'he methanol photoreduction reaction has been reported in acid $(\mathrm{pH}=1)$ solution to be 
Table 2.1

Absolute Rate Constants and Isotope Effects for the Interaction Between Electronically Excited $\mathrm{UO}_{2}{ }^{2+}$ and Alcohols Measured by Laser Flash Photolysis (From Burrows and Kemp ${ }^{2}$ )

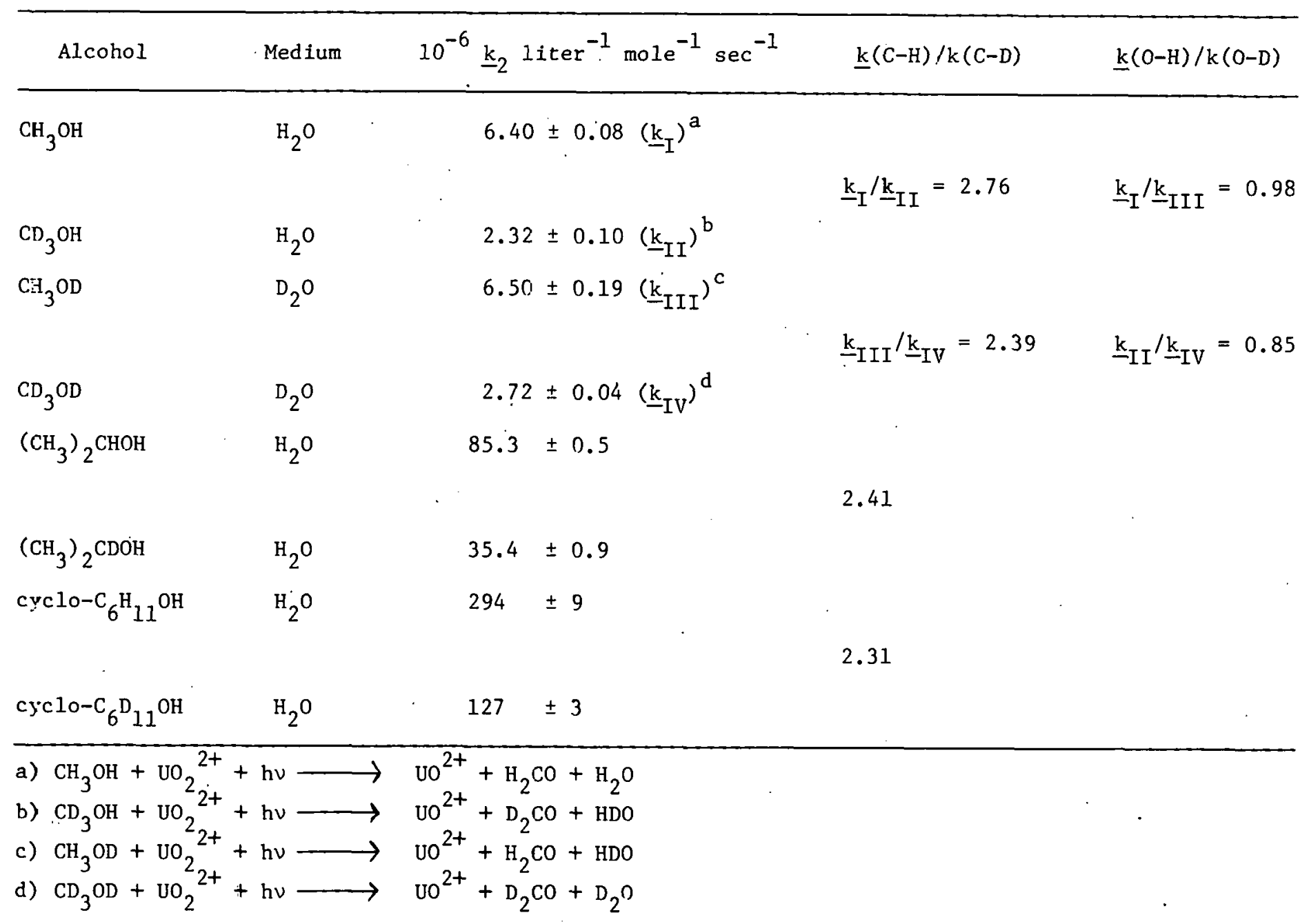




$$
\mathrm{UO}_{2}{ }^{2+}+\mathrm{CH}_{3} \mathrm{OH} \underset{\mathrm{HClO}_{4}}{\longrightarrow} \mathrm{UO}^{2+}+\mathrm{H}_{2} \mathrm{CO}+\mathrm{H}_{2} \mathrm{O}, \text { (Reaction 2) }
$$

where hv is illumination of $\lambda=253.7 \mathrm{~nm}$. The yield of $\mathrm{UO}^{2+}$ was found to increase following excitation, as shown in Figure 2.1, and was attributed to the disproportionation of $\mathrm{UO}^{+}$.

The most extensively studied alcohol system is ethanol. One proposed reaction ${ }^{1}$ is

$$
\mathrm{UO}_{2}^{2+}+\mathrm{CH}_{3} \mathrm{CH}_{2} \mathrm{OH} \stackrel{\text { hv }}{\longrightarrow} \mathrm{UO}^{2+}+\mathrm{CH}_{3} \mathrm{CHO}+\mathrm{H}_{2} \mathrm{O}, \quad \text { (Reaction 3) }
$$

where hv is illumination at one of three wavelengths, 366,406 , or $436 \mathrm{~nm}$. The large yields of aldehyde in these studies were interpreted as evidence for a chain mechanism but further work on this system is needed. In sulfuric acid solution the acid-alcohol photochemical precipitation reaction ${ }^{4-6}$

$$
\mathrm{UO}_{2}{ }^{2+}+\mathrm{CH}_{3} \mathrm{CH}_{2} \mathrm{OH}+\mathrm{SO}_{4}^{2-} \frac{\text { Sunlight }}{\mathrm{H}_{2} \mathrm{SO}_{4} / \mathrm{CH}_{3} \mathrm{CH}_{2} \mathrm{OH} / \mathrm{HCOOH}} \longrightarrow \mathrm{UOSO}_{4} \downarrow+\mathrm{CH}_{3} \mathrm{CHO}+\mathrm{H}_{2} \mathrm{O}
$$

(Reaction 4)

was used to quantitatively separate uranium from aluminum and vanadium. ${ }^{4}$ Similarly, the uranous ion was precipitated as the formate, ${ }^{8}, 8$ acetate, 9 fluoride, ${ }^{10-13}$ carbonate, ${ }^{14}$ succinate, ${ }^{15}$ and tartrate $^{15}$ following photochemical reduction by sunlight of the uranyl ion using ethanol in the presence of the corresponding acids.

In the processing of spent fuel rods from nuclear reactors, the separation of the lanthanides from the actinides is difficult because of their very similar chemical properties. Important results bearing directly on this 


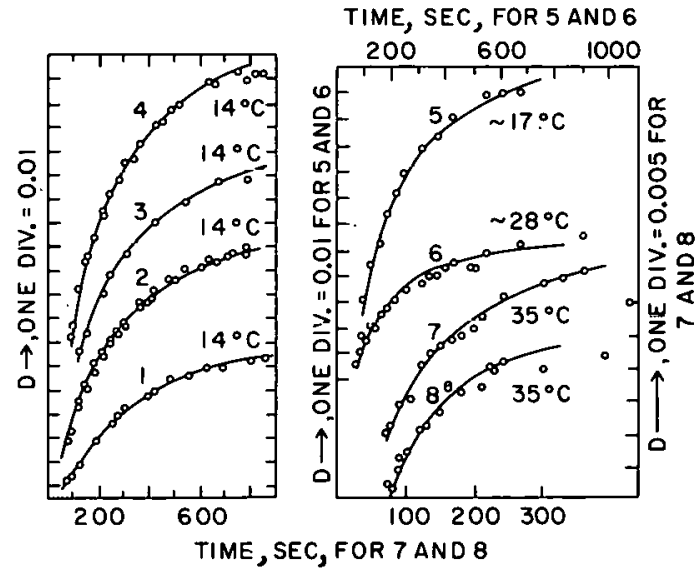

Figure 2.1. Transient increase in optical density, $\underline{D}$, at the absorption peak $\left(2650 \mathrm{~cm}^{-1}\right)$ of $\mathrm{U}^{4+}$ folwing illumination $(253.7 \mathrm{~nm})$ of aqueous solutions $\left[0.01 \mathrm{M} \mathrm{UO}_{2}\left(\mathrm{ClO}_{4}\right)_{2}, 0.2 \mathrm{M} \mathrm{MeOH}\right]$ buffered with $\mathrm{HClO}_{4}$ to $\mathrm{pH} \overline{1} .03 \pm 0.02$ and brought to ionic strength of unity with $\mathrm{NaClO}_{4}$. The absorption path was $10 \mathrm{~cm}$. The time origin was the end of the actinic 1llumination. The points are experimental, the lines, theoretical. (From Rabinowitch and Belford.1) 
lanthanide-actinide separation problem have been reported ${ }^{6,13,1.6}$ for the photochemical precipitation of uranium in the presence of various ions. Separation of uranium from a solution containing $\mathrm{La}^{3+}$ or $\mathrm{Ce}^{3+}$ via the acid-alcohol photochemical precipitation reaction

$$
\frac{\mathrm{La}(\mathrm{III})_{\mathrm{aq}}}{\mathrm{Ce}(\mathrm{III})_{\mathrm{aq}}}+\mathrm{U}(\mathrm{VI})_{\mathrm{aq}} \frac{\mathrm{Sunlight}}{\mathrm{CH}_{3} \mathrm{CH}_{2} \mathrm{OH} / \mathrm{HCOOH} / \mathrm{H}_{2} \mathrm{SO}_{4}}>\mathrm{UOSO}_{4} \downarrow+\frac{\mathrm{La}(\mathrm{III})_{\mathrm{aq}}}{\mathrm{Ce}(\mathrm{III})_{\mathrm{aq}}}
$$

(Reaction 5)

resulted in quantitative prec1pitalion of 99.1 to $99.8 \%$ of the uranium as UOSO $_{4}$ with purities of 99.4 to $99.9 \%$ for $\mathrm{pH}=2$ to 2.5 acid solutions. 16 A second study reported that the separation of uranium from thorium, zirconium, and manganese was effected by photochemical precipitation of uranous oxysulphate with yields of 92,95 , and $89 \%$ and purities of 97,99 , and $99 \%$, respectively. ${ }^{6}$ The photolytic precipitation of uranous tetrafluoride in the presence of aluminum or a mixture of thorium, cerium, and lanthanum gave $\sim 100 \%$ pure uranium precipitate with yields of $99 \%$ r Another important result relevant to the use of photoreduction to partition the actinides is the photochemical procedure used to quantitatively analyze tor uranium. 17 As sliown in Table 2.2, determination of U(VI) at trace levels (20 to $7 \times 10^{-6}$ mole/liter) was achieved by first reducing the uranyl ion via the isopropanol photochemical reaction

$$
\mathrm{U}(\mathrm{VI}) \underset{5 \underline{\mathrm{M}}\left(\mathrm{CH}_{3}\right)_{2} \mathrm{CHOH} / 1 \stackrel{\mathrm{N}}{\mathrm{H}} \mathrm{SO}_{4}}{\longrightarrow} \mathrm{U}(\mathrm{IV}), \quad \text { (Reaction 6) }
$$


Table 2.2

Results of Quantitative Photolytical Analysis of Uranium Solutions (From Riggs ${ }^{17}$ )

\begin{tabular}{|c|c|}
\hline Uranium(VI) & concentration, $\mu \mathrm{g} / \mathrm{ml}$ \\
\hline Added & Found \\
\hline 20.00 & 19.80 \\
\hline 16.00 & $16.14^{\mathrm{a}}$ \\
\hline 12.00 & 12.07 \\
\hline 8.00 & 8.02 \\
\hline 4.00 & 4.46 \\
\hline 2.00 & 2.11 \\
\hline
\end{tabular}

average of 4 determinations. 
where hv is the full spectrum of a medium-pressure mercury lamp and air was excluded by bubbling with nitrogen. This photoreduction was found to be quantitative and allowed analysis of the uranium content of micromolar solutions using a $\mathrm{Fe}(\mathrm{III}) \mathrm{Fe}(\mathrm{II})$ colorimetric procedure. The sensitivity of the U(VI) photoreduction to other inorganic ions was found to be independent of the ions $\mathrm{Na}^{+}$, $\mathrm{K}^{+}, \mathrm{NH}_{4}^{+}, \mathrm{Ca}^{2+}, \mathrm{Al}^{3+}, \mathrm{Sr}^{2+}, \mathrm{F}^{-}, \mathrm{PO}_{4}{ }^{2-}$, and $\mathrm{ClO}_{4}^{-}$, whose concentrations are in large excess of the uranyl ion, and independent of the ions $\mathrm{Ti}^{4+}, \mathrm{Mo}^{6+}, \mathrm{w}^{6+}$, $\mathrm{As}^{3+}, \mathrm{Cu}^{2+}, \mathrm{Cl}^{-}, \mathrm{NO}_{3}^{-}, \mathrm{Mn}^{2+}$, and $\mathrm{Ni}^{2+}$, whose concentrations are at levels comparable with that of the uranyl ion. This quantitative photoreduction of the uranyl ion in the presence of other inorganic ions suggests that it may be possible to use photochemistry in the partitioning of trace levels of the actinides. The limiting parameter may be extraction efficiencies and/or nonselective excited-state generation by ionizing radiation.

Recent work on the photoreduction of the uranyl ion using ethanol clarifies the reaction mechanism, establishes kinetics, and provides quantum yields for the free uranyl ion in perchloric acid solution and the sulfate complexed uranyl ion in sulfuric acid solution. In aqueous sulfuric acid the complexed uranyl ion undergoes the photochemical reaction 18,19

$$
\mathrm{UO}_{2}^{2-\mathrm{-}}+\mathrm{CH}_{3} \mathrm{CH}_{2} \mathrm{UH} \stackrel{\mathrm{hv}}{\longrightarrow} \mathrm{UO}^{2+}+\mathrm{CH}_{3} \mathrm{CHO}+\mathrm{H}_{2} \mathrm{O}, \quad \text { (Reaction 7) }
$$

where $h \nu$ is one of the argon ion laser lines 472.7, 476.5,488.0, 496.5, 501.7, and $514.5 \mathrm{~nm}$, or the helium neon laser line $632.8 \mathrm{~nm}$. As shown in Figure. 2.2, the quantum yield $(\phi)$ for $\mathrm{UO}^{2+}$ generation reaches a plateau, for high ethanol concentrations in $3 \underline{\mathrm{M} \mathrm{H}}_{2} \mathrm{SO}_{4}$, at a value of $\sim 0.6$. The $\phi\left(\mathrm{UO}^{2+}\right)$ is dependent on the complexing by sulfate ion and/or acidity, as shown in Figure 2.3. As shown 


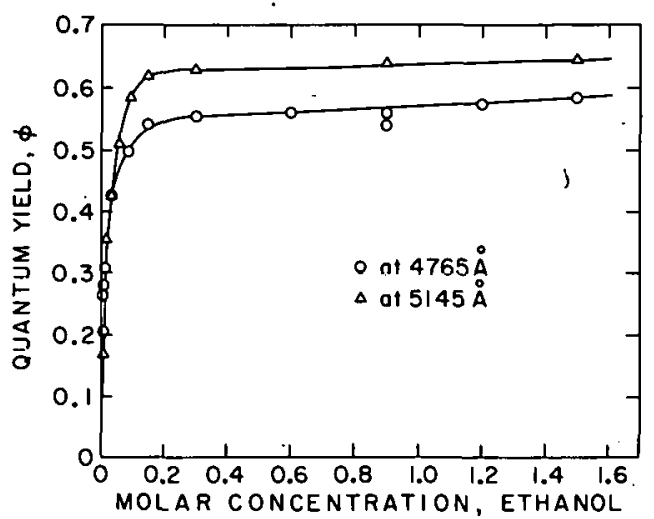

Figure 2.2. Changes in the $\mathrm{UO}_{2}{ }^{2+}$ quantum yield $\phi$ with the concentration of ethanol at two argon laser wavelengths. Temperature, $25^{\circ} \mathrm{C}$. (From Bell and Buxton.18)

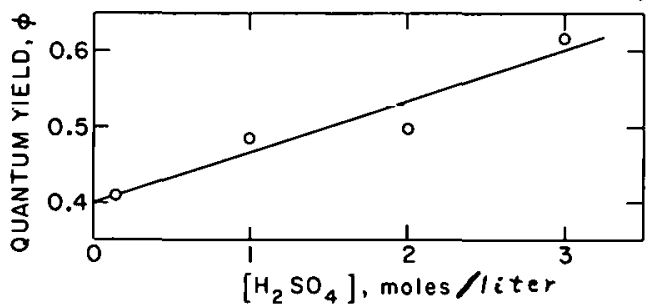

Figure 2.3. Quantum yijeld $\phi$ vs, the concentration of $\mathrm{H}_{2} \mathrm{SO}_{4}$ for the 4765-A argon laser photoreduction of $\mathrm{UO}_{2}{ }^{2+}$ with ethanol. [UO $\left.{ }^{2+}\right]=0.00686, \mathrm{I}_{\mathrm{O}}=200$ $\mathrm{mW},[$ ethanol] $=1.5$. Least-squares $f$ it gave a slope of 0.0656 and an intercept of 0.4013. (From Bel1 and Bux(un. ${ }^{18}$ ) 
in Table $2.3, \phi\left(\mathrm{UO}^{2+}\right)$ is roughly constant at 0.67 over the argon excitation wavelengths. For He-Ne excitation at $332.8 \mathrm{~nm}$, where there is essentially no $\mathrm{UO}_{2}{ }^{2+}$ absorption, a value of $\phi\left(\mathrm{UO}^{2+}\right) \sim 0.5$ is attributed to excitation of water complexed with uranyl ion leading to the photoreduction. A rate constant for photoreaction of excited $\mathrm{UO}_{2}{ }^{2+}$ ions with ethanol has been reported ${ }^{21}$ to be $4.2 \times 10^{7} \underline{\mathrm{M}}^{-1} \mathrm{sec}^{-1}$.

A slow thermochemical reduction (i.e., dark reaction) of the uranyl ion by ethanol does occur. This thermal reaction has a small equilibrium quotient of $10^{-7}$ at $25^{\circ} \mathrm{C}$ and an activation energy of $10.2 \mathrm{kcal} / \mathrm{mole} .{ }^{19}$ Since the uranyl ion absorption spectrum is a function of temperature and ion concentration, $\phi\left(\mathrm{UO}^{2+}\right)$ will vary with these solution conditions, as shown in Figure 2.4.

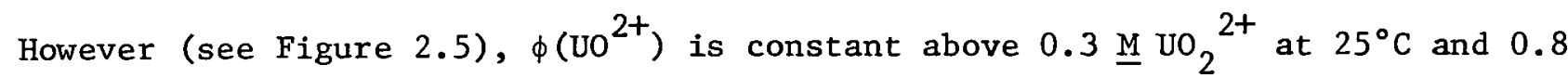
$\underline{\mathrm{M}} \mathrm{UO}_{2}{ }^{2+}$ at $49^{\circ}$ to $87^{\circ} \mathrm{C}$, with a value of $\sim 0.70$ to $\sim 0.75$.

The mechanism proposed in most studies for the uranyl photochemical reduction involves going through the $U(V)$ oxidation state which disproportionates

$$
\begin{gathered}
U(V I) \frac{h v}{\text { reductant }} \longrightarrow U(V), \\
2 U(V) \longrightarrow U(I V)+U(V I) .
\end{gathered}
$$

(Reaction 8)

(Reaction 9)

The maximum quantum yiéld for this mechanism, if only excited U(VI) undergoes photochemical reaction, is 0.5 . To explain yields $>0.5$ it has been speculated that either $U(V)$ is excited and undergoes photoreduction ${ }^{19,20,26}$ or that U(VI) to $U(I V)$ conversion occurs directly without going through the intermediate $U(V)$ state. $^{1,2}$ In support of the mechanism given by reactions 8 and 9 , the $U(V)$ 
Table 2.3

Quantum Yields $\phi$ at the Ar Laser Wavelengths for the Photoreduction of $\mathrm{UO}_{2}{ }^{2+}$ by Light and Ethanol (From Bell and Buxton ${ }^{19}$ )

$\left(5 \mathrm{ml} \mathrm{vo}{ }_{2}{ }^{2+}\right.$ solution and $0.5 \mathrm{ml}$ ethanol; $1.5 \mathrm{M}$ ethanol; $3.0 \mathrm{M} \mathrm{H}_{2} \mathrm{SO}_{4} ; 25^{\circ} \mathrm{C}$ )

\begin{tabular}{|c|c|c|c|c|c|c|}
\hline $\begin{array}{l}\text { Wavelength } \\
\text { (A) }\end{array}$ & $\begin{array}{l}\text { Time } \\
(\mathrm{sec})\end{array}$ & $\begin{array}{l}\text { Beam } \\
\text { Power } \\
\text { (mW) }\end{array}$ & {$\left[\mathrm{UO}_{2}{ }^{2+}\right]$} & $\begin{array}{l}{\left[\mathrm{UO}^{2+}\right]} \\
\left(\mathrm{x} 10^{4}\right)\end{array}$ & & $\phi$ \\
\hline 4727 & 90 & 100 & 0.00666 & 3.93 & & 0.594 \\
\hline 4727 & 90 & 100 & 0.00666 & 3.93 & & 0.594 \\
\hline 4727 & 90 & 100 & 0.00667 & 3.73 & $\mathrm{Av}$ & $\begin{array}{l}0.564 \\
0.584\end{array}$ \\
\hline 4765 & 60 & 200 & 0.00664 & 4.44 & & 0.632 \\
\hline 4765 & 60 & 200 & 0.00664 & 4.33 & & 0.618 \\
\hline \multirow[t]{2}{*}{4765} & 60 & 200 & 0.00664 & 4.44 & & 0.632 \\
\hline & & & & & & 0.627 \\
\hline 4880 & 195 & 200 & 0.00667 & 3.73 & \multirow{3}{*}{ Av } & 0.577 \\
\hline 4880 & 210 & 200 & 0.00665 & 4.13 & & 0.623 \\
\hline \multirow[t]{2}{*}{4880} & 210 & 200 & 0.00666 & 3.93 & & 0.593 \\
\hline & & & & & $\mathrm{Av}$ & 0.598 \\
\hline 4965 & 600 & 200 & 0.00667 & 3.80 & \multirow[b]{4}{*}{$\mathrm{Av}$} & 0.579 \\
\hline 4965 & 600 & 200 & 0.00666 & 3.93 & & 0.560 \\
\hline \multirow[t]{2}{*}{4965} & 600 & 200 & 0.00687 & 3.83 & & 0.583 \\
\hline & & & & & & 0.574 \\
\hline 5017 & 420 & 100 & 0.136 & 5.99 & & 0.672 \\
\hline 5017 & 420 & 100 & 0.136 & 6.21 & & 0.697 \\
\hline \multirow{2}{*}{5017} & 420 & 100 & 0.136 & 6.10 & & 0.684 \\
\hline & & & & & $\mathrm{Av}$ & 0.684 \\
\hline 5145 & 600 & 200 & 0.136 & 5.64 & \multirow[b]{4}{*}{$\mathrm{Av}$} & 0.660 \\
\hline 5145 & 600 & 200 & 0.136 & 6.05 & & 0.707 \\
\hline \multirow[t]{2}{*}{5145} & 600 & 200 & 0.136 & 5.54 & & 0.648 \\
\hline & & & & & & 0.672 \\
\hline
\end{tabular}




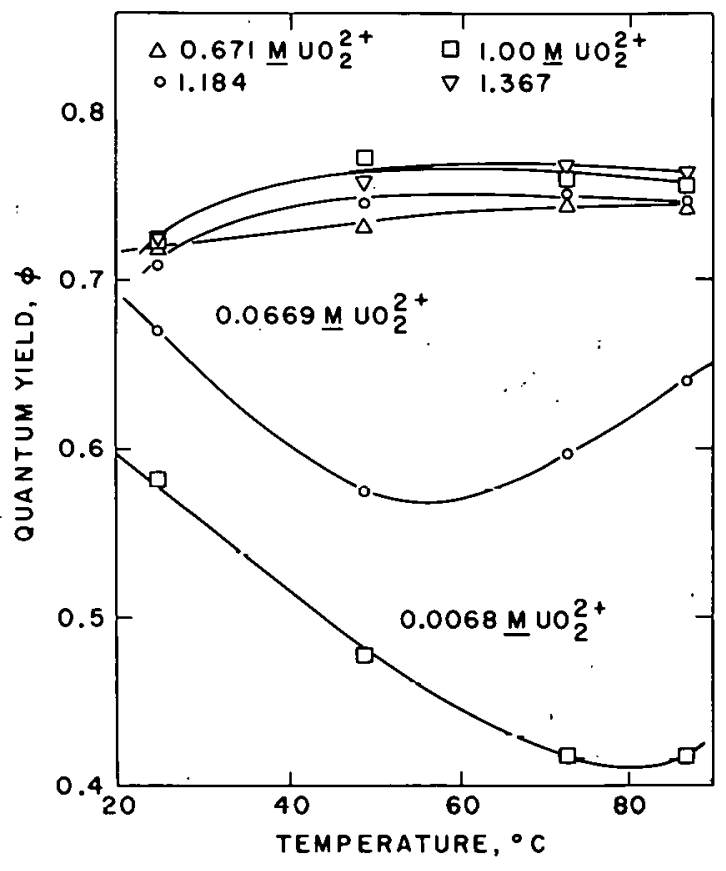

Figure 2.4. Quantum yield $\phi$ vs. temperature for the photochemical reduction of $\mathrm{UO}_{2} 2+$ to $\mathrm{U}^{4+}$. The $4765 \AA$ laser light was the excitation source for the two lowest $\mathrm{UO}_{2}{ }^{2+}$ concentrations, and the $5145 \AA$ laser light was used with the four higher $\mathrm{UO}_{2}{ }^{2+}$ concentrations. All samples at $25^{\circ} \mathrm{C}$ were $1.5 \mathrm{M}$ in ethanol. (From Bell and Buxton. ${ }^{19}$ )

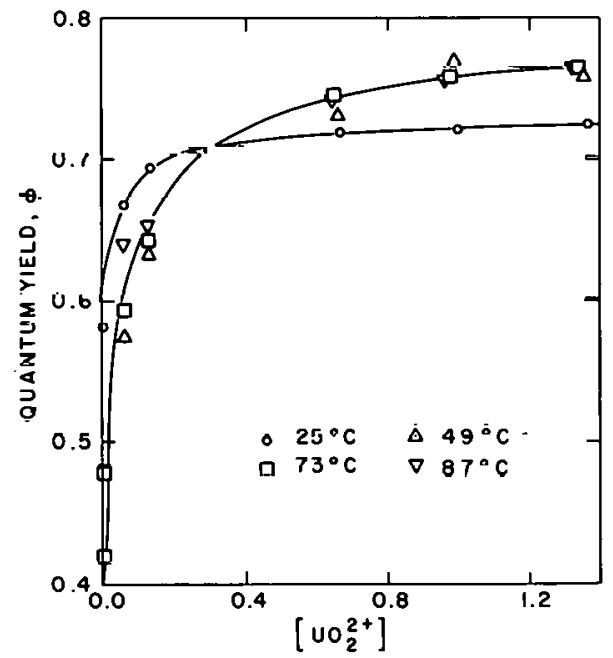

Figure 2.5. Isotherms of quantum yield $\phi$ vs. uranyl concentration. The two lines are drawn through the $25^{\circ}$ and $87^{\circ} \mathrm{C}$ data. (From Bell and Buxton.19) 
oxidation state has becn generated by photochemical 20 and electrolytic reduction of the uranyl ion in various solutions and its spectra have been recorded. From the temperature dependence of the equilibrium constant for $U(V)$ disproportionation in aqueous perchloric acid,

$$
2 \mathrm{UO}_{2}^{+}+\mathrm{HH}^{+} \rightleftharpoons \mathrm{U}^{4+}+\mathrm{UO}_{2}^{2+}+2 \mathrm{H}_{2} \mathrm{O}, \quad \text { (Reaction 10) }
$$

the thermodynamic values of $\mathrm{K}, \Delta \mathrm{F}^{0}, \Delta \mathrm{H}^{0}$ and $\Delta \mathrm{S}^{0}$ were determined to be $7 \times 10^{4}$, $-6.6 \mathrm{kcal} / \mathrm{mole},-18.6 \mathrm{kcal} / \mathrm{mole}$, and $-40 \mathrm{e.u}$, respectively. ${ }^{22}$ At 1 ow acidity $U(V)$ was found not to disproportionate significantly and could therefore be studied. Irradiation of perchloric acid solutions of uranyl ion, using the 476.5-nm line of the argon ion laser, gave quantum yields for $U(V)$ generation of essentially unity. ${ }^{20}$ To obtain optimum U(IV) concentrations in photoreduction of the uranyl ion, the acidity of the solution must be high so that the $\mathrm{U}(\mathrm{V})$ disproportionation is quantitative. Under such conditions a quantum yield of 0.6 has been measured for $\mathrm{U}^{4+}$ production via photoreduction of $\mathrm{UO}_{2}{ }^{2+}$ using ethanol (mole ratio of 1 to 10 ) in 1.8 Merchloric acid. ${ }^{20}$ Attempts to directly observe $\mathrm{UO}_{2}{ }^{+}$under these steady-state photolysis conditions were unsuccessful because of rapid disproportionation. ${ }^{20}$ Pulse photolytic techniques are required to observe $\mathrm{UO}_{2}^{+}$under such short-lived conditions and should be pursued.

Several investigations of the detailed mechanism for the photooxidation of aliphatic alcohols by uranyl ions present data that exclude complex formation prior to photolysis. ${ }^{25-28}$ l'he proposed mechanism involves collisional energy transfer from the excited uranyl ion to the alcohol molecule, followed by the rate determining $\alpha$-hydrogen abstraction step. As shown in Figure 2.6, 


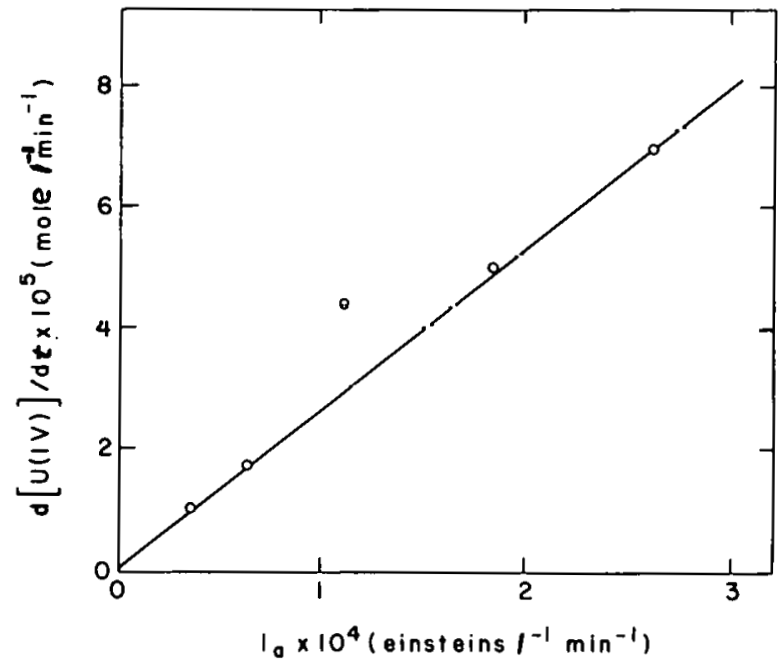

Figure 2.6. Effect of light intensity $I_{a}$ on the rale of $U(I V)$ formation $\left[\mathrm{HO}_{2}{ }^{2+}\right]=0.02 \mathrm{M},\left[\mathrm{CH}_{3} \mathrm{CH}_{2} \mathrm{OH}\right]$ $=0.21 \underline{\mathrm{M}}, \mathrm{pH}=1.0, \lambda=4047,4358 \AA$. (From Sakuraba and Matsushima. ${ }^{25}$ ) 
the rate of $U(I V)$ formation for ethanol solutions is directly proportional to the absorbed light intensity. Thus the quantum yield is independent of the absorbed light intensity. The product molar ratio $[U(\mathrm{IV})] /\left[\mathrm{CH}_{3} \mathrm{CHO}_{\text {o }}\right.$ was unity and independent of $\mathrm{pH}$ from 1.0 to 3.8. The quantum yield increases with temperature, as shown in Figure 2.7, with an apparent activation energy of 8.5 kcal/mole for ethanol and propanol.

The quantum yield $\phi$, rate parameter $\beta^{-1}$, and quenching constant $\mathrm{K}_{\mathrm{q}}$ for various alcohol systems are given in Table 2.4. $\beta^{-1}$, obtained from the slope of plots like that in Figure 2.8, is a measure of the photoreactivity. $\mathrm{K}_{\mathrm{q}}$, obtained from fluorescence Stern-Volmer data, is a measure of the rate for radiationless deactivation of the excited uranyl ion by the quenching alcohol. Since the natural lifetime $\tau_{0}$ of the excited uranyl ion in solution ${ }^{21}$ is $\sim 1.3$ $\times 10^{-6} \mathrm{sec}$, the quenching rate constant $k_{q}$, equal to $k_{q} / \tau_{0}$, ranges from $1.4 \mathrm{x}$ $10^{8}$ to $9.6 \times 10^{6} \underline{\mathrm{M}}^{-1} \mathrm{sec}^{-1}$, which is smaller than the diffusion-controlled rate constant of $\sim 10^{10} \mathrm{sec}^{-1}$. This is interpreted as indicating that the quenching process is endothermic by several kilocalories per mole.

It was suggested that, since the energetics of its quenching and photoredox processes are nearly comparable, the rate-determining step of the photoredox reaction is the same as that of the quenching reaction. 26

2.1.2 Photochemistry of the Urany1 Ion Using Carboxylic Acids. The second class of solutes showing photochemical reaction with excited uranyl ions are carboxylic acids, divided into three subclasses: monocarboxylic, dicarboxylic, and hydroxyl carboxylic. The first monocarboxylic, and one of the more promising photochemical candidates, is formic acid. It undergoes the overall reaction 


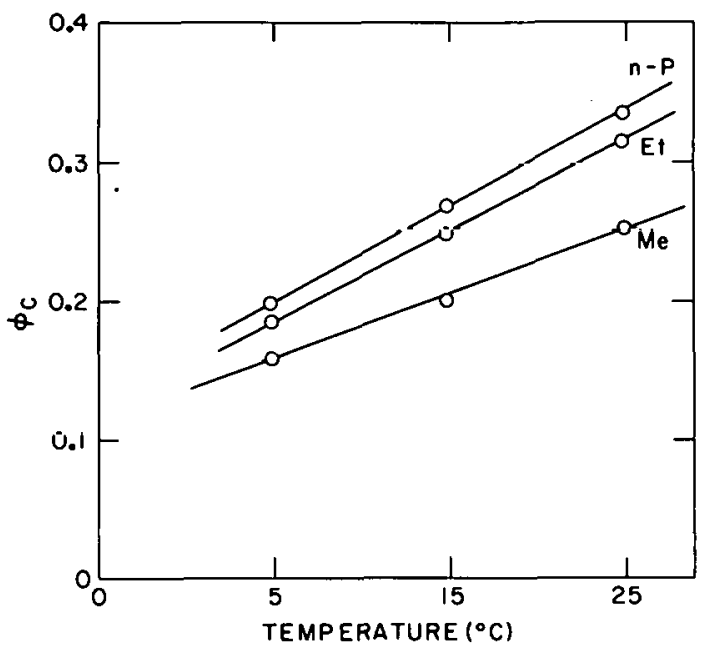

Figure 2.7. Effect of temperature on the rate of $\mathrm{U}(\mathrm{IV})$ formation, $\left[\mathrm{UO}_{2}{ }^{2+}\right]=0.02 \mathrm{M},{ }_{0}[$ alcohol $]=$ $0.2 \mathrm{M}, \mathrm{pH}=1.5, \lambda=3650$ to $3660 \AA$. The quantum yields $\phi_{c}$ were corrected for the self-quenching; $\left(\mathrm{In}_{2}^{2+}\right) *+\mathrm{Jn}_{2}{ }^{2+}+2 \mathrm{UO}_{2}{ }^{2+}$; on the assumption that the temperature dependence of the self-quenching is mainly due to that of the viscosity of the medium. Apparent activation energy, $\underline{E}$, obtained was $8.5 \mathrm{kcal} / \mathrm{mole}$ for both ethy 1 alcohol and n-propyl alcoho1. (From Sakuraka and Matsushima. ${ }^{25}$ ) 
Table 2.4

Substituent Effects of Aliphatic Alcohols

on the Rate Parameters

(From Matsushima and Sakuraba ${ }^{26}$ )

\begin{tabular}{llcr}
\hline \multicolumn{1}{c}{ Alcohol } & $\phi^{\mathrm{a}}$ & $\beta^{-1^{\mathrm{b}}}$ & $\mathrm{K}_{\mathrm{q}}^{\mathrm{c}}$ \\
\hline & & & \\
sec-Buty1 & 0.36 & 46 & 174 \\
Isopropyl & 0.35 & 35 & 113 \\
Isobuty1 & 0.36 & 47 & 138 \\
n-Butyl & 0.36 & 46 & 130 \\
E-Propy1 & 0.34 & 35 & 105 \\
Methyl & 0.31 & 27 & 12 \\
Ethylene glycol & 0.15 & 7.2 & 40 \\
\hline
\end{tabular}

${ }^{\text {a }}$ Quantum yield of the photolysis under the conditions $\left[\mathrm{UO}_{2}{ }^{2+}\right.$ ] $=0.02 \mathrm{M} ;\left[\right.$ alcohol] $=0.06 \underline{\mathrm{M}} ; \mathrm{pH} 1 ; 20^{\circ}, \lambda=$ $405^{2} \mathrm{~nm}$.

$b_{\text {The reciprocal of the slope of the } \phi^{-1} \text { vs. [alcohol] }}$ plot at $\mathrm{pH} 1,20^{\circ}\left[\mathrm{UO}_{2}{ }^{2+}\right]=0.02 \mathrm{M},[$ alcohol] $=0.005$ to $0.2 \underline{M}$.

$\mathrm{C}_{\text {The quenching constants measured under the conditions }}$ $\left[\mathrm{UO}_{2}{ }^{2+}\right]=0.02 \mathrm{M}$, (alcohol $]=0.002$ to $0.2 \mathrm{M} ; \mathrm{pH} 1 ; 20^{\circ}$ $\pm 2^{\frac{2}{\sigma}} ; \lambda($ excitation $)=405 \mathrm{~nm} ; \lambda$ (emission) $=510 \mathrm{~nm}$. 


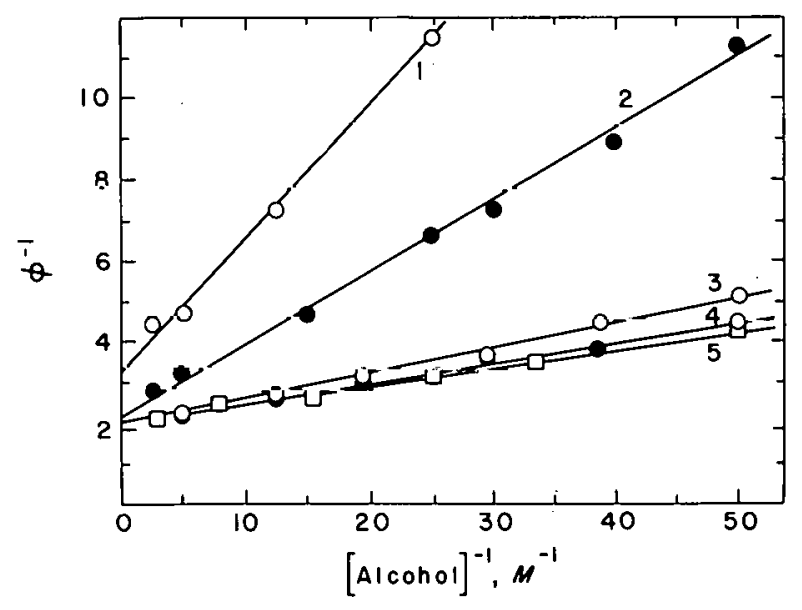

Figure 2.8. Plot of $\phi^{-1}$ as a function of [alcohol] ${ }^{-1}$ $\left[\mathrm{UO}_{2}{ }^{2+}\right]_{i}=0.02 \mathrm{M} ; \mathrm{pH} 1.0 ; 20^{\circ}$. (1) Ethylene glycol; (2) methyl alcohol; (3) ethyl alcohol; (4) n-propyl alcohol; (5) n-butyl, sec-buty $\frac{1}{2}$, and isobutyl alcohols. (From Marsishima and sakuraba. ${ }^{26}$ ) 


$$
\mathrm{UO}_{2}^{2+}+\mathrm{H}^{+}+\mathrm{HCOO}^{-} \frac{\mathrm{hv}}{\mathrm{H}_{2} \mathrm{SO}_{4} / \text { deoxygenated }} \longrightarrow \mathrm{UO}^{2+}+\mathrm{CO}_{2}+\mathrm{H}_{2} \mathrm{O} \text {. }
$$

(Reaction 11)

This reaction is irreversible and produces the ideal byproducts $\mathrm{CO}_{2}$ and $\mathrm{H}_{2} \mathrm{O}$. In the presence of excess formic acid the uranous ion precipitates. The quantum yield for this photoreduction of the uranyl ion under visible light has been reported as 0.97 . The reaction rate is inhibited by additives, as shown in Figure 2.9. In Table 2.5 numerous additives are classified according to degree of rate inhibition. The rate increases as the formic acid concentration increases and plateaus at $\sim 10 \%\left(\sim 2\right.$ M) formic acid. The rate of $\mathrm{UO}^{2+}$ formation also increases with increasing uranyl concentration; it reaches a maximum at $1.6 \underline{\mathrm{MO}}_{2}^{2+}$ and then decreases.

Acetic acid gives both photoreduction of the uranyl ion,

$$
\mathrm{UO}_{2}^{2+}+2 \mathrm{CH}_{3} \mathrm{COO}^{-}+2 \mathrm{H}^{+} \stackrel{\mathrm{hv}}{\longrightarrow} \mathrm{UO}^{2+}+\mathrm{C}_{2} \mathrm{H}_{6}+2 \mathrm{CO}_{2}+\mathrm{H}_{2} \mathrm{O},
$$

(Reaction 12)

and uranyl photosensitized decomposition,

$$
\mathrm{CH}_{3} \mathrm{COOH} \underset{\mathrm{UO}_{2}{ }^{2+}}{\stackrel{\mathrm{hv}}{\mathrm{C}}} \rightarrow \mathrm{CH}_{4}+\mathrm{CO}_{2} \text {, }
$$

(Reaction 13)

when subjected to polychromat1c light. ${ }^{1}$ It may be possible to avold reaction 13 by proper choice of solution conditions or excitation wavelength. The reaction 12 rate constant has been reported ${ }^{21}$ as $4.9 \times 10^{6} \underline{\mathrm{M}}^{-1} \mathrm{sec}^{-1}$ at $\mathrm{pH} 5$. 


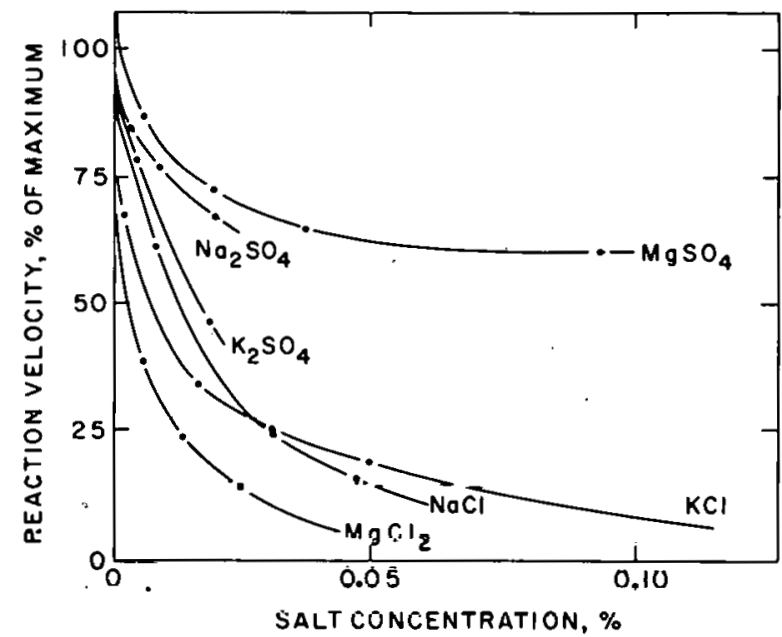

Higure 2.9. Effect of salts on the uranyl-formic acid reaction. (From Rabinowitch and Belford. ${ }^{1}$ )

Table 2.5

Inhibitors of Reaction 11

\begin{tabular}{llll}
\hline \multicolumn{1}{c}{ Strong } & Medium & Weak & No effect \\
\hline $\mathrm{Cr}_{2} \mathrm{O}_{7}^{2-}$ & $\mathrm{Ag}^{+}$ & $\mathrm{NO}_{3}^{-}$ & $\mathrm{Na}_{3} \mathrm{PO}_{4}$ \\
$\mathrm{NO}_{2}^{-}$ & $\mathrm{CN}^{-}$ & $\mathrm{Co}^{2+}$ & $\mathrm{NH}_{4} \mathrm{COOCH}_{3}$ \\
$\mathrm{Fe}^{2+}$ & $\mathrm{Hg}^{+}$ & $\mathrm{Cr}^{3+}$ & \\
$\mathrm{Cl}^{-}$ & $\mathrm{U}_{2} \mathrm{O}_{5}$ & $\mathrm{Cu}^{2+}$ & \\
$\mathrm{I}^{-}$ & $\mathrm{UO}^{2+}$ & $\mathrm{Mn}^{2+}$ & \\
Hydroquinone & $\mathrm{SO}_{4}^{2-}$ & $\mathrm{F}^{-}$ & \\
& & $\mathrm{HSO}_{3}^{-}$ \\
\hline
\end{tabular}


Addition of $\mathrm{Cl}^{-}$or $\mathrm{Hg}^{2+}$ inhibits reactions 12 and 13 , and $\mathrm{FeSO}_{4}$ or $\mathrm{HCOOH}$ prevents them from occurring.

Monochloroacetic acid photoreduces the uranyl ion with an optimum quantum yield of 20.1 . It has been estimated that the rates of excited uranyl ion self-quenching and photoreduction are approximately equal but are a factor of $\sim 10^{2}$ faster than internal deexcitation. Other monocarboxylic acids reported as showing photochemical reduction of the uranyl ion are propionic, butyric, isobutyric, valerıc, and isovaleric acid, where the products are U(IV), $\mathrm{CO}_{2}$, and hydrocarbons.

The photochemistry of the dicarboxylic acid compound uranyl oxalate has been extensively studied because of its use as an actinometer in quantum yield determinations. The use of oxalic acid as a photoreductant of uranyl ion to uranous ion would not be a straightforward process because most of the photochemical reaction is sensitized oxalate decomposition. The quantum yield for oxalate disappearance is 20.6 , but $<0.01$ of that is due to photoreduction of the uranyl ion. As shown in Figure 2.10, because of strong complexing of the uranyl ion with oxalate, significant photoreduction does not occur until > $80 \%$ of the oxalate ion has been decomposed. The yield of U(IV) increases as the acidity increases. This suggests that photoreduction takes place between free uranyl and oxalate ions. Perhaps going to a photochemical system in which the uranyl ion is complexed by a stronger ligand than the oxalate ion would result in predominance of the photoreduction reaction

$$
\mathrm{UO}_{2}^{2+}+\mathrm{C}_{2} \mathrm{O}_{4}^{2-}+2 \mathrm{H}^{+} \stackrel{\mathrm{hv}}{\longrightarrow} \mathrm{UO}^{2+}+2 \mathrm{CO}_{2}+\mathrm{H}_{2} \mathrm{O} . \quad \text { (Reaction 14) }
$$

Addition of $\mathrm{I}^{-}$increases the U(IV) yield. ${ }^{1}$ 


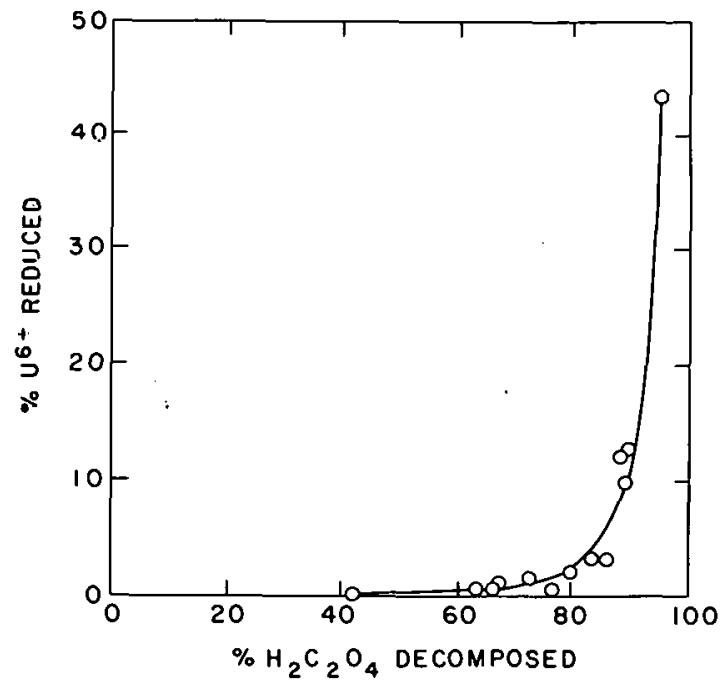

Figure 2.10. Reduction of $U(V I)$ as a function of the fraction of $\mathrm{H}_{2} \mathrm{C}_{2} \mathrm{O}_{4}$ decomposed. (From Rabinowitch and Belford. ${ }^{1}$ ) 
Succinic acid photochenical reduction of the uranyl ion gives a quantum yield of 0.06 . The kinetic data for this system indicate that the low quantum yield is due to the rate of self-quenching of excited uranyl ions being about twice as fast as the photoreduction.

In the hydroxyl subclass, the lactic acid photoreduction

$$
\begin{gathered}
\mathrm{In}_{2}{ }^{2+}+\mathrm{CH}_{3} \mathrm{CH}(\mathrm{OH}) \mathrm{COO}^{-}+\mathrm{H}^{+} \frac{\mathrm{hv}}{\mathrm{pH}=1.8 \text { to } 2.6 / \text { deoxygenated }} \\
\mathrm{UO}^{2+}+\mathrm{CH}_{3} \mathrm{CHO}+\mathrm{CO}_{2}+\mathrm{H}_{2} \mathrm{O}
\end{gathered}
$$

appears to be an excitation-wavelength-dependent chain reaction having quantum yields of 1,4 , and 6 at $\lambda=436,406$, and $366 \mathrm{~nm}$. The fact that there are quantum yields > 1 suggest a chain reaction mechanism. Such systems need further investigation. The rate of reaction was reported to slow as the reaction proceeded. At $\mathrm{pH}=1.5$, the photoreaction rate constant has been reported 21 as $9.8 \times 10^{6} \underline{\mathrm{M}}^{-1} \mathrm{sec}^{-1}$.

The mandelic acid photoreduction

$$
\mathrm{UO}_{2}{ }^{2+}+\mathrm{C}_{6} \mathrm{H}_{5} \mathrm{CH}(\mathrm{OH}) \mathrm{COO}^{-}+\mathrm{H}^{+} \underset{\mathrm{HNO}_{3}}{\stackrel{\mathrm{h \nu}}{\longrightarrow}} \mathrm{UO}^{2+}+\mathrm{C}_{6} \mathrm{H}_{5} \mathrm{CHO}+\mathrm{CO}_{2}+\mathrm{H}_{2} \mathrm{O}
$$

also gives quantum yields $\geq 1$ for excitation at 334 or $313 \mathrm{~nm} .^{1}$ Excitation at $\lambda=436,366,254 \mathrm{~nm}$ results in quantum yields of unity for solutions with high uranyl ion concentration and excess acid. An analytical expression for the rate of uranous ion generation has been reported $^{1}$ :

$$
\frac{\mathrm{d}\left[\mathrm{UO}^{2+}\right]}{\mathrm{dt}}=\frac{\mathrm{k}_{\mathrm{o}} \mathrm{I}_{\mathrm{abs}}}{1+17\left[\mathrm{In}_{2}^{2+}\right]}
$$


where $k_{0}$ is a constant at a given wavelength $\lambda$ and $I_{a b s}$ is the intensity of the light absorbed. The values of $k_{0}$ are given in Table 2.6. The dependence of $k_{0}$ on mandelic acid concentration is shown in Figure 2.11. The rate was found to be independent of $\mathrm{pH}$ in the acid region.

A third hydroxyl carboxylic acid showing quantum yields $\phi$ for uranyl photoreduction $\geq 1$ is tartaric acid, $\mathrm{HOOCCH}(\mathrm{OH}) \mathrm{CH}(\mathrm{OH}) \mathrm{COOH}$. Table 2.7 lists the yields and shows the excitation wavelength dependence. ${ }^{1}$ The rate of uranous ion production upon photolyzing at $\lambda=313,406$, or $436 \mathrm{~nm}$ was found to obey the equation $^{1}$

$$
\frac{\mathrm{d} U(I V)}{\mathrm{dt}}=2.05 \times 10^{-7} \frac{\mathrm{I}_{\mathrm{abs}[\text { tartrate }]_{\mathrm{o}}}}{0.2+[\text { tartrate] }},
$$

where $I_{a b s}$ is absorbed energy in ergs, $\left[\mathrm{UO}_{2}{ }^{2+}\right]_{\mathrm{o}}=0.125$ to $0.500 \mathrm{M}$, [tartaric acid] $=0.063$ to $0.500 \underline{\mathrm{M}}, \mathrm{T}=28^{\circ} \mathrm{C}$, and $\mathrm{pH} \sim 1$.

Glycolic acid undergoes the overall photoreduction ${ }^{1}$

$$
\mathrm{UO}_{2}^{2+}+5 \mathrm{CH}_{2}(\mathrm{OH}) \mathrm{COOH} \stackrel{\mathrm{hu}}{\rightarrow} \mathrm{U}(\mathrm{COOH})_{4}+5 \mathrm{H}_{2} \mathrm{CO}+\mathrm{CO}_{2}+2 \mathrm{H}_{2} \mathrm{O}+2 \mathrm{H}^{+} \text {, }
$$

(Reaction 16)

where little or no sensitized acid decomposition occurs. This is in contrast to some other systems where, in addition to the uranyl reduction reacilun, there is quenching of the excited uranyl fon by the additive which subsequently decom poses. Benzilic and 2-hydroxyisobutyric acid also are reported to give photochemical reduction of the uranyl ion. ${ }^{1}$

\subsubsection{Photochemistry of the Urany1 Ion Using Other Organic Solutes. In} the miscellaneous organic class the most extensively studied systems are the 


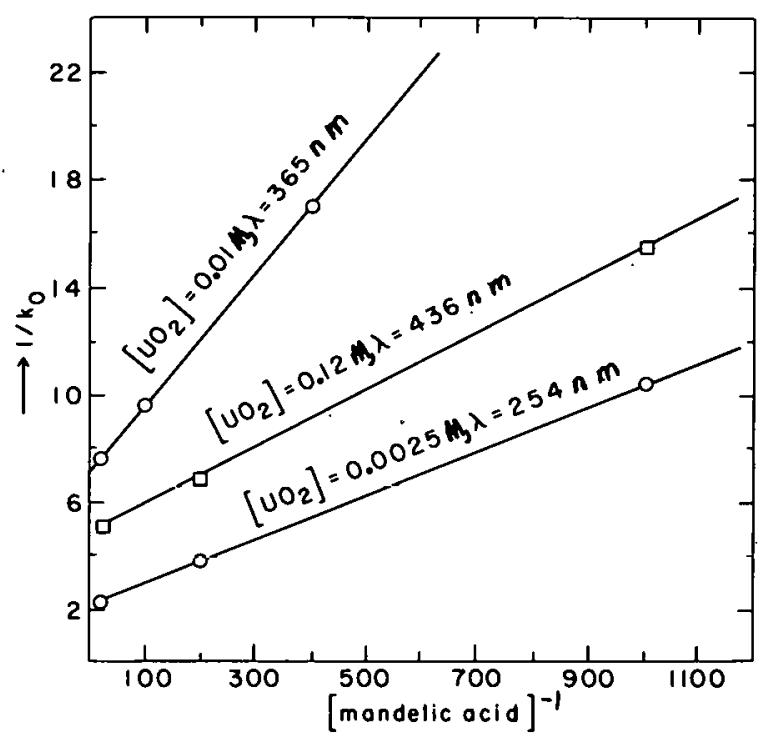

Figure 2.11. Reciprocal of the rate constant for bleaching of methylene blue $(1 / k)$ in a mixture with uranyl salt and mandelic acid, as a function of reciprocal concentration of mandelic acid. (From Rabinowitch and Belford. ${ }^{1}$ )

Table 2.6

Wavelength Dependence of $k$ (From Rabinowitch and Belford ${ }^{1}$ )

\begin{tabular}{ll}
\hline$v, \mathrm{~nm}$ & $\frac{k_{0}}{4.0} \times 10^{-3}$ \\
\hline 436 & $4.0 \times 10^{-3}$ \\
366 & $4.0 \times 10^{-3}$ \\
$334+313$ & $7.6 \times 10^{-3}$ \\
254 & $2.36 \times 2$. \\
\hline
\end{tabular}


Table 2.7

Quantum Yield of the Urany1-Tartrate Reaction

(From Rabinowitch and Belford ${ }^{1}$ )

$\left(28^{\circ} \mathrm{C}, \mathrm{pH}=0.9\right.$ to 1.2$)$

\begin{tabular}{cccccc}
\hline \multicolumn{2}{c}{ Conc. (moles/liter) } & & \multicolumn{3}{c}{$\phi$ of $U($ IV) formation at $\lambda$} \\
\cline { 5 - 6 }$[$ tartaric acid] & {$\left[\mathrm{UO}_{2}{ }^{2+}\right]$} & & $313 \mathrm{~nm}$ & $406 \mathrm{~nm}$ & $436 \mathrm{~nm}$ \\
\hline 0.50 & 0.50 & & 4.7 & 3.6 & 3.4 \\
0.25 & 0.25 & 3.6 & 2.8 & 2.6 \\
0.125 & 0.125 & 2.5 & 2.1 & 1.8 \\
\hline
\end{tabular}


carbohydrate photoreductions ${ }^{1}$

$$
\mathrm{UO}_{2}^{2+}+\mathrm{C} \frac{\mathrm{hv}}{\text { deoxygenated }}>\mathrm{uo}^{2+}+\text { products, (Reaction } 17 \text { ) }
$$

where $\mathrm{C}$ is the carbohydrate glucose, gluconic acid, or methyl glucopyranoside. These reactions are generally slow, with U(IV) quantum yields of 0.2 .

Complexing of the uranyl ion with aromatic molecules results in exiplex (an excited molecular complex that is dissociated in the ground state) formation due to photochemically induced electron transfer to the aromatic molecule on excitation of the uranyl ion. ${ }^{27,28}$ Since this exiplex process efficiently quenches the excited uranyl luminescence it may provide an efficient, useful partitioning pathway. If this type of exiplex $\left(\mathrm{UO}_{2}^{+} \mathrm{Ar}^{-}\right)$is sufficiently stable it may be possible to selectively partition it into an organic phase or perhaps do selective chemistry on the $U(V)$ in the complex.

Amine complexes of the uranyl ion have been reported to undergo photoreduction. $^{1}$ The reported results, however, are only qualitative.

2.1.4 Photochemistry of the Uranyl Ion Using Inorganic Solutes. The most extensively studied photochemical solute in the inorganic class is the iodide ion, which photoreduces the uranyl ion in the reaction ${ }^{1,2}$

$$
\mathrm{UO}_{2}^{2+}+2 \mathrm{I}^{-}+2 \mathrm{H}^{+} \frac{\mathrm{h \nu}}{\mathrm{pH}>1.0 / \text { deoxygenated }} \rightarrow \mathrm{UO}^{2+}+\mathrm{I}_{2}+\mathrm{H}_{2} \mathrm{O} \text {. }
$$

(Reaction 18)

From the luminescence quenching data shown in Figure 2.12 and described by the empirical expression ${ }^{1}$ 


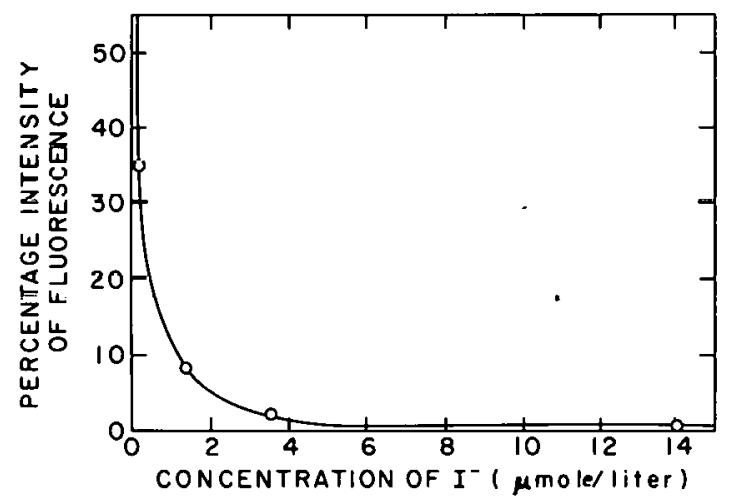

Figure 2.12. Quenching of the fluorescence of uranium ions by iodide ions (KI). (From Rabinowitch and Belford.1) 


$$
F=\frac{F_{0}}{1+5 \times 10^{3}\left[I^{-}\right]} \text {, }
$$

where $\mathrm{F}$ is the 1uminescence intensity, a photoreaction rate constant of $4 \times 10^{9}$ $\underline{M}^{-1} \sec ^{-1}$ is calculated. This fast reaction suggests that iodide photoreduction may be a very efficient process. Its exact mechanism is unknown and needs to be studied further, but it probably proceeds through a $U(V)$ intermediate which disproportionates.

When subjected to broad-band light the uranyl/iodide system approaches a steady state due to the photooxidation reaction

$$
\mathrm{I}_{2}+\mathrm{UO}^{2+}+\mathrm{H}_{2} \mathrm{O} \underset{\text { deoxygenated }}{\mathrm{h}} \mathrm{UO}_{2}^{2+}+2 \mathrm{I}^{-}+2 \mathrm{H}^{+}
$$

(Reaction 19)

This reaction can be readily avoided by exciting only the uranyl ion so that only reaction 18 occurs. Reaction 19 is retarded by increasing the acidity of the solution. The literature is not clear as to whether this photooxidation is due to excitation of $\mathrm{UO}^{2+}$ or $\mathrm{I}_{2}$. This point needs investigation. If it is the former then the uranous ion can be photoselectively oxidized in the presence of other actinides. If it is the latter, the photooxidation may be either a general or a selective process, depending on the other actinide photochemistry. One interesting aspect of the iodine system is the reaction ${ }^{1}$

$$
\mathrm{I}_{2}+\mathrm{C}_{2} \mathrm{O}_{4}^{2-} \stackrel{\mathrm{h \nu}}{\longrightarrow} 2 \mathrm{CO}_{2}+2 \mathrm{I}^{-}
$$

(Reaclion 20)

which suggests that one could internally regenerate $\mathrm{I}^{-}$for reaction by adding oxalic acid to the uranyl-iodide system. 
Inhibition of uranyl-photosensitized acetic acid decomposition by $\mathrm{Fe}^{2+}$ and uranyl photoreduction with alcohols by $\mathrm{Hg}^{2+}$ and $\mathrm{Cu}^{2+}$ suggests that these ions may undergo photoredox reactions with uranium ions. Excitation of the uranyl ion in solution with the hydrophosphate ion results in precipitation of the uranium from solution as a complexed uranous ion. The photoreaction rate constant for the uranyl- $\mathrm{H}_{2} \mathrm{PO}_{4}{ }^{-}$photochemical system has been reported 21 as $3.1 \times 10^{7} \mathrm{M}^{-1 .} \sec ^{-1}$.

One serious limitation on the above inorganic systems is their thermal chemistry. For example, I- reduces neptunium and plutonium ions. ${ }^{23}$ Thus, the viability of a given inorganic 1on phuluclemical reaction will depend on the absence of unwanted thermochemistry.

Recent work on plutonium-uranium mixtures reports that the photochemical reaction 24

$$
2 \mathrm{Pu}^{3+}+\mathrm{UO}_{2}^{2+}+2 \mathrm{H}^{+} \stackrel{\mathrm{hv}}{\longrightarrow} 2 \mathrm{Pu}^{4+}+\mathrm{UO}^{2+}+\mathrm{H}_{2} \mathrm{O} \quad \text { (Reaction }
$$

takes place under room light conditions. The reaction was found to be reversible. The extent of reaction was sensitive to the light intensity.

\subsection{Neptunium Photochemistry}

The literature on neptunium photochemistry is quite limited, 30,31 but two detailed studies suggest neptunium and uranium display simflar phuluchemLsLy. However, there are signiticant photoredox rediliull differences.

In perchloric acid solutions containing a mixture of neptunium oxidation states, the photochemical reactions 30

$$
\mathrm{Np}(\mathrm{IV}) \cdot \frac{\mathrm{h \nu}}{\mathrm{HC}_{4}} \mathrm{~Np}(\mathrm{~V})
$$




$$
\mathrm{Np}(\mathrm{V}) \underset{\mathrm{HC10}}{4} \rightarrow \mathrm{Np}(\mathrm{VI}), \quad \text { (Reaction 23) }
$$

result in an equilibrium population of $\mathrm{Np}(\mathrm{V})$ and $\mathrm{Np}(\mathrm{VI})$. Here $\mathrm{h} \nu$ is the entire light emitted by a mercury-quartz lamp. The ratio of $\mathrm{Np}(\mathrm{V})$ to $\mathrm{Np}(\mathrm{VI})$ after photochemical equilibrium is attained is independent of the original neptunium valence distribution. Figure 2.13 shows that for reaction 23 both a rate increase and an equilibrium shift toward $\mathrm{Np}(\mathrm{VI})$ occur as the concentration of perchloric acid is increased. However, addition of alkali metal perchlorate does not affect the equilibrium, which suggests that the effects shown in Figure 2.13 are due to $\mathrm{pH}$ changes. This interpretation is consistent with the fact that neptunium ions exist as free, hydrated species in perchloric acid solution. The $\mathrm{Np}(\mathrm{V})$ to $\mathrm{Np}(\mathrm{VI})$ ratios obtained with argon-saturated solutions are the same as those for aerated solutions. These ratios were observed to be stable for at least $24 \mathrm{hr}$ following irradiation.

Addition of ethanol to perchloric acid solutions of neptunium results in the photoreductions 30

$$
\begin{array}{ll}
\mathrm{Np}(\mathrm{VI}) \frac{\mathrm{hv}}{\mathrm{HClO}_{4} / \mathrm{CH}_{3} \mathrm{CH}_{2} \mathrm{OH}} \mathrm{Np}(\mathrm{V}), & \text { (Reaction 24) } \\
\mathrm{Np}(\mathrm{V}) \stackrel{\mathrm{hv}}{\stackrel{\mathrm{HC10}}{4} / \mathrm{CH}_{3} \mathrm{CH}_{2} \mathrm{OH}} \mathrm{Np}(\mathrm{IV}), & \text { (Reaction 25) }
\end{array}
$$

where hv is the radiation from a mercury-quartz lamp. As shown in Figure 2.14, the yield of $\mathrm{Np}($ IV) is a function of the perchloric acid concentration, with quantitative reduction occurring. for $1.5 \underline{M}$ or higher concentrations. As for reactions 22 and 23, this perchloric acid concentration behavior most likely reflects a $\mathrm{pH}$ dependence of the $\mathrm{Np}$ (IV) yield. As seen in Figure 2.15, the con- 


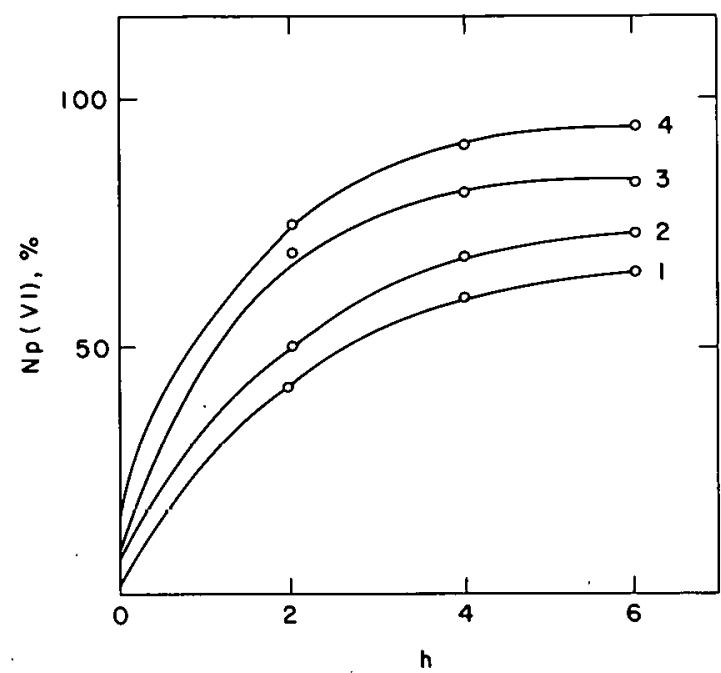

Figure 2.13. Photochemical oxidation of $\mathrm{Np}(\mathrm{V})$ to $\mathrm{Np}(\mathrm{VI})$ as a function of irradiation time $(\mathrm{h})$ and $\mathrm{HClO}_{4}$ concentration. $\mathrm{Np}(\mathrm{V})$ concentration of the solution before irradiation, $2 \times 10^{-3} \mathrm{~g}$-atom/ liter: (1) $0.5 \mathrm{M} \mathrm{HClO}_{4}$; (2) $1.1 \mathrm{M} \mathrm{HClO} \mathrm{M}_{4}$ (3) $3.2 \mathrm{M}$
$\mathrm{HClO}_{4}$; (4) $4.8 \mathrm{M} \mathrm{HClO}_{4}$. (From Nemodruck et al. 30 )

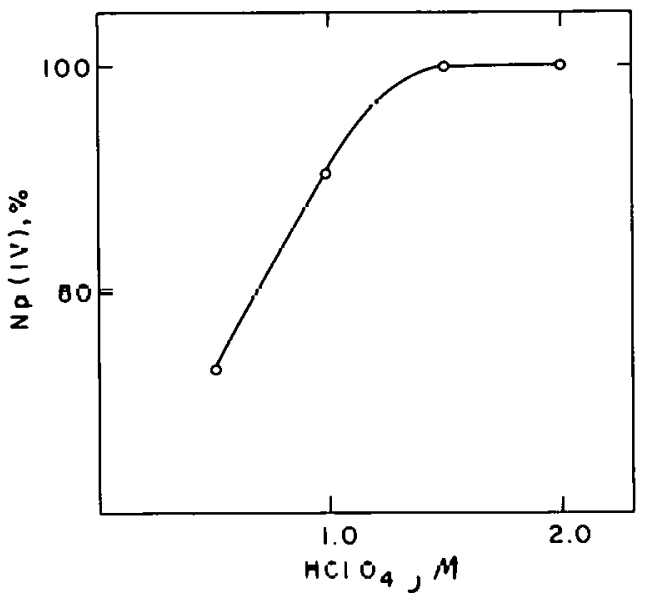

Figure 2.14. Photochemical reduction of $\mathrm{Np}(\mathrm{V})$ to $\mathrm{Np}$ (IV). Ethanol concentration, $0.5 \%$; irradiation time, 20 min; $N p(V)$ concentration of the solucion before irradiation, $2 \times 10^{-3} \mathrm{~g}$-atom/liter. (From Nemodruck et al. ${ }^{30}$ ) 


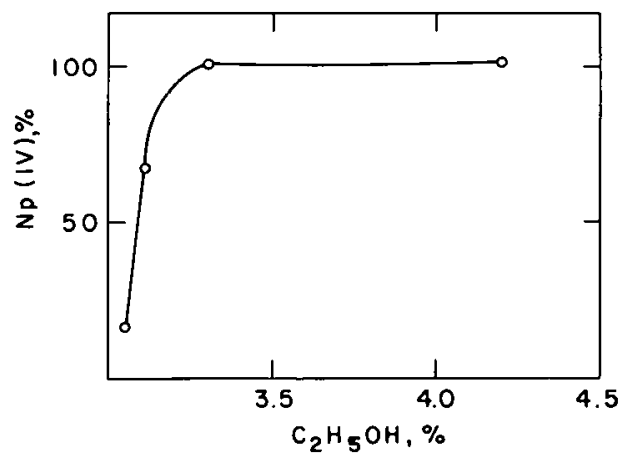

Figure 2.15. Effect of ethanol concentration on $\mathrm{Np}$ (IV) yield. Irradiation time, $20 \mathrm{~min} ; 1 \mathrm{M}$ $\mathrm{HClO}_{4}$; $\mathrm{Np}(\mathrm{V})$ concentration of the solution before irradiation, $1.5 \times 10^{-3} \mathrm{~g}$-atom/liter. (From Nemodruck et al.30) 
version to $\mathrm{Np}(\mathrm{IV})$ is quantitative for solutions containing $3.3 \%$ or higher concentrations of ethanol. The conversion results were the same for argon and air saturated solutions. Following irradiation the resultant $\mathrm{Np}$ (IV) concentration was found to be stable for several days. Formic acid is reported to be equivalent to ethanol for these photoreductions, although no data were presented. 31 In the presence of hydrogen peroxide 30 the photooxidation reaction

$$
\mathrm{Np}(\mathrm{IV}) \underset{\mathrm{HClO} / 4}{\mathrm{~h} / \mathrm{H}_{2} \mathrm{O}_{2}} \rightarrow \quad \mathrm{Np}(\mathrm{V}) \quad \text { (Reaction 26) }
$$

occurs, where hv is again the entire mercury-quartz lamp radiation. As shown in Figure 2.16, the photochemical oxidation is quantitative and faster than the corresponding thermochemical oxidation. The resultant $\mathrm{Np}(\mathrm{V})$ solutions are exceptionally stable.

No photochemical change in $\mathrm{Np}(\mathrm{V})$ was observed when 0.1 to $6 \underline{\mathrm{M}}$ nitric acid solutions were subjected to the mercury-quartz lamp radiation. ${ }^{31}$ However, the following photoredox reactions were observed ${ }^{31}$ :

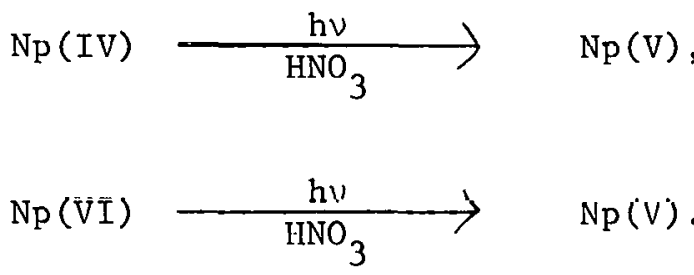

(Rcaction 27)

Figure 2.17 shows the dependence of reaction 27 on nitric acid concentration. Although optimum conditions are observed for $0.5 \underline{M}$ nitric acid solutions, quantitative conversion at higher acid concentrations is obtained with longer irradiation times (Figure 2.18 ). The results ${ }^{31}$ of a kinetic study of the reaction order and rate constants for reaction 27 are given in Table 2.8. Reaction 


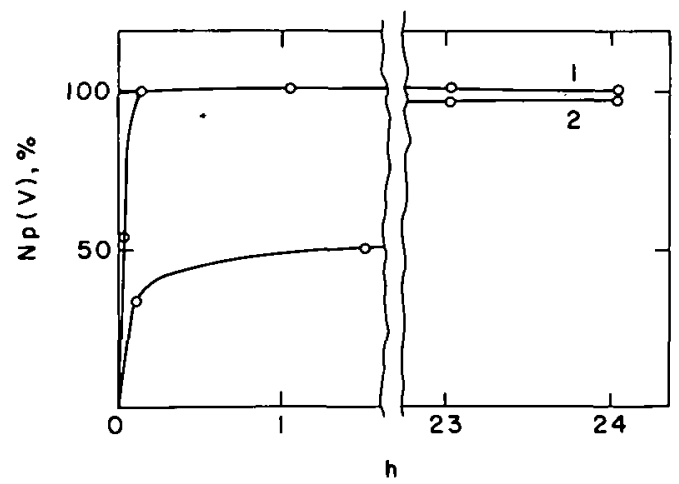

Figure 2.16: Oxidation of $N p$ (IV) to $N p(V)$ by hydrogen peroxide as a function of time (h). Concentrations in solution before irradiation: $0.5 \% \mathrm{H}_{2} \mathrm{O}_{2}, 1.5 \mathrm{M}$ $\mathrm{HClO}_{4}, 1 \times 10^{-3}$ g-atom $\mathrm{Np}$ (IV)/1iter. (1) On irradiation; (2) no irradiation. (From Nemodruck et al.30)

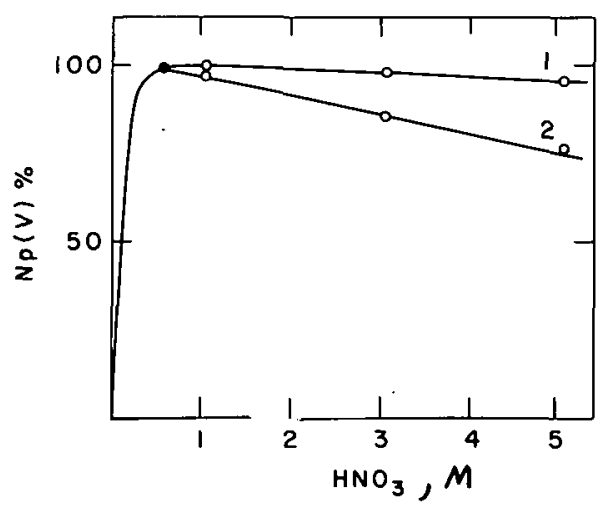

Figure 2.17. Photochemical oxidation of $\mathrm{Np}$ (IV) to $\mathrm{Np}(\mathrm{V})$ as a function of $\mathrm{HNO}_{3}$ concentration. Original $\mathrm{Np}$ (IV) concentration $2 \times 10^{-3} \mathrm{M}$. Irradiation time (min): (1) 90 ; (2) 30 . (From Nemodruck et al.31)

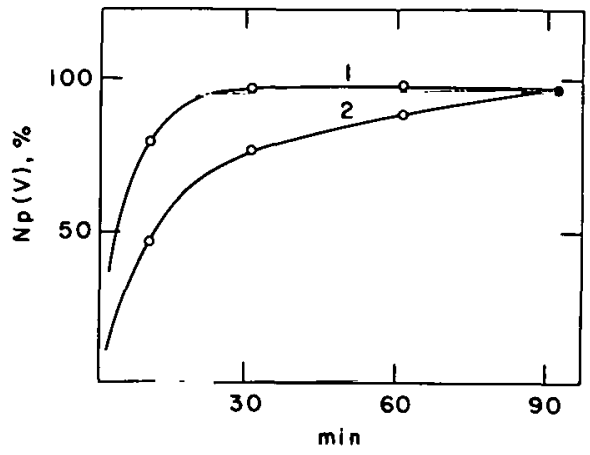

Figure 2.18. Photochemical oxidation of $\mathrm{Np}$ (IV) to $\mathrm{Np}(\mathrm{V})$ as a function of irradiation time (min). Original Np(IV) concentration, $2 \times 10^{-3} \underline{\mathrm{M}}$. (1) $1 \underline{\mathrm{M}}$ $\mathrm{HNO}_{3}$; (2) $3 \mathrm{M} \mathrm{HNO}_{3}$. (From Nemodruck et al. 31 ) 
Table 2.8

Reaction Constants and the Orders of the Photochemical Oxidation of $\mathrm{Np}(\mathrm{IV})$ to $\mathrm{Np}(\mathrm{V})$ and of $\mathrm{Np}(\mathrm{V})$ to $\mathrm{Np}(\mathrm{VI})$ Under Variuus Conditions $\left(22^{\circ} \mathrm{C}\right)$

\begin{tabular}{|c|c|c|c|c|c|}
\hline \multirow[b]{2}{*}{ Reartinn } & \multicolumn{3}{|c|}{ Concentrations, $\mathrm{M}$} & \multirow{2}{*}{$\begin{array}{l}\text { Reaction } \\
\text { order, } \underline{n}\end{array}$} & \multirow{2}{*}{$\begin{array}{l}\text { Reaction rate } \\
\text { constants } \\
\underline{M}^{1-\underline{n}} \min ^{-1}\end{array}$} \\
\hline & $\mathrm{HNO}_{3}$ & $\mathrm{NaNO}_{3}$ & Urea & & \\
\hline $\mathrm{Np}(I V) \rightarrow \mathrm{Np}(\mathrm{V})$ & 1.0 & --- & - & 1.2 & 0.53 \\
\hline $\mathrm{Np}(I V) \rightarrow \mathrm{Np}(\mathrm{V})$ & 3.0 & --- & -- & 1.6 & 2.04 \\
\hline $\mathrm{Np}(\mathrm{V}) \rightarrow \mathrm{Np}(\mathrm{VI})$ & 1.5 & -- & 0.1 & 2.2 & $1.56 \times 10^{3}$ \\
\hline$N_{p}(V) \rightarrow N p(V I)$ & 1.5 & 4.0 & 0.1 & 1.2 & 0.36 \\
\hline $\mathrm{Np}(\mathrm{V}) \rightarrow \mathrm{Np}(\mathrm{V} 1)$ & 3.0 & $=-$ & 0.1 & 0.85 & 0.09 \\
\hline
\end{tabular}


28 is also quite sensitive to nitric acid concentration, showing a sharp increase in rate as the concentration is increased to the 0.2 to $0.5 \mathrm{M}$ region, where reduction becomes quantitative. At higher acid concentrations the rate decreases slightly, but quantitative conversion is still attained by increasing the irradiation time.

In the presence of urea only photooxidation reactions are observed ${ }^{31}$ :

$$
\begin{aligned}
& \mathrm{Np} \text { (IV) } \underset{\mathrm{HNO}_{3} / \mathrm{NH}_{2} \mathrm{CONH}_{2}}{\rightarrow} \mathrm{Np}(\mathrm{V}), \quad \text { (Reaction 29) } \\
& \mathrm{Np}(\mathrm{V}) \quad \frac{\mathrm{hv}}{\mathrm{HNO}_{3} / \mathrm{NH}_{2} \mathrm{CONH}_{2}} \mathrm{~Np}(\mathrm{VI}) \cdot \quad \text { (Reaction 30) }
\end{aligned}
$$

As shown in Figure 2.19, quantitative conversion of $\mathrm{Np}(\mathrm{V})$ to $\mathrm{Np}(\mathrm{VI})$ occurs in $6 \underline{M}$ nitric acid solutions for short irradiation times. At the $3.0 \underline{M}$ acid level, quantitative conversion is achieved after longer exposure times (Figure 2.20), while yields drop off at lower acid concentrations. Comparison of curve 3 in Figure 2.20 with the data in Figure 2.19 indicates that the effect of nitric acid concentrations on reaction 30 is probably a result of $\mathrm{pH}$ rather than nitrate ion dependence. The rate of reaction 29 is reported to be much faster than that for reaction 30 . The results ${ }^{31}$ of a kinetic study of the reaction order and constants for reaction 30 are given in Table 2.8. Figure 2.21 shows that quantitative conversion is attained when the urea-to-neptunium mole ratio is $\sim 100$.

Addition of hydrogen peroxide to $0.1 \underline{M}$ nitric acid solutions of $\mathrm{Np}(\mathrm{IV})$ results in the photooxidation reaction 31

$$
\begin{gathered}
\mathrm{Np}(\mathrm{IV}) \frac{\mathrm{hv}}{\mathrm{HNO}_{3} / \mathrm{H}_{2} \mathrm{O}_{2}} \rightarrow \quad \mathrm{Np}(\mathrm{V}), \quad \text { (Reaction 31) } \\
-41-
\end{gathered}
$$




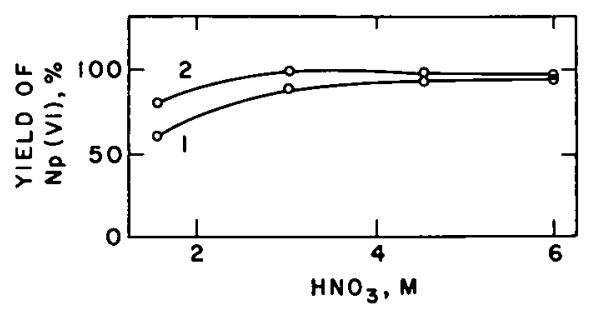

Figure 2.19. Photochemical oxidation of $\mathrm{Np}(\mathrm{V})$ to $\mathrm{Np}(\mathrm{VI})$ as a function of $\mathrm{HNO}_{3}$ concentration when urea is present. Original $\mathrm{Np}(\mathrm{V})$ concentration, $1 \times 10^{-3}$ $\mathrm{g}$-atom/liter; urea, $0.1 \mathrm{M}$. Irradiation time (min): (1) 10 ; (2) 20 . (From Nemodruck et al.31)

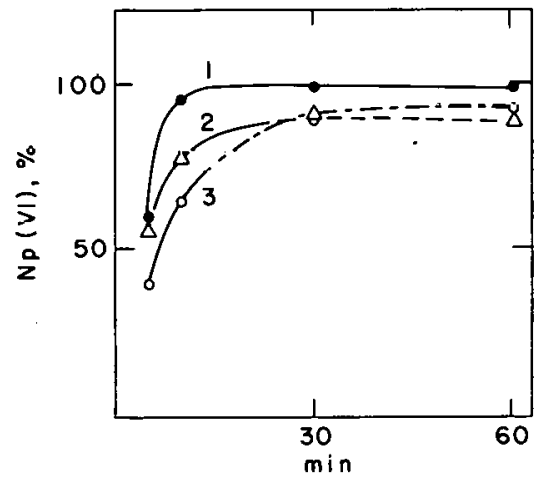

Figure 2.20. Photochemical oxidation of $\mathrm{Np}(\mathrm{V})$ to $\mathrm{Np}(\mathrm{VI})$ as a function of irradiation time (min). Original $\mathrm{Np}(\mathrm{V})$ concentration, $1 \times 10^{-3} \mathrm{~g}$-atum/11Lei; urea, $0.1 \mathrm{M}$. (1) $3.0 \mathrm{M} \mathrm{HNO}_{3}$; (2) $1.5 \underline{\mathrm{M}} \mathrm{HNO}_{3}$; (3) $1.5 \mathrm{M} \mathrm{HNO}_{3}+4.0 \mathrm{M} \mathrm{NaNO} 3$. (From Nemodruck et al. ${ }^{31}$ )

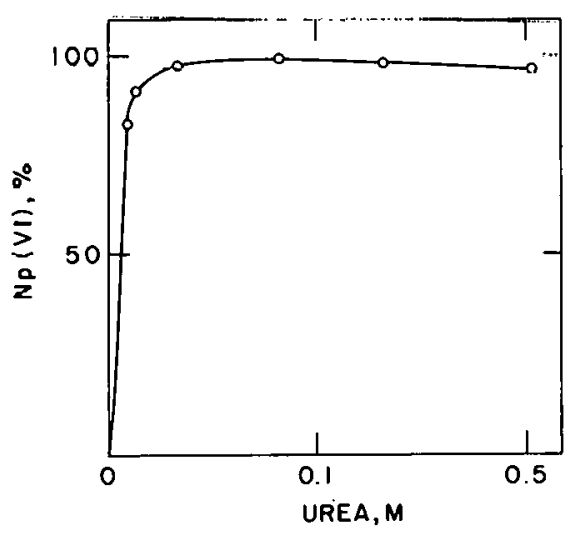

Figure 2.21. Effect of urea concentration on the oxidation of $\mathrm{Np}(\mathrm{V})$ to $\mathrm{Np}(\mathrm{VI}) .1 \times 10^{-3} \mathrm{M} \mathrm{NpO}_{2} \mathrm{NO}_{3}$; $3 \mathrm{M} \mathrm{HNO}_{3}$; irradiation time, $10 \mathrm{~min}$. (From Nemodruck et a1.31) 
which is rapid and quantitative for $0.1 \%$ by volume or higher peroxide concentrations. The thermochemical analog of reaction 31 is much slower and not quantitative. No photoreduction of $\mathrm{Np}(\mathrm{V})$ was observed for nitric acid solutions containing ethanol or formic, acetic, tartaric, or oxalic acids. ${ }^{31}$.

\subsection{Plutonium Photochemistry}

Although the literature on plutonium photochemistry is limited, 24,32-36 data are sufficient to support the expectation that the photochemistry of plutonium and that of uranium will prove to be similar. One result of the present study is based on this line of reasoning. It was proposed that the photochemistry of the formic acid reduction of urany1 ion (reaction 11) might be ana1ogous to that of plutonium ions. The formic acid-plutonium system proposed was subsequently studied by J.T. Bell, L.M. Toth, and H.A. Friedman at Oak Ridge National Laboratory and found to display the anticipated photochemistry. The photochemical reductions of $\mathrm{PuO}_{2}{ }^{2+}$ and $\mathrm{Pu}^{4+}$ with formic acid were observed. This system is being investigated further by this group. The plutonium photochemistry provides several other potential reactions for partitioning.

Photochemical generation of $\mathrm{Pu}(\mathrm{IV})$ from $\mathrm{Pu}(\mathrm{III})$ and $\mathrm{Pu}(\mathrm{VI})$ has been reported in aqueous sulfuric acid. ${ }^{32}$ The reactions are

$$
\begin{aligned}
& \mathrm{Pu}(\mathrm{III}) \underset{\mathrm{H}_{2} \mathrm{SO}_{4}}{\longrightarrow} \quad \mathrm{Pu}(\mathrm{IV}), \quad \text { (Reaction 32). } \\
& \mathrm{Pu}(\mathrm{VI}) \underset{\mathrm{H}_{2} \mathrm{SO}_{4} / 3 \% \mathrm{CH}_{3} \mathrm{CH}_{2} \mathrm{OH}}{\mathrm{hu}} \mathrm{Pu}(\mathrm{IV}) \text {, (Reaction 33) }
\end{aligned}
$$

where $h \nu$ is the entire spectrum of a mercury-quartz lamp and the ethanol concentration is given in volume \%. This system displays no redox behavior in the absence of light either before or after irradiation. No photochemical oxidation 
of Pu(IV) takes place, and ethanol does not photochemically reduce Pu(IV). Figure 2.22 shows the dependence of reaction 32 on irradiation time and acid concentration, while Figures 2.23 and 2.24 show the effect of adding ethanol on the concentrations of $\mathrm{Pu}(\mathrm{IV})$ and $\mathrm{Pu}(\mathrm{VI})$.

The photochemistry of perchloric acid solutions of plutonium ${ }^{35}$ resembles that of the sulfuric acid system. ${ }^{32}$ Photooxidation of $\mathrm{Pu(III)}$ to $\mathrm{PU}(\mathrm{IV})$ is observed:

$$
\operatorname{Pu}(\text { III }) \frac{\text { hv }}{\mathrm{HClO}_{4}} \mathrm{Pu}(\mathrm{IV}), \quad \text { (Reaction 34) }
$$

which is followed by $\mathrm{Pu}(\mathrm{IV})$ disproportionation:

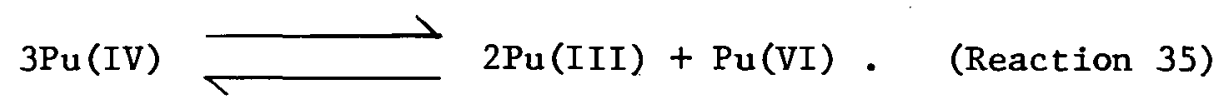

The study of this disproportionation is a keystone in the photochemistry of

the actinides because it clearly shows light-induced rate and equilihrium shifts, 35 In Figure 2.25 it can be seen that $27 \mathrm{hr}$ after solution preparation the thermochemical disproportionation equilibrium condition has not been reached, as shown by the $\mathrm{Pu}(\mathrm{IV})$ and $\mathrm{Pu}(\mathrm{III})$ concentrations. 35 However, upon repeated exposire to 260 to $380-\mathrm{nm}$ light, the rate of $\mathrm{Pu}(\mathrm{IV})$ disproportination is greatly accelerated. Furthermore, once thermochemical equilibrium is attained, irradiation leads to a new photochemically maintained equilibrium. An estimated $20 \%$ decrease in $\mathrm{Pu}$ (IV) concentration with respect to the thermochemical value results after two hours of exposure. Such a photochemically increased rate of reaction (as compared with the thermochemical reaction) and shifted equilibrium show the potential advantages of photoprocessing. In the above experiment $\mathrm{Pu}(\mathrm{III})$ and $\mathrm{Pu}(\mathrm{VI})$ are prob- 


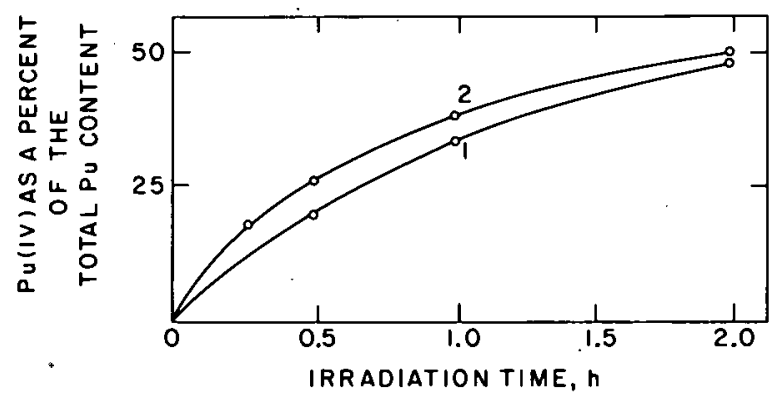

Figure 2.22. Oxidation of $\mathrm{Pu}$ (III) to $\mathrm{Pu(IV)}$ in sulfuric acid solutions in relation to irradiation time

(h) and $\mathrm{H}_{2} \mathrm{SO}_{4}$ concentration. (1) $1.5 \mathrm{~N} \mathrm{H}_{2} \mathrm{SO}_{4}$;

(2) $4.5 \mathrm{~N} \mathrm{H}_{2} \mathrm{SO}_{4}$. (From Palei et al.32)

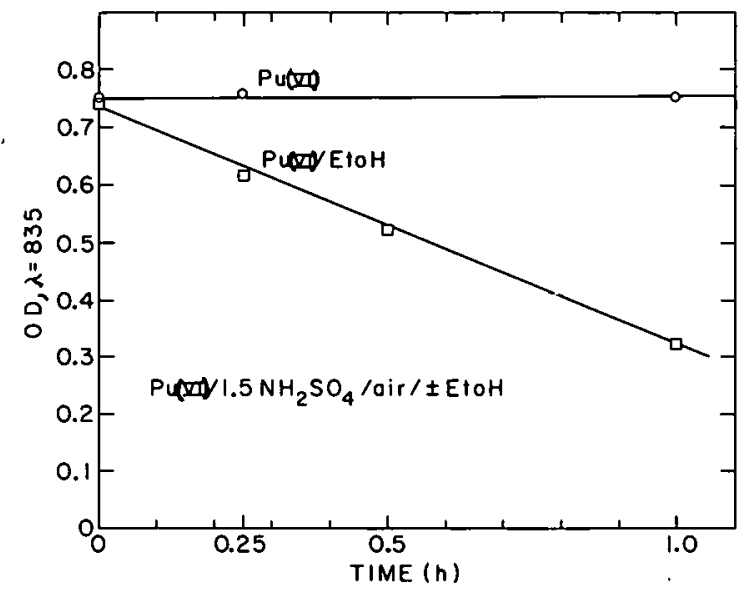

Figure 2.23. Relationship of the optical density of $\mathrm{Pu}(\mathrm{VI})$, in the absence ( 0 ) and presence of $\sim 3 \%$ ethanol, to 1rradiation llue $\left(l_{1}\right)$. Initial solution conditions were $1.59 \mathrm{mg} \mathrm{Pu(VI)/liter} \mathrm{in} 1.5 \mathrm{~N} \mathrm{H}_{2} \mathrm{SO}_{4}$. The $\mathrm{Pu}(\mathrm{VI})$ optical data were monitored at $83 \overline{5} \mathrm{~nm}$. (Data extracted from Palei et al. ${ }^{32}$ ) 


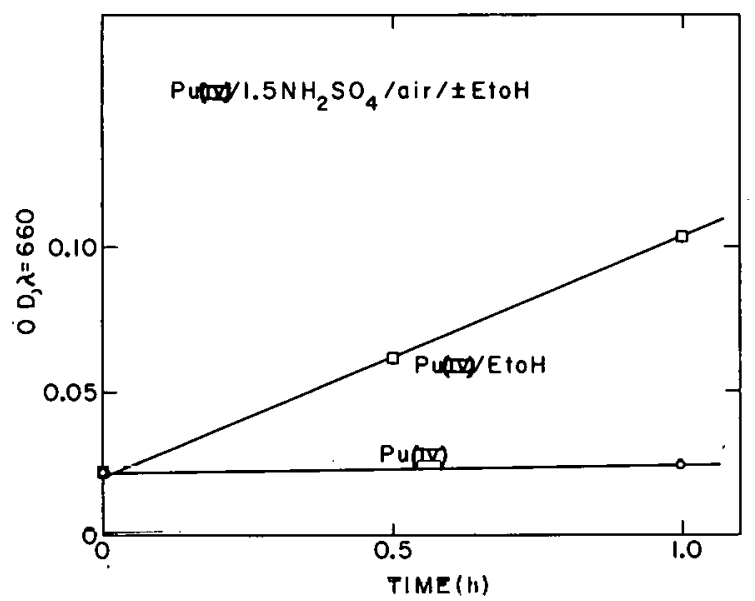

Figure 2.24. Relationship of the opt1cal density of $\mathrm{Pu}(\mathrm{IV})$, in the absence ( 0 ) and presence ( $\square$ ) of n.3\% ethanol, to irradiation time (li). Inllial su-. lution conditions were $1.59 \mathrm{mg} \mathrm{Pu}(\mathrm{VI}) / 1$ iter in 1.5 $\mathrm{N} \mathrm{H}_{2} \mathrm{SO}_{4}$. The $\mathrm{Pu}(\mathrm{IV})$ optical data were monitored at $660 \mathrm{~nm}$. (Data extracted from Palei et al. ${ }^{32}$ )

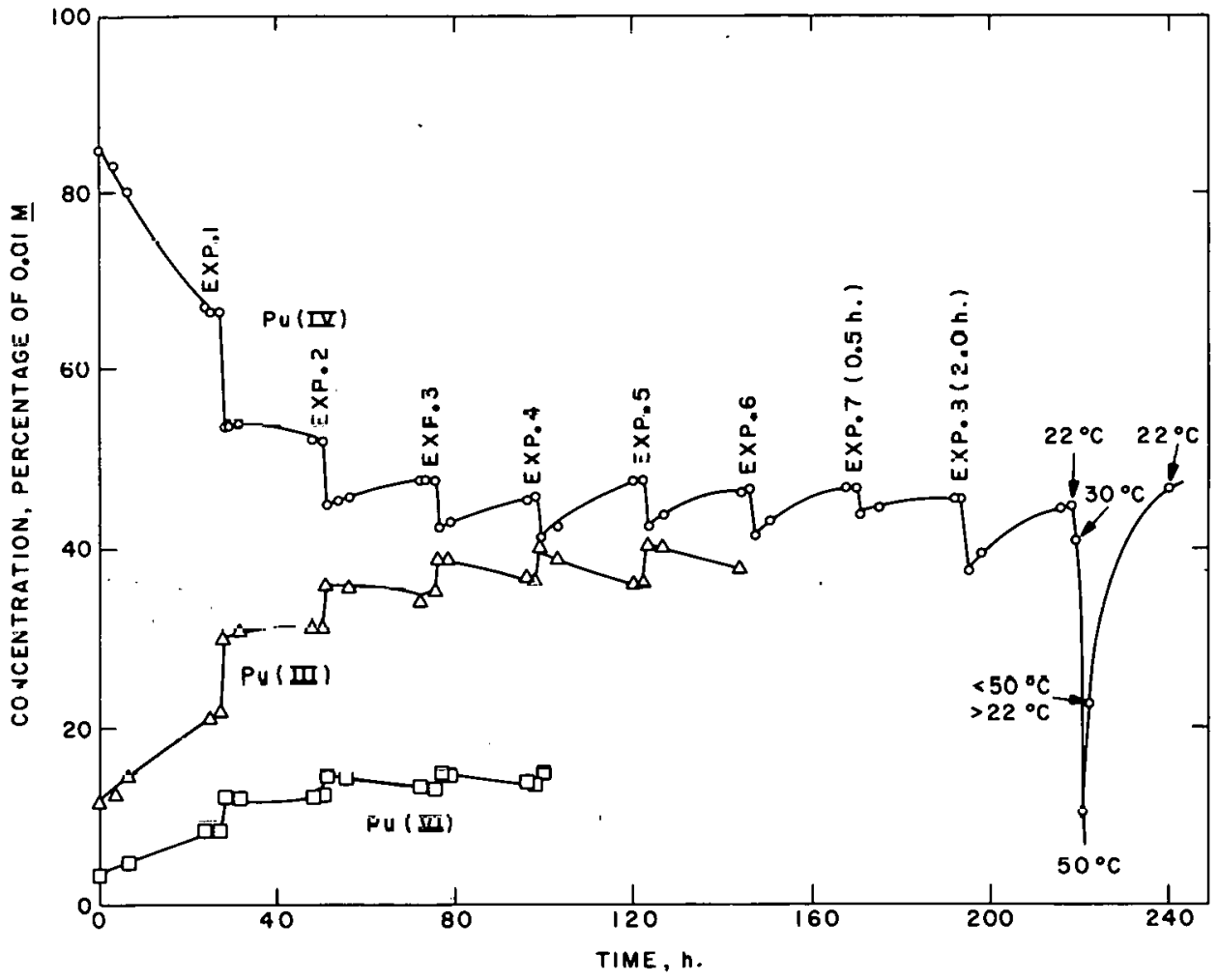

Figure 2.25. Effect of ultraviolet $(\lambda=260$ to 380$)$

light exposure and temperature on the disproportionation of $\mathrm{Pu}$ (IV) (reaction 35). (From Bell and Friedman.35) 
ably being excited, as well as the disproportionating Pu(IV). It may be possible to increase the reaction rate and/or shift the equilibrium to an even greater extent by selective plutonium ion excitation.

Another plutonium reaction affected by light is the polymerization of $\mathrm{Pu}(\mathrm{IV})$ polymer, in which the rate of depolymerization is greater by a factor of $\sim 4$ in the presence of 260 to $380-\mathrm{nm}$ light than in the dark. 35

The photoreduction of $\mathrm{Pu}(\mathrm{VI})$ by ethanol has been reported for perchloric $\operatorname{acid}^{35}:$

$$
\mathrm{Pu}(\mathrm{VI}) \frac{\mathrm{hv}}{\mathrm{HClO}_{4} / \mathrm{CH}_{3} \mathrm{CH}_{2} \mathrm{OH}} \mathrm{Pu}(\mathrm{III}) \text {, (Reaction 36) }
$$

with a quantum yield $>0.02$. However, unlike the sulfuric acid system, there is also photoreduction of $\mathrm{Pu}(\mathrm{IV})$ by ethanol ${ }^{35}$ :

$$
\mathrm{Pu}(\mathrm{IV}) \frac{\mathrm{hv}}{\mathrm{HClO}_{4} / \mathrm{CH}_{3} \mathrm{CH}_{2} \mathrm{OH}} \mathrm{Pu}(\mathrm{III}) \text {, (Reaction 37) }
$$

with a quantum yield of 0.03 . In these studies hv refers to exciting light of wavelength 260 to $380-\mathrm{nm}$. No reduction reactions were observed in the absence of 1ight. Hydrochloric acid solutions like sulfuric acid give photochemical generation of $\mathrm{Pu}(\mathrm{IV})$ from $\mathrm{Pu}(\mathrm{III})$ but no further oxidation of $\mathrm{Pu}(\mathrm{IV})$ as in nitric acid solution. ${ }^{32}$ The difference in photoredox behavior between nitric acid and the other acids suggests that complexing of the plutonium ion with the acid nitrate anion is important in determining the photochemical behavior. Photochemical dependence on the type of complexing anion is clearly illustrated by the perchloric acid system, in which plutonium ions undergo photochemical redox reactions 36 and 37 , which are not found in the sulfuric or nitric 
acid systems. The data in Figure 2.26 further illustrate this point. ${ }^{33}$. That is, in perchloric acid there is no $\mathrm{Pu}(\mathrm{VI})$ to $\mathrm{Pu}(\mathrm{IV})$ photoreduction, but introduction of thenoyl trifluoroacetone results in this photoreduction. Thus complexing of $\mathrm{Pu}(\mathrm{VI})$ with thenoyl trifluoroacetone gives photoreduction, whereas solvated $\mathrm{Pu}(\mathrm{VI})$ does not.

In nitric acid the following photochemical reactions have been observed ${ }^{32}$ :

$$
\begin{aligned}
& \mathrm{Pu}(\mathrm{III}) \underset{\mathrm{hv}}{\mathrm{HNO}_{3} \rightarrow \mathrm{Pu}(\mathrm{IV}),} \quad \text { (Reaction 38) } \\
& \mathrm{Pu}(\mathrm{IV}) \frac{\mathrm{hv}}{\mathrm{HNO}_{3}}-\mathrm{Pu}(\mathrm{VI}), \quad \text { (Reaction 39) }
\end{aligned}
$$

where hv is again the light of a mercury-quartz lamp. Figure 2.27 shows the initial rapid decay of $\mathrm{Pu}(\mathrm{III})$ and growth of $\mathrm{Pu}(\mathrm{IV})$, followed by the slower $\mathrm{Pu}(\mathrm{VI})$ growth. 32 As shown in Figure 2.28 the rate of reaction 38 (curve 1) is faster than that of reaction 39 (curve 2). Reaction 38 increacco with increasing acid concentration, as shown in Figure 2.29, and is not affected by nitrite ion. In llie alsence of 1ight, the rate for oxidation of $\mathrm{Pu}(\mathrm{III})$ to $\mathrm{Pu}(\mathrm{IV})$ proceeds at a slower rate than that of reaction 38 at low acid concentrations. However, for solutions in which the nitric acid concentration is $5.5 \underline{\mathrm{M}}$, these two races become comparable. No evidence of oxidation of $\mathrm{Pu}($ IV) in the absence of light was found at any nitric acid concentration studied.

In the presence of hydrogen peroxide, $\mathrm{Pu}(\mathrm{IV})$ is photoreduced in nitric acid solution,

$$
\mathrm{Pu}(\mathrm{IV}) \frac{\mathrm{hv}}{\mathrm{HNO}_{3} / \mathrm{H}_{2} \mathrm{O}_{2}} \rightarrow \quad \mathrm{Pu}(\mathrm{III}), \quad \text { (Reaction 40) }
$$




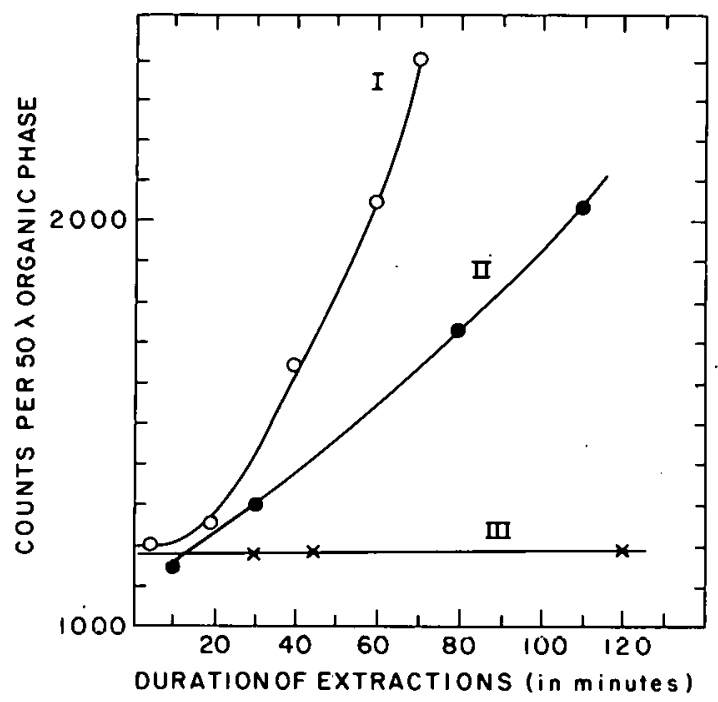

Figure 2.26. Rate of extraction of $\mathrm{Pu}$ in presence and in absence of light. $0,6 \times 10^{-4} \mathrm{M} \mathrm{Pu}$ in $0.5 \mathrm{M} \mathrm{HClO}_{4}$, no holding oxidant, in presence of light. $0, \overline{6} \times 10^{-4}$ $\mathrm{M} \mathrm{Pu}$ in $0.5 \mathrm{M} \mathrm{HClO} 4+10^{-2} \mathrm{M} \mathrm{K}_{2} \mathrm{Cr}_{2} \mathrm{O}_{7}$, in presence of light. $\mathrm{X}, 6 \times 10^{-4} \mathrm{M} \mathrm{Pu}$ in $0.5 \mathrm{M} \mathrm{HClO}_{4}$, no holding oxidant, in absence of light. The solvent extraction system was plutonium in perchloric acid washed with benzene containing the chelating agent thenoyl tri- 33 fluoroacetone. (From Mazumdar and Sivaramakrishnan. ${ }^{33}$ )

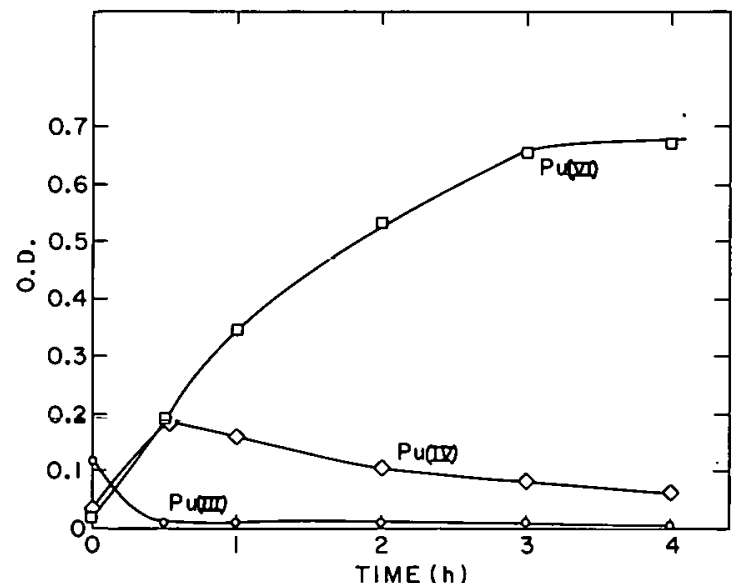

Figure 2.27. Relation of optical density , Pu(VI), $O, \mathrm{Pu}(\mathrm{IV})$; and $0, \mathrm{Pu}(\mathrm{III})$ to irradiation time (h). Intial solution conditions were $0.96 \mathrm{~g}$ of $\mathrm{Pu}(\mathrm{VI}) / 1$ iter in $3.0 \mathrm{M} \mathrm{HNO}_{3}$. The monitoring wavelengths are 835,480 and $600^{-} \mathrm{nm}$ for $\mathrm{Pu}(\mathrm{VI}), \mathrm{Pu}(\mathrm{IV})$, and $\mathrm{Pu}$ (ITT), respectively. (Data extracted from Palei et a1.32) 


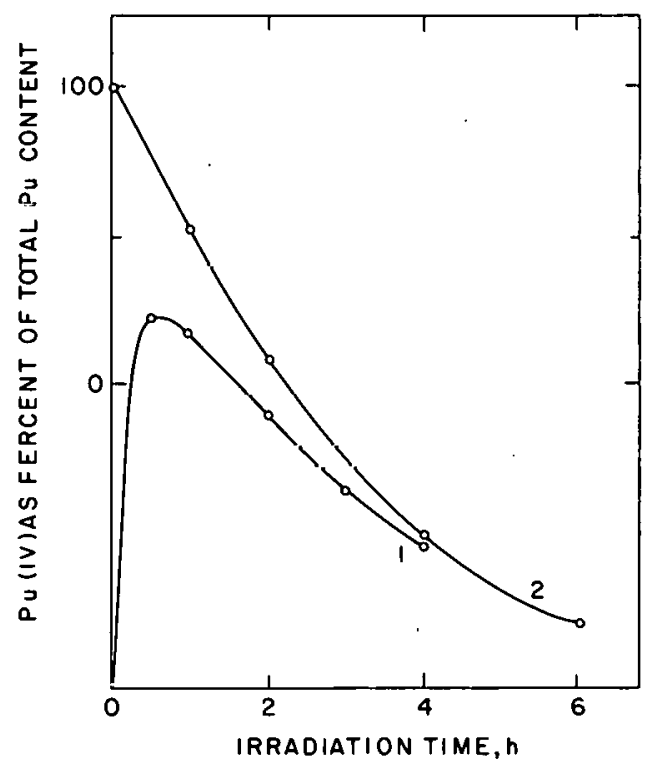

Figure 2.28. (Pu(IV) content of $3.5 \mathrm{~N} \mathrm{HNO}_{3}$ in relation to the irradiation time $(h)$ and the initial valence ctato of the plutonium. Tutal plutunlum concencration, $59.7 \mu \mathrm{g} / \mathrm{ml}$. (1) In solution before irradiation - only $\mathrm{Pu}(\mathrm{III})$; (2) in solution before irradiation - only $\mathrm{Pu}$ (IV). (From Pálel et a1.32) 
with high efficiency (Figure 2.30). The peroxide reduces $\mathrm{Pu}(\mathrm{IV}$ ) in the absence of light, but irradiation greatly increases the rate and yield due to reaction 40, as shown in Figure 2.30.

It has been reported that even under room light conditions Pu(IV) is reduced in acid solutions. ${ }^{36}$ The extent of net photochemical reduction was reported to be sensitive to the nitric acid concentration is being smaller for higher $\mathrm{HNO}_{3}$ concentrations. Under $\mathrm{HNO}_{3}$-deficient conditions the Pu(IV) extraction distribution coefficient was significantly lowered for room light intensities.

As discussed in section 2.1.4, recent work ${ }^{24}$ on plutonium-uranium mixtures indicates that $\mathrm{Pu}$ (III) oxidation (reaction 21) takes place under room light conditions. The reaction was sensitive to light intensity and gave 1 to $2 \%$ oxidation yields at room light intensities.

\subsection{Fission Product Photochemistry}

The photochemistry of various fission product ions has been reported, but only for complexes of these ions not found in the Purex solutions. ${ }^{37-42}$ The photochemistry of the fission product ions is a function of the ligands, such as cyano, halide, amino, ammonium, pyridine, and carboxylic acid, that make up the complex. Therefore the fission product photochemistry will be discussed only in general terms, and only the simpler complexes in solution will be covered. Specific complex photochemistry will not be discussed, since such species do not exist in common Purex solutions. This does not rule out the possibility of adding solutes to Purex solutions for the purpose of carrying out fission product fractionating photochemistry. Such procedures may have value in treating the high-level waste stream, but a detailed evaluation of possible photochemical approaches to fractionation of the fission products in the high-level waste stream 


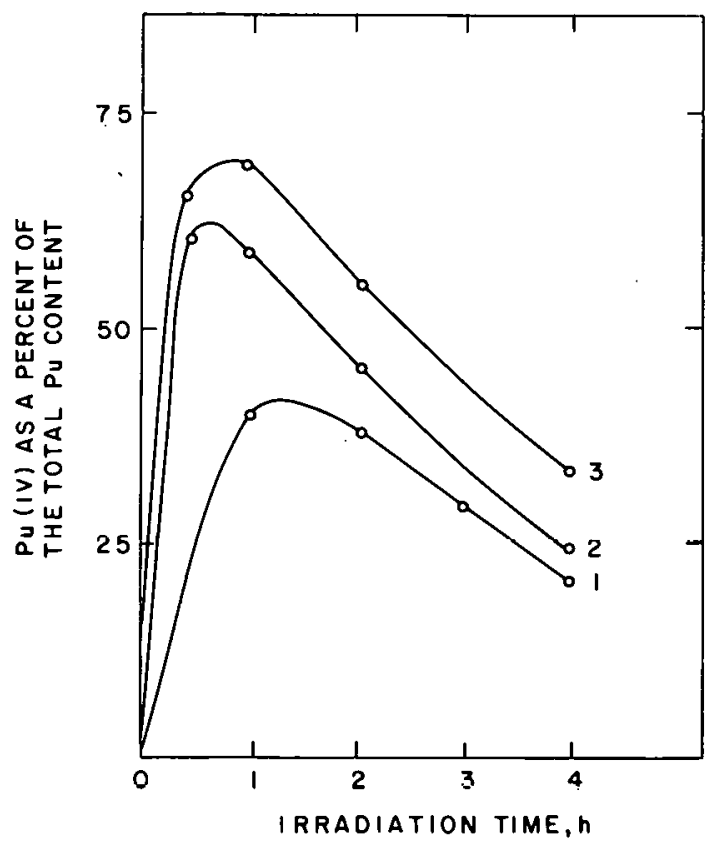

Figure. 2.29. Effect of $\mathrm{HNO}_{3}$ concentration as a function of irradiation time (h) on the oxidation of $\mathrm{Pu}$ (III). (1) $1.5 \underline{\mathrm{N}} \mathrm{HNO}_{3}$; (2) $3.5 \underline{\mathrm{N}} \mathrm{HNO}_{3}$; (3) $5.5 \underline{\mathrm{N}}$ $\mathrm{HNO}_{3}$. (From Pale1 et al.32)

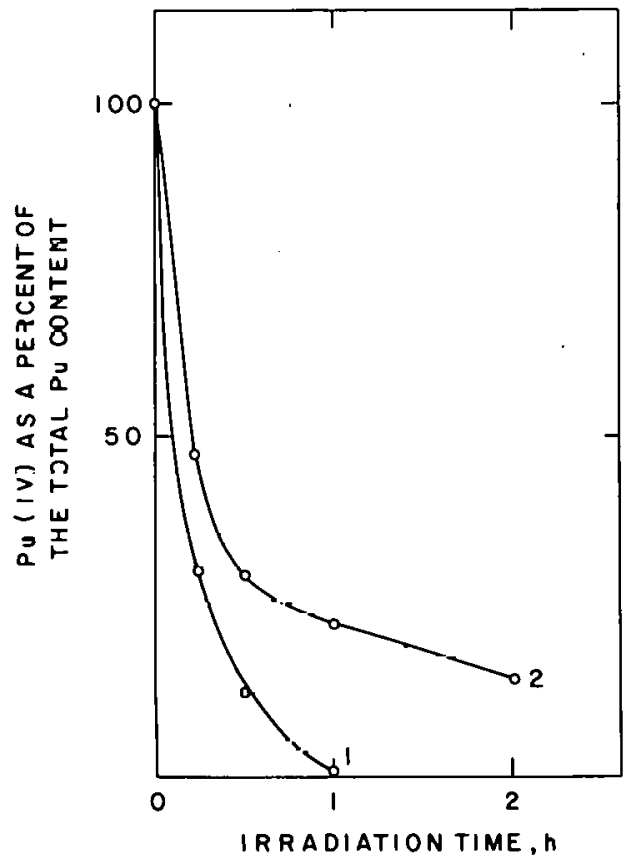

Figure 2.30. Reduction of $\mathrm{Pu}(\mathrm{IV})$ to $\mathrm{Pu}$ (III) in a solution containing $2 \% \mathrm{H}_{2} \mathrm{O}_{2}$ in relation to time. (1) With irradiation; (2) without irradiation. (From Palei et al.32) 
must wait for more pertinent experimental data. Fission product photochemistry is very sensitive to the solution conditions and the nature of the complex.

The $\mathrm{Nb}$ (III) and $\mathrm{Nb}(\mathrm{IV})$ species in water were found to bleach when irradiated and to yield a precipitate of $\mathrm{Nb}_{2} \mathrm{O}_{5}$ after prolonged exposure. ${ }^{42}$

Complexes of Mo(IV) in water undergo wavelength-dependent photosubstitution and photooxidation. $37,38,42$ The photooxidation, associated with shortwavelength photolysis $(\leq 313 \mathrm{mn})$, involves photoelectron and Mo(V) formation. Irradiation at longer wavelengths results in photosubstitution, which may involve a ligand-field triplet state. The photoreduction of Mo(V) has been reported to give quantum yields greater than unity because decomposition of an initial Mo(IV) photoproduct produces a thermochemical reducing agent.

The Tc(IV) complex $\mathrm{TcCl}_{6}{ }^{2+}$ undergoes photoaquation when its charge transfer to metal (CTTM) bands are irradiated. $38-40,42$

The photochemistry of $\mathrm{Ru}(\mathrm{II})$ complexes in solution shows both photosubstitution and photooxidation reactions. $37,38,40,42$ The extent and relative yield of these two reactions are a function of the 1igands, excitation band, and $\mathrm{pH}$. The Ru(III) complexes are relatively insensitive to photolysis, showing low photoaquation reactivity. $37,38,40,42$

Photolysis of aqueous $\mathrm{Rh}$ (III) complexes leads only to photosubstitution reactions. $37,38,40,42$ The efficiency of the intersystem crossing from the singlet to triplet manifold for $\mathrm{Rh}$ (III) is unity, with the result that the photochemistry arises from triplet, ligand-field excited states. The same net photosubstitution products are obtained for irradiation of the ligand field or charge transfer to metal bands, but the quantum yields are lower for the CTTM case. This difference has been interpreted in terms of a photoredox 
pathway for the CTTM case. Some of the ligand-substitution reactions for Rh(III) compounds have proved useful for the synthesis of new compounds. Photoredox reactions have been reported for solvated Pd(II) complexes when the CTTM bands were photolyzed. $37,38,42$ Photoreduction of the Pd(II) with associated ligand oxidation has been observed and in the case of one complex yielded metallic palladium.

Photochemical oxidation of $S n(I I)$ to $S n(I V)$ in solution, with an $S n$ (II) dimer complex as the light absorber, has been reported. 41

Several rare earth ions display solution photochemistry. ${ }^{37,38,42}$ The photochemistry of the $\mathrm{Ce}$ (IV)-Ce(III) couple has been of interest because of the net decomposition of water to oxygen and hydrogen. The Ce(IV) ion oxidation of organic substrates is accelerated when they are subjected to light. A similar photoredox couple is the Eu(III)-Eu(II) system, which generates hydrogen gas in acidic aqueous solutions. In the presence of isopropanol the hydrogen atom photogenerated by this couple oxidizes the alcohol to acetone and forms hydrogen gas. Similar photochemistry is observed for the Sm(III)$\mathrm{Sm}(\mathrm{II})$ and $\mathrm{Yb}(\mathrm{III})-\mathrm{Yb}(\mathrm{II})$ couples. Photolysis of aqueous nitric acid solutions of $\mathrm{Ce}(\mathrm{IV})$ has been reported to result in $\mathrm{Ce}(\mathrm{III})$ and $\mathrm{NO}_{3}$ generation. 43,44 The solvated halate anions $\mathrm{IO}_{3}{ }^{-}$and $\mathrm{BrO}_{3}{ }^{-}$undergo photoreduction to give $\mathrm{IO}^{-}$or $\mathrm{BrO}^{-}$and oxygen. 42

Utilization of the photochemical reactions discussed here in separating fission products from the nuclear waste solutions could be envisioned for photoredox and photosubstitution reactions. The photoredox fractionating process could possibly involve solvent extraction schemes such as those proposed for the ion exchange-separations or precipitations of actinides. The 
photosubstitution reactions could conceivably lead to increased solubility of a complex in an extracting solvent or precipitation.

\subsection{Nitric Acid Photochemistry}

Photochemical decomposition of nitric acid by sunlight was first observed in 1777. It was reported that oxygen was evolved and the liquid turned yellow. 45 Later work indicated that the photodecomposition was reversible. 45 A solidstate electron-spin-resonance study ${ }^{46}$ showed the primary photolysis products to be $\mathrm{OH}$ and $\mathrm{NO}_{2} \cdot$

Nitrate solutions photolyzed in the $300-\mathrm{nm}$ band were found to give a $\mathrm{NO}_{2}{ }^{-}$ quantum yield of 0.04 which was independent of light intensity and nitrate concentration. The reaction mechanism proposed is 47

$$
\begin{gathered}
\mathrm{NO}_{3}^{-} \longrightarrow \mathrm{NO}_{2}^{-}+\mathrm{hv}, \\
\mathrm{O}+\mathrm{NO}_{3}^{-} \longrightarrow \mathrm{O}_{2}+\mathrm{NO}_{2}^{-}, \\
\mathrm{O}+\mathrm{NO}_{2}^{-} \longrightarrow \mathrm{NO}_{3}^{-} .
\end{gathered}
$$

In the presence of radical scavangers the $\mathrm{NO}_{2}{ }^{-}$quantum yield increases to a maximum of 0.15 . The quantum yield for nitrite formation is roughly constant in the acid region. 47,48

Shuali et al., 48 in a study on the photochemistry of aqueous nitrate solutions excited in the 195-nm band region, obtained results that appear to be inconsistent with a mechanism involving intermediate oxygen atoms. They suggested that $\mathrm{NO}_{3}{ }^{-}$photodecomposition consisted of four primary independent proc- 
esses resulting in generation of pernitrite, hydroxyl radical, and molecular oxygen.

In a study of the $200-\mathrm{nm}$ band photochemistry it was proposed that the primary process is

$$
\mathrm{NO}_{3}^{-}+\mathrm{H}_{2} \mathrm{O} \longrightarrow \mathrm{NO}_{2}+\mathrm{OH}+\mathrm{OH}^{-} \text {, }
$$

similar to the photodecomposition observed for the halate ions, ${ }^{49}$ with the recombination of $\mathrm{NO}_{2}$ and $\mathrm{OH}$ explaining the peroxynitrous acid product.

Although the question of the mechanism for photochemical decomposition of the nitrate ion is unsettled, it is clear that nitrous acid is an end photoproduct. As discussed in section 3, sodium nitrite is an important additive in the Purex process. Since the Purex aqueous solutions are 2 to $3 \underline{M}$ nitric acid, this gives a system in which the required oxidant $\mathrm{NO}_{2}{ }^{-}$could possibly be generated photochemically. Furthermore, generation of $\mathrm{NO}_{2}^{-}$need not. he restricted to the aqueous solutions, since the photolysis of the organic TBP phase also produces nilrous ac1d. 50 Thus some of the initial $\mathrm{NO}_{2}^{-}$. loss to the organic phase probably can be recovered photochemically.

\subsection{Excited State Quenching}

In addition to the problem of interfering light absorption (covered in section 4), which prevents excitation of the desired ion or results in unwanted photochemistry, there is the problem of interfering excited-state quenching, which results in lower yields or in unwanted chemistry via energy transfer mechanisms. $21,25-29,51$ Quenching of excited uranyl ion by organic molecules can be advantageous or undesirable. For example, it is suggested that the desired photoreduction of excited $\mathrm{UO}_{2}{ }^{2+}$ by alcohols (see section 2.1.1) occurs by a quench- 
ing mechanism ${ }^{25-28}$ with a quenching rate constant of $10^{8}$ to $10^{7} \underline{\mathrm{M}}^{-1} \mathrm{sec}^{-1}$. However, excitation of uranyl ion in the presence of aromatic molecules results in complex quenching which does not give photochemistry. $27,28,51$

Energy transfer to inorganic ions may interfere with desired photochemistry. Energy transfer occurs from a donor to an acceptor with energy levels at lower energies than the emitting level of the donor. The usual criterion for energy transfer is that the fluorescence spectrum of the donor should overlap the absorption spectrum of the acceptor. The rare earth Eu(III) ion satisfied these conditions and has been reported 29,51 to quench the uranyl fluorescence with a quenching rate constant of $\sim 10^{7} \underline{M}^{-1} \sec ^{-1}$. As is evident in Figure 2.31, the only rare earth ions expected not to quench the uranyl ion by the above criterion are $\mathrm{Ce}(\mathrm{III}), \mathrm{Gd}(\mathrm{III})$, and $\mathrm{Yb}(\mathrm{III})$. It has been reported that $\mathrm{Gd}^{3+}$ does not quench $\mathrm{UO}_{2}{ }^{2+}$ fluorescence. ${ }^{29}$ The $\mathrm{Tl}(\mathrm{I})$ ion quenches excited $\mathrm{UO}_{2}{ }^{2+}$ and thereby prevents the $\mathrm{UO}_{2}{ }^{2+}$-lactic acid photoreaction. ${ }^{51}$ The $\mathrm{Tl}$ (I) quenching rate constant reported was $5 \times 10^{9} \underline{M}^{-1} \mathrm{sec}^{-1}$, which is close to the diffusion limit (this is not a Purex solution component and is presented only because it is the largest actinide quenching rate constant found in the literature).

Very little work has been reported on the quenching of excited actinide ions by inorganic ions. Let us explore a hypothetical situation, in which the net concentration of species that can quench the excited actinide ion is assumed to be $20.1 \mathrm{M}$. For the initial Purex solution conditions given in Table 3.3 this would approximate the concentration of fission products. Thus a quenching pseudo rate constant of $\sim 10^{6} \mathrm{sec}^{-1}$ would apply to these solutions, assuming the rare earth ions have quenching rate constants comparable with that for Eu ${ }^{3+}$ For an alcohol photochemical reduction with this solution, assuming rate constants for neptunium and plutonium comparable with the value of $24 \times 10^{7}$ for the ethanol- 


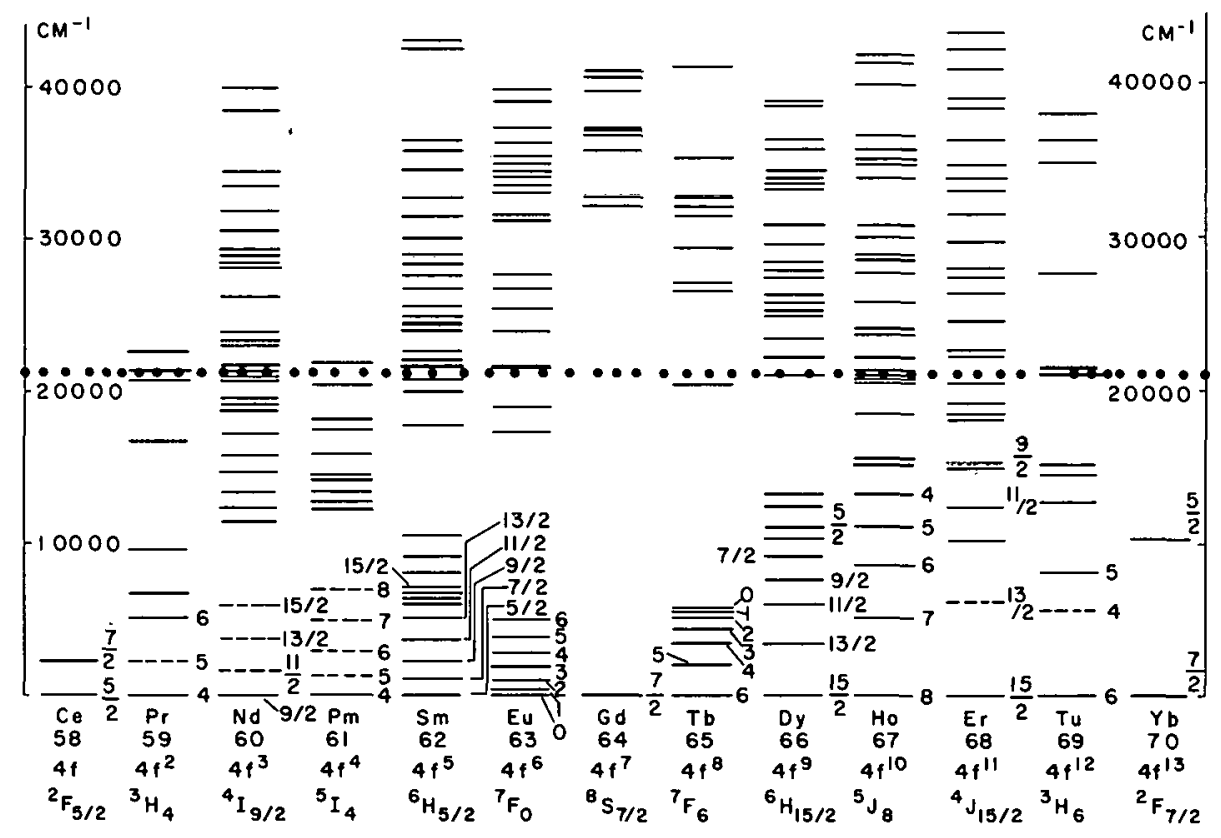

Figute 2.31. Cumparison of the electronic levels of the triply charged ions of the lanthanides. Levels of the deepest multiplet term are distinguished by heavy lines. The dashed lines relate to the levels whose pusition was determined by means of calculation. The dotted line represents the bottom of the fluores: cence band of the excited uranyl ion. (From El'yashevich. 78) 
urany1 system, ${ }^{21}$ the photochemical pseudo rate constant for $1.0 \underline{M}$ ethanol solutions would be $4 \times 10^{7} \mathrm{sec}^{-1}$ for the uranium, neptunium, and plutonium ion systems. That is, $\sim 2 \%$ of the excited actinide ions could be quenched by the rare earth ions and thereby lost to photoreduction for the initial Purex solutions under the above assumptions. The details are as follows:

Known Photochemistry:

$$
\begin{gathered}
\mathrm{UO}_{2}{ }^{2+} \stackrel{\mathrm{hv}}{\longrightarrow}\left(\mathrm{UO}_{2}{ }^{2+}\right) * \\
\left(\mathrm{UO}_{2}{ }^{2+}\right) *+2 \mathrm{CH}_{3} \mathrm{CH}_{2} \mathrm{OH} \stackrel{\mathrm{k}_{\mathrm{r}} \sim 4 \times 10^{7} \underline{\mathrm{M}}^{-1} \mathrm{sec}^{-1}}{\longrightarrow} \mathrm{UO}^{2+}+2 \mathrm{CH}_{3} \mathrm{CH}_{2} \mathrm{O}+2 \mathrm{H}_{2} \mathrm{O} \\
\left(\mathrm{UO}_{2}{ }^{2+}\right) *+\mathrm{Eu}^{3+} \stackrel{\mathrm{k}_{\mathrm{q}} \sim 10^{7} \underline{\mathrm{M}}^{-1} \mathrm{sec}^{-1}}{\longrightarrow} \mathrm{UO}_{2}{ }^{2+}+\left(\mathrm{Eu}^{3+}\right) *
\end{gathered}
$$

Assume:

$$
\begin{aligned}
& \mathrm{k}_{\mathrm{r}}=4 \times 10^{7} \underline{\mathrm{M}}^{-1} \mathrm{sec}^{-1} \\
& \mathrm{k}_{\mathrm{q}}=10^{7} \underline{\mathrm{M}}^{-1} \mathrm{sec}^{-1} \\
& \text { Quencher concentration }=[\mathrm{Q}]=0.1 \underline{\mathrm{M}} \\
& \text { Alcohol concentration }=[\mathrm{R}]=1.0 \underline{\mathrm{M}}
\end{aligned}
$$

Define:

$$
\begin{aligned}
& \mathrm{Q}=\% \text { of excited actinide lost due to quenching } \\
& \mathrm{Q}=\frac{\mathrm{k}_{\mathrm{q}}[\mathrm{Q}]}{\mathrm{k}_{\mathrm{r}}[\mathrm{R}]+\mathrm{k}_{\mathrm{q}}[\mathrm{Q}]} \longrightarrow \times 100
\end{aligned}
$$

Quenching losses for the photochemical system.

$$
\begin{aligned}
Q= & \frac{10^{7} \times 0.1}{4 \times 10^{7} \times 1.0+10^{7} \times 0.1} \\
& =2.4 \%
\end{aligned}
$$


Thus quenching processes may be important in evaluating the actinide photochemistry. The above numerical argument assumes that all the rare earth ions quench each of the excited actinides, that the rare earth quenching-rate constant is $10^{7} \underline{M}^{-1} \mathrm{sec}^{-1}$, the photoredox reaction rate constant in $4 \times 10^{7} \underline{M}^{-1} \sec ^{-1}$, and the solution composition is that of the initial Purex solution. The viability of the first three assumptions is not known and therefore must be investigated experimentally before the exact limitations of rare earth quenching can be evaluated. Only a few studies have been reported which contain reliable photuchemical reaction rate constants. More rate data on the various promising photochemical systems are needed before the role of interfering quenching can be evaluated.

The last assumption assumes the worst conditions under which rare earth quenching will prevail in the Purex processing. As discussed in section 3 , after the first step of the Purex process (see Figure 3.1) $299 \%$ of the rare earths are removed to the fission product aquenus phase. For oubsequent sululluns the rare earth quenching losses would be $\sim 2 \times 10^{-2} \%$ under the above assumptions.

The abuve dlscussion on quenching ignores the other fission product inns listed in Table 3.3 because data in the literature are insufficient. However, they could be important. For example, if the combined fission product quencher concentration was $1.0 \underline{\mathrm{M}}$ the excited actinide loss would be $2.24 \%$ under the above assumptions. Experimental data are needed in this area.

The limitations imposed on the actinide photochemistry by interfering fissilon product quenching are important. Experimental data must be generated before these limits can be defined. 
2.7 Effects of Radiation on Photochemical and Thermochemical Yields

For solutions containing radioactive spent fuel rod components, there will be constant emission of high energy radiation. The extent of direct interactions of ionizing radiation with a component of a multicomponent solution is proportional to the component's electron fraction in the mixture. Table 2.9 gives the relevant information and calculation of the extent of direct interaction for. the Purex solution components of interest. The last column shows that $\sim 71 \%$ of the absorbed ionizing radiation interacts with water, $13 \%$ and $15 \%$ of the interaction occurs with $\mathrm{HNO}_{3}$ and $\mathrm{UO}_{2}{ }^{2+}$, and negligible interaction occurs with the neptunium or plutonium ions. Since neptunium and plutonium are the elements chemically changed to achieve partitions, the direct ionizing radiation interactions with these ions will not play a significant role in changing their oxidation states. However, indirect radiation effects on these ions could be important.

For the aqueous Purex solutions the predominant direct interaction with ionizing radiation will involve water molecules. The water-radiation interaction will produce light (Cerenkov radiation), excited molecules (electronic and vibrational), and free radicals as the radiation passes through the solution, the end result being generation of heat and chemical products. $52-58$

Reaction of the free radicals, generated by the interaction of ionizing radiation with $\mathrm{H}_{2} \mathrm{O}$ and $\mathrm{HNO}_{3}$, with the actinides must be considered for the $99.9 \%$ recovery level. Thus the free radical chemistry could alter the yields of a given actinide valence state and prevent achievement of the required recovery levels. Such interfering free radical chemistry can occur in thermochemical or photochemical processing. 
Table 2.9

Distribution of Direct Interaction of Ionizing

Radiation for a Purex Solution

\begin{tabular}{lcccc}
\hline $\begin{array}{c}\text { Mixture } \\
\text { component }\end{array}$ & $\mathrm{F}^{\mathrm{a}}$ & $\mathrm{C}$ (moles/liter) & $\mathrm{F} \cdot \mathrm{C}$ & $\% \mathrm{DI}^{\mathrm{b}}$ \\
\hline $\mathrm{H}_{2} \mathrm{O}^{2}$ & 10 & 50 & 500 & 71 \\
$\mathrm{HNO}_{3}$ & 32 & 3 & 96 & 13 \\
$\mathrm{UO}_{2}{ }^{2+}$ & 106 & 1 & 106 & 15 \\
$\mathrm{NpO}_{2}{ }^{2+}$ & 107 & $8 \times 10^{-4}$ & 0.09 & 0.01 \\
$\mathrm{PuO}_{2}{ }^{2+}$ & 108 & $1 \times 10^{-2}$ & 1.1 & 0.16 \\
\hline
\end{tabular}

$a_{\text {Number of electrons in molecule. }}$

${ }^{\mathrm{b}_{\text {Percent }}}$ direct interaction $\equiv \% \mathrm{DI}$, where $\% \mathrm{DI}_{\mathbf{x}}=\mathrm{F}_{\mathbf{x}} \mathrm{C}_{\mathbf{x}} / \sum_{i} \mathrm{~F}_{\mathbf{x}} \mathrm{C}_{\mathbf{x}} \mathbf{x} 100$ 
The thermal power levels calculated for the actinide elements in a spent LWR fuel $\operatorname{rod}^{61}$ change from $10^{5}$ watts/MT at discharge from the reactor to $9 \times 10^{2}$, $4 \times 10^{2}$, and $2 \times 10^{2}$ watts/MT for 90 days, 1 year and 3 years after discharge respectively (data from ORNL-4451, Table 3.18). 61

The corresponding high energy radiation dose rates in electron volts per liter (assuming dissolution of one metric ton of fuel in 3590 1iters) per second are $2 \times 10^{20}$ at discharge and $2 \times 10^{18}, 7 \times 10^{17}$, and $4 \times 10^{17}$ for 90 days, 1 year, and 3 years respectively. The extremes of $2 \times 10^{20}$ and $4 \times 10^{17}$ ev/liter are taken as a representative range for the following calculations.

The number of species produced per $100 \mathrm{ev}$ of ionizing radiation absorbed is defined as the G-value and is the unit of measure for radiation chemical yields. The above extremes in terms of product production rate are thus $3 \times 10^{-6} \times G$ and $6 \times 10^{-9} \times G$, where the units are moles liter ${ }^{-1} \sec ^{-1}$. The Gvalues for free radical redox reactions of metal ions in water are a sensitive function of $\mathrm{pH}, 52,53,55$
solution composition to the difference in energy deposition properties for the various forms $(\alpha, \beta, \gamma)$ and energies of ionizing radiation]. The $G$ (redox) value can vary over several orders of magnitude, depending on the ion undergoing the redox reaction and solution conditions. For the $\mathrm{Fe}^{2+}-\mathrm{Fe}^{3+}$ system in $0.8 \underline{\mathrm{N}}$ sulfuric acid $\left.\mathrm{G}^{52} \mathrm{Fe}^{3+}\right)=$ 15.5, but in the presence of methanol $\mathrm{G}\left(\mathrm{Fe}^{3+}\right)=30$, and in the presence of $0.1 \mathrm{M}$ formic acid $\mathrm{G}\left(\mathrm{Fe}^{3+}\right)=230$. In the presence of $\mathrm{Co}^{2+}, \mathrm{G}\left(\mathrm{Fe}^{3+}\right)$ decreases to 4.1. The $G($ redox) values for the actinide ions in Purex type solutions will be arbitrarily assumed to fall within the $G\left(\mathrm{Fe}^{3+}\right)=15.5$ to 230 range.

For a $G$ of 15.5 the product production rate range is $4 \times 10^{-5}$ to $9 \times 10^{-8}$ mole liter ${ }^{-1} \mathrm{sec}^{-1}$, while for $G=230$ it is $6 \times 10^{-4}$ to $10^{-6}$. Let us assume a process extraction time of $1 \mathrm{hr}$ during which a given actinide has its valence 
state chemically changed and is separated from the process stream. The ionizing radiation during this time could interfere with the desired valence state change to the extent of 0.2 to $3 \times 10^{-4} \underline{M}$ for a G of 15.5 , and 2.3 to $4 \times 10^{-3}$ M for a $G$ of 230 . For $99.9 \%$ recovery of uranium and plutonium one will be working with $10^{-3} \underline{M}$ and $10^{-5} \underline{M}$ solutions, respectively. Therefore the radiation chemistry could be a limiting factor to their recovery if the above conditions exist in the reprocessing stream. This argument is independent of how the desired valence state change is brought about. Thus either thermochemical or photochemical processes may be limited by the radiation chemistry. However, one advantage that photochemistry has over thermochemistry is the reaction rate. The photochemical redox rates are much faster and this should decrease processing time and more rapidly correct any interfering valence state change.

The extent of electronic excitation due to ionizing radiation is sma11. 56,58 It is not certain whether electronically excited solute species are generated via energy transfer from excited solvent or by subexcitation electrons. The use of $x-$ and $\gamma$-irradiation to induce light emission from aqueous salicylate solutions 56,59 gave an upper limit for $G$ (excitation) of 20.25 . An earlier formic acid study 58 based on carbon monoxide photodecomposition quantum yields and ionizing radiation yields found the G-value for excitation by ionizing radiation to be in the 0.4 to 1.7 range. Comparison of the radiation chemistry G-values with these radiation excitation $G$-values indicates that the yields of excited states by ionizing radiation in aqueous solutions will be from 11 to $0.1 \%$ of those for the radiation chemistry. Thus, electronic excitation due to ionizing radiation is not expected to be a limitation on the photochemical approach. 


\subsection{NUCLEAR WASTE PROCESSING}

Nuclear waste processing normally consists of chopping up the spent reactor fuel rods, dissolving the solid in 2 to $3 \underline{M}$ nitric acid, and fractionating $\mathrm{U}, \mathrm{Np}$, and $\mathrm{Pu}$ in a Purex process. In this process, these three actinides are coextracted from the rest of the aqueous components into an organic phase composed of normal tributyl phosphate dissolved in kerosene. Subsequent separation of these three actinides from each other involves selective oxidation state changes coupled with solvent extraction.

At present, no spent nuclear fuel reprocessing plants are in operation. The Nuclear Fuel Services plant, the only large-scale, commercial facility with processing experience, is being modified. This plant, using a Purex separation flow sheet, had uranium and plutonium recovery levels of about $98.5 \%$ on the aveage. Neptunium was not recovered in the NFS plant since there was no economic incentive. However, Ỹemoval of neptunium via the Purex process has reached 90 to $99 \%$ recovery levels at Hanford and Savannah River.

Partitioning of spent nuclear rods was initially undertaken to recover the commercially valuable uranium and plutonium and therefore processing was pursued only to the extent that it was economically advantageous. Because of the long-lived, hazardous radionuclides (actinides) present in the waste streams from the partitioning process, the wastes must be isolated from the general environment for a million years or longer. Fractionating these waste solutions to remove a significant portion of the actinides could alleviate some of the long-term storage and hazard problems.

About 60 wt \% of the fission products decay to stable daughters in 100

years. After 1000 years, only a few fission products (e.g., ${ }^{129} \mathrm{I},{ }^{83} \mathrm{Zr},{ }^{99} \mathrm{Tc}$, ${ }^{107} \mathrm{Pd},{ }^{135} \mathrm{Cs}$ ) and the actinides present any hazard due to radioactivity. Based 
on Bond and Leuze, ${ }^{60}$ removal of the actinides to the extent indicated in Table 3.1 for various spent reactor fuel rods will yield waste solutions that will decay in 1000 years to hazard levels comparable with those for natural existing uranium ores. To attain these recovery levels, an add-on process utilizing ion exchange columns ${ }^{60}$ has been proposed and is being developed. The alternative approach proposed here is to utilize photochemistry to drive the Purex redox reactions further toward completion and thereby improve the extraction process. Both add-on and replacement photochemical processing modifications should be considered.

In the present study the waste stream conditions and actinide removal levels specified by Bond and Leuze ${ }^{60}$ are used. Thus all the rare gases, $100 \%$ of the tritium, $99.9 \%$ of the iodine, and all the activation products produced in the fuel and cladding are assumed not to be present in the process fraction. Al1 other fission products and actinides are assumed to be in the process fraction to the levels specified by the ORIGEN codes (see Table 3.2).

The nuclear waste solutions used in processing spent fuel rods are chemically complex multicomponent mixtures. To attain the removal levels indicated in Table 3.1 will require development of new processing schemes which could either be added to an existing Purex process or replace part of it. Bond and Leuze propose a scheme based on exhaustive extraction-ion exchange add-on procedures. One task of the present report is to evaluate the potential of photochemistry for developing into a viable add-on or replacement process.

\subsection{Composition of Reprocessing Solutions}

Table 3.2 lists the total masses of significant actinides and fission product elements calculated to be present in the spent fuel and in the wastes generated by reprocessing of this fuel. 
Table 3.1

Percentage Removals From Spent Fuels Required To Reduce the Hazard Index ${ }^{a}$ of Aged Wastes to $25 \%$ of that of Pitchblende. ${ }^{b}$

(Fröm Bond and Leuze). 60

\begin{tabular}{lllll}
\hline Actinide & PWR-U & PWR-Pu & LMFBR & HTGR \\
\hline Th & & & & 95.5 \\
$\mathrm{~Pa}$ & & & & 95.0 \\
$\mathrm{U}$ & 99.9 & 99.9 & 99.9 & 99.99 \\
$\mathrm{~Np}$ & 95.0 & 95.0 & 70.0 & 95.0 \\
$\mathrm{Pu}$ & 99.95 & 99.99 & 99.99 & 99.9 \\
$\mathrm{Am}$ and Cm & 99.9 & 99.9 & 99.9 & 95.0 \\
\hline
\end{tabular}

a The hazard index is defined as the volume of water required to dilute a unit volume of a radionuclide mixture to the levels defined in the Code of Federal Regvilations ( $10 \mathrm{CFR}$, Part 20) as the maximum permissible concentration for unrestricted use of water. The hazard index provides only an approximate comparison of radiological risks since it does not allow for accumulation or reconcentration of a nuclide in environmental media, or for the total impact of a number of nuclides. For limited comparisons, it is an acceptable alternative to dose calculations if used with caution.

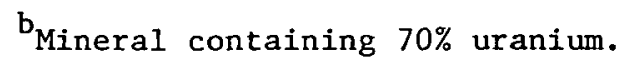


Table 3.2

\section{Actinides and Fission Products in Waste}

Total masses of important actinide and significant fission product elements calculated to be present in spent Diablo Canyon reference LWR fuel and in wastes generated by the reprocessing of this fuel, 90 days after discharge from the reactor. The reactor operating power was taken as $30.00 \mathrm{MW} / \mathrm{MT}$, the byrnup as 33000 $\mathrm{MWD} / \mathrm{MT}$, and the flux as $2.91 \times 10^{13}$ neutrons $\mathrm{cm}^{2} \mathrm{sec}^{-1}$. The concentrations are given in grams per metric ton of fuel charged to the reactor. Data calculated by using the ORIGEN code, ORNL$4451^{61}$ (Tables 3.8 and 3.14).

\begin{tabular}{|c|c|c|c|c|}
\hline Element & $\mathrm{g} / \mathrm{MT}$ & & Element. & $\mathrm{g} / \mathrm{MT}$ \\
\hline Th & $2.56 \times 10^{-4}$ & & $\mathrm{Pd}$ & $1.28 \times 10^{3}$ \\
\hline $\mathrm{Pa}$ & $2.11 \times 10^{-6}$ & & $\mathrm{Ag}$ & $6.01 \times 10^{1}$ \\
\hline $\mathrm{U}$ & $9.55 \times 10^{5}$ & & $C d$ & $8.35 \times 10^{1}$ \\
\hline $\mathrm{Np}$ & $7.62 \times 10^{2}$ & & In & 1.20 \\
\hline $\mathrm{Pu}$ & $9.08 \times 10^{3}$ & & Sn & $5.16 \times 1.0^{1}$ \\
\hline Am & $1.44 \times 10^{2}$ & & $\mathrm{Sb}$ & $1.80 \times 10^{1}$ \\
\hline$-C m$ & $3.68 \times 10^{1}$ & & $\mathrm{Te}$ & $5.66 \times 10^{2}$ \\
\hline $\mathrm{H}$ & $7.20 \times 10^{-2}$ & & I & $2.71 \times 10^{2}$ \\
\hline Ga & $1.04 \times 10^{-19}$ & & $\mathrm{Xe}$ & $5.42 \times 10^{3}$ \\
\hline$\overline{\mathrm{Ge}}$ & $3.79 \times 10^{-1}$ & & Cs & $2.74 \times 10^{3}$ \\
\hline Ao & $8.78 \times 10^{-2}$ & & $\mathrm{Ba}$ & $1.37 \times 10^{3}$ \\
\hline Se & $5.20 \times 10$ & & La & $1.27 \times 10^{3}$ \\
\hline $\mathrm{Br}$ & $1.51 \times 10$ & . & $\mathrm{Ce}$ & $2.92 \times 10^{3}$ \\
\hline $\mathrm{Kr}$ & $3.74 \times 10^{2}$ & & $\operatorname{Pr}$ & $1.19 \times 10^{3}$ \\
\hline $\mathrm{Rb}$ & $3.33 \times 10^{2}$ & & Nd & $3.87 \times 10^{3}$ \\
\hline $\mathrm{Sr}$ & $9.02 \times 10^{2}$ & & $\Gamma_{\mathrm{Tii}}$ & $1.12 \times 10^{2}$ \\
\hline $\mathrm{Y}$ & $4.71 \times 10^{2}$ & & $\mathrm{Sm}$ & $8, n 3 \times 10^{2}$ \\
\hline $\mathrm{zr}$ & $3.66 \times 10^{3}$ & & $\mathrm{Eu}$ & $1.82 \times 10^{2}$ \\
\hline $\mathrm{Ml}$ & $2.22 \times 10^{1}$ & & Gd & $1.02 \times 10^{2}$ \\
\hline Mo & $3.42 \times 10^{3}$ & & $\mathrm{Ilb}$ & 1.82 \\
\hline Tc & $8.35 \times 10^{2}$ & & Dy & $9.93 \times 10^{-1}$ \\
\hline $\mathrm{Ru}$ & $2.28 \times 10^{3}$ & & Ho & $8.49 \times 10^{-2}$ \\
\hline $\mathrm{Rh}$ & $3.84 \times 10^{2}$ & & Er & $2.79 \times 10^{-2}$ \\
\hline
\end{tabular}


Table 3.3 lists the predominant valence state species and concentrations expected for initial dissolution of the fuel rods. Here 1 MT of fuel was assumed to be present in 3590 liters of $2 \underline{\mathrm{M}}_{\mathrm{HNO}_{3}}$.

During the Purex process sodium nitrite and ferrous sulphamate are added to carry out required thermochemistry. The organic phase in the Purex process consists of $30 \%$ tri-n-butyl phosphate (TBP) in kerosene. The TBP is an extracting agent used to increase the solubilities of the actinides in the organic phase.

\subsection{Purex Chemistry}

The Purex schemes utilize the differences in solubility of the various $\mathrm{U}, \mathrm{Np}, \mathrm{Pu}$, and fission product valence states in aqueous and organic phases to achieve fractionation. In particular $\mathrm{Np}(\mathrm{V})$ and $\mathrm{Pu}(\mathrm{II})$ are soluble in the aqueous 2 to $3 \underline{M}$ nitric acid phase but insoluble in the organic phase.

As indicated in Figure 3.1, coextraction of $U, N p$; and $U$ into the organic phase is accomplished in the first cycle of the Purex process. This requires adjusting the valence states of neptunium and plutonium to $\mathrm{Np}(\mathrm{VI})$ and $\mathrm{Pu}(\mathrm{IV})$. The neptunium is raised to the (VI) oxidation state, $\mathrm{NpO}_{2}{ }^{2+}$, by nitrous acidcatalyzed oxidation of $\mathrm{Np}(\mathrm{V})$ with nitric acid. 'The plutonium ion $\mathrm{Pu}^{4+}$ results from reduction of $\mathrm{PuO}_{2}{ }^{2+}$ by nitrous acid. The U(VI) valence state of $\mathrm{VO}_{2}{ }^{2+}$ is a result of air oxidation and is the desired species.

These three actinide ions àre then complexed by TBP and partitioned to the organic kerosene phase as the neutral, nitrated TBP complexes ${ }^{62}$ : $\mathrm{UO}_{2}\left(\mathrm{NO}_{3}\right)_{2} \cdot 2 \mathrm{TBP}, \mathrm{NpO}_{2}\left(\mathrm{NO}_{3}\right) \cdot 2 \mathrm{TBP}$, and $\mathrm{Pu}\left(\mathrm{NO}_{3}\right)_{4} \cdot 2 \mathrm{TBP}$. Similar neutral, TBP-solvated complexes have been reported for some fission product nitrate species. ${ }^{62}$

The aqueous phase resulting from this initial extraction cycle is referred to as the high level waste. This waste contains the fission products, including 
Table 3.3

Initial Purex Solution Composition

(Based on the Data in Table 3.2).

One metric ton of fuel was assumed to be dissolved in 3590 liters of solution. The molecular weights used in calculating moles per liter are those for the uncomplexed species shown.

\begin{tabular}{|c|c|c|c|c|c|}
\hline Ion & g/liter & moles/liter & Ion & g/1iter & moles/liter \\
\hline $\mathrm{Th}^{4+}$ & $7.13 \times 10^{-8}$ & $3.07 \times 10^{-10}$ & $\mathrm{Ag}^{+}$ & $1.67 \times 10^{-2}$ & $1.55 \times 10^{-4}$ \\
\hline $\mathrm{PaO}_{2}^{+}$ & $5.88 \times 10^{-10}$ & $2.23 \times 10^{-12}$ & $\mathrm{Cd}^{2+}$ & $2.33 \times 10^{-2}$ & $2.08 \times 10^{-4}$ \\
\hline $\mathrm{UO}_{2}{ }^{2+}$ & $2.66 \times 10^{2}$ & $9.85 \times 10^{-1}$ & $\mathrm{In}^{3+}$ & $3.34 \times 10^{-4}$ & $2.91 \times 10^{-6}$ \\
\hline $\mathrm{NpO}_{2}{ }^{2+}$ & $2.12 \times 10^{-1}$ & $7.88 \times 10^{-4}$ & $\mathrm{Sn}^{4+}$ & $1.44 \times 10^{-2}$ & $1.21 \times 10^{-4}$ \\
\hline $\mathrm{Pu}^{4+}$ & 2.53 & $1.05 \times 10^{-2}$ & $\mathrm{Sb}^{5+}$ & $5.01 \times 10^{-3}$ & $4.11 \times 10^{-5}$ \\
\hline $\mathrm{Am}^{3+}$ & $5.93 \times 10^{-1}$ & $2.44 \times 10^{-3}$ & $\mathrm{Te}^{4+}$ & $1.58 \times 10^{-1}$ & $1.23 \times 10^{-3}$ \\
\hline $\mathrm{Cm}^{3+}$ & $1.49 \times 10^{-1}$ & $6.11 \times 10^{-4}$ & $\mathrm{Cs}^{+}$ & $7.63 \times 10^{-1}$ & $5.74 \times 10^{-3}$ \\
\hline $\mathrm{Ga}^{3+}$ & $2.90 \times 10^{-23}$ & $4.14 \times 10^{-25}$ & $\mathrm{Ba}^{2+}$ & $3.82 \times 10^{-1}$ & $2.79 \times 10^{-3}$ \\
\hline $\mathrm{Ge}^{4+}$ & $1.06 \times 10^{-4}$ & $1.45 \times 10^{-6}$ & $\mathrm{La}^{3+}$ & $3.54 \times 10^{-1}$ & $2.55 \times 10^{-3}$ \\
\hline $\mathrm{AsO}_{4}^{3-}$ & $2.45 \times 10^{-5}$ & $1.76 \times 10^{-7}$ & $C e^{3+}$ & $8.13 \times 10^{-1}$ & $5.81 \times 10^{-3}$ \\
\hline $\mathrm{SeO}_{3}{ }^{2+}$ & $1.45 \times 10^{-2}$ & 1.14 & $\operatorname{Pr}^{3+}$ & $3.31 \times 10^{-1}$ & 2.35 \\
\hline $\mathrm{Rb}^{+}$ & $9.28 \times 10^{-2}$ & $1.09 \times 10^{-3}$ & $\mathrm{Nd}^{3+}$ & 1.02 & $7.49 \times 10^{-3}$ \\
\hline $\mathrm{Sr}^{2+}$ & $2.51 \times 10^{-1}$ & $2.86 \times 10^{-3}$ & $\mathrm{Pm}^{3+}$ & $3.12 \times 10^{-2}$ & $2.12 \times 10^{-4}$ \\
\hline $\mathrm{Y}^{3+}$ & $1.31 \times 10^{-1}$ & $1.47 \times 10^{-3}$ & $\mathrm{Sm}^{3+}$ & $2.24 \times 10^{-1}$ & $1.49 \times 10^{-3}$ \\
\hline $\mathrm{ZrO}^{2+}$ & 1.02 & $9.53 \times 10^{-3}$ & $\mathrm{Eu}^{3+}$ & $5.07 \times 10^{-2}$ & $3.31 \times 10^{-4}$ \\
\hline $\mathrm{Nb}^{5+}$ & $6.18 \times 10^{-3}$ & $6.65 \times 1.0^{-5}$ & $\mathrm{Gd}^{3+}$ & $2.84 \times 10^{-2}$ & $1.82 \times 10^{-4}$ \\
\hline $\mathrm{Mo}^{6+}$ & $9.53 \times 10^{-1}$ & $9.92 \times 10^{-3}$ & $\mathrm{~Tb}^{3+}$ & $5.07 \times 10^{-4}$ & $3.19 \times 10^{-6}$ \\
\hline $\mathrm{TcO}_{4}^{-}$ & $2.33 \times 1.0^{-1}$ & $1.44 \times 10^{-3}$ & $\mathrm{Dy}^{3+}$ & $2.77 \times 10^{-4}$ & $1.70 \times 10^{-6}$ \\
\hline $\mathrm{Ru}^{4+}$ & $6.35 \times 10^{-1}$ & $6.29 \times 10^{-3}$ & $\mathrm{Ho}^{3+}$ & $2.37 \times 10^{-5}$ & $1.43 \times 10^{-7}$ \\
\hline $\mathrm{Rh}^{3+}$ & $1.07 \times 10^{-1}$ & $1.04 \times 10^{-3}$ & $\operatorname{Er}^{3+}$ & $7.77 \times 10^{-6}$ & $4.65 \times 10^{-8}$ \\
\hline $\mathrm{Pd}^{2+}$ & $3.57 \times 10^{-1}$ & $3.36 \times 10^{-3}$ & & & \\
\hline
\end{tabular}




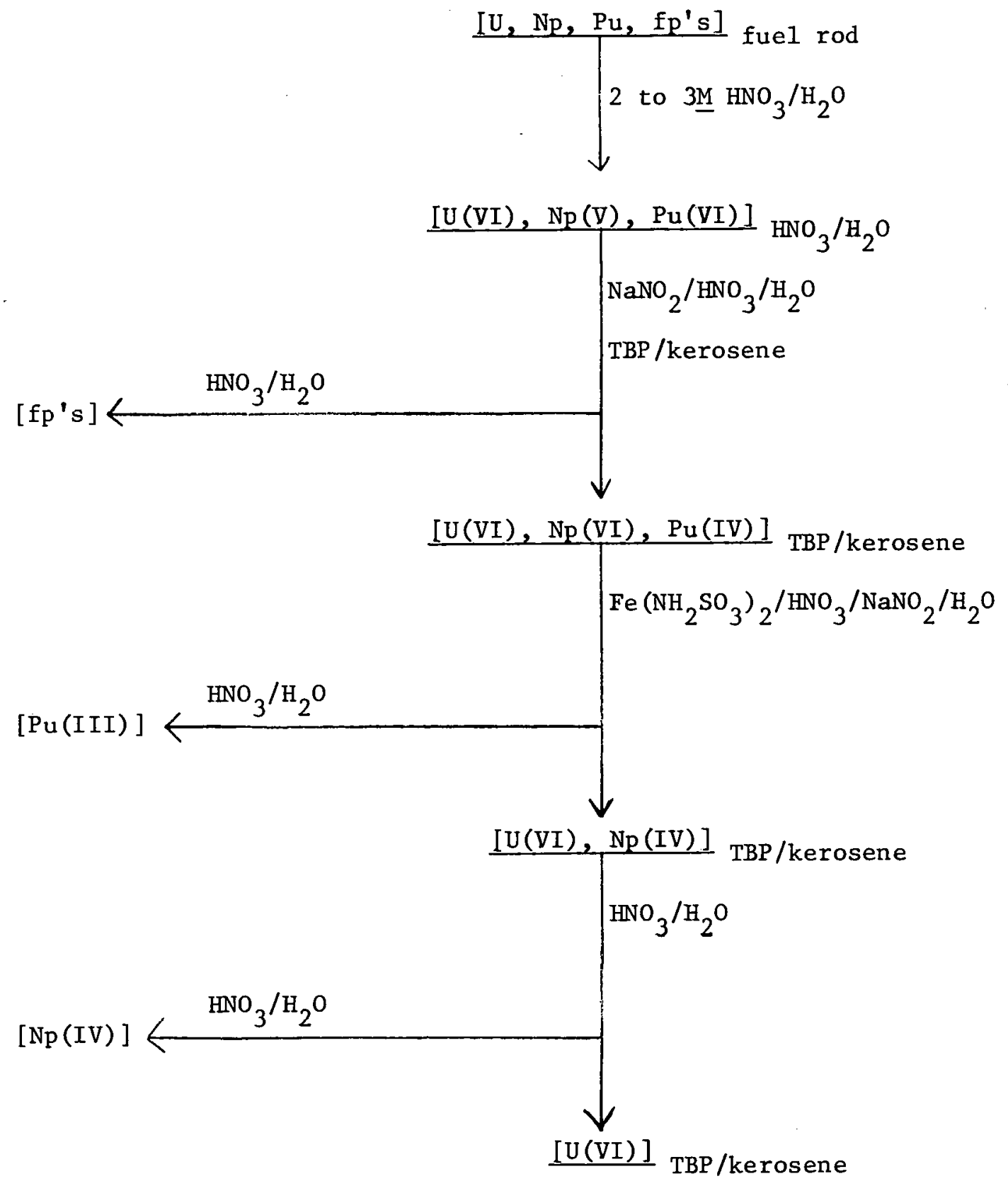

Figure 3.1. Chemical flow sheet for a Purex Process. 
Am, $\mathrm{Cm}$, and residual $\mathrm{U}, \mathrm{Np}$, and $\mathrm{U}$. In the NFS plant the high level waste contained $99.9 \%$ of the fission products plus $0.4 \%$ of the uranium and $1 \%$ of the plutonium. 60 Additional uranium (0.5\%) and plutonium (0.3\%) 1osses resulted from solvent purification steps at the NFS plant.

The washing of aqueous nitric acid solutions with the organic phase also results in extraction of the species $\mathrm{TBP} \cdot \mathrm{HNO}_{3}$ and $\mathrm{TBP} \cdot \mathrm{HNO}_{3} \cdot \mathrm{H}_{2} \mathrm{O}$ into the organic phase. 63-65 The resultant nitric acid depletion must be corrected during processing.

The second cycle of the Purex process involves fractionating the plutonium from the uranium and neptunium by extracting $\mathrm{Pu}^{3+}$ from the organic into the aqueous phase. The $\mathrm{Pu}(\mathrm{III})$ valence state is generated by adding a chemical reductant, such as ferrous sulphamate, $\mathrm{Fe}\left(\mathrm{NH}_{2} \mathrm{SO}_{3}\right)_{2}$, as shown in Figure 3.1. Because of $\mathrm{Np}(\mathrm{VI})$ reactivity with this reductant, excess $\mathrm{Fe}\left(\mathrm{NH}_{2} \mathrm{SO}_{3}\right)_{2}$ is required to ensure quantitative conversion to $\mathrm{Pu}^{3+}$ and $\mathrm{Np}^{4+}$. An alternative scheme to be used at the Barnwell plant involves electrolytic reduction of the $U(V I)$ to $U(I V)$, which then reduces $P u(I V)$ to $P u(I I I)$, regenerating $U(V I)$.

In the third cycle the neptunium is forced 1nto the aqueous wash pliase by keeping the organic phase highly saturated with uranium.

There are several recovery limitations, chemical complications, and recycling difficulties in the Purex process as outlined above. These subjects and possible thermochemical solutions are covered adequately by Bond and Leuze 60 and will not be repeated here. The particular problems that photochemistry may help alleviate are discussed ín section 5 .

\subsection{SPECTROSCOPY}

As shown in section 3 , the process solution is a complex mixture of clemental ions. To evaluate the utility of photochemical processing in such solu- 
tions, the spectral region of interest must be examined for interfering absorption bands. The interfering ion absorption band regions are identified and quantified below. Although a multicomponent system is involved, the fission product interfering band regions are not extensive or limiting with respect to the introduction of the exciting light required to carry out photochemical reactions of the actinides.

\subsection{Photochemical Spectral Range}

The wavelength range over which the actinides can be excited, with resultant photochemistry, extends from the visible through the ultraviolet. However, as discussed below, the usable photochemical wavelength region in the complex Purex solutions extends from $\sim 350$ to $\sim 1100 \mathrm{~nm}$. This wavelength range will be referred to as the Purex photochemical spectral range. Note that wavelengths shorter than $350 \mathrm{~nm}$ can be used to carry out actinide photochemistry if appropriately transparent solutions can be obtained.

Because of the high nitric acid concentrations, coupled with the large ultraviolet extinction coefficients for $\mathrm{NO}_{3}{ }^{-}$and many of the other ions in the process solution, one is limited to wavelengths longer than $\sim 350 \mathrm{~nm}$. The solutions are sufficiently opaque at shorter wavelengths that light could not be introduced into the system and/or large absorption losses due to unwanted light absorption by various interfering ions would occur. For photochemical processing of the actinides in other systems with fewer solution components, the upper limit could be extended into the ultraviolet.

The lower limit on the Purex photochemical spectral range is set by the lowest electronic transition that results in photochemical reaction. At present this has not been experimentally determined; therefore the lower limit will 
be taken as $\sim 1100 \mathrm{~nm}$, which corresponds to the lower actinide electronic transition bands.

It may be possible to extend the range of the exciting light to the region around $300 \mathrm{~nm}$ for the Purex process solutions and still get efficient, selective photochemistry. However, this would have to be determined experimentally since information on the composition of the complexes absorbing light in this region is currently too limited for useful evaluation.

\subsection{Preliminary Considerations and Simplifications}

Certain elements listed in Table 3.1 can be eliminated from the present spectroscopic considerations for trivial and/or straightforward reasons. As discussed in section 3.0 , all the rare gases, tritium, and iodine are assumed not to be present in the process solutions. Gallium is too minor a component to be considered. $\mathrm{Pa}, \mathrm{Ge}$, In, and $\mathrm{Nb}$ are at too low a concentration to have any significant impact on light absorption.

The following elements can be eliminated on the basis of their process valence states and resultant optical properties ${ }^{38,66-79}: \mathrm{As}(\mathrm{V}),{ }^{68} \mathrm{Rb}(\mathrm{I}), \mathrm{Sr}(\mathrm{II})$, $\mathrm{Y}(\mathrm{III}),{ }^{\prime /} \mathrm{Zr}(\mathrm{IV}), \operatorname{Tc}(\mathrm{VII}),{ }^{69,70} \mathrm{Ag}(\mathrm{I}), \operatorname{Cd}(\mathrm{II}),{ }^{71} \mathrm{Sn}(\mathrm{IV}),{ }^{72,73} \mathrm{Cs}(1), \mathrm{Ba}(11)$, $\mathrm{La}(\mathrm{III}),{ }^{77}$ and $\mathrm{Th}(\mathrm{IV}) .^{71,79}$ Because of the unoccupied electronic transition levels corresponding to the present Purex photochemical spectral range, these species will not have significant absorption bands (i.e., their extinction coefficients are considerably less than $1.0 \mathrm{M}^{-1} \mathrm{~cm}^{-1}$ ). Although they have the appropriate levels occupied, the ions As(III), ${ }^{68} \mathrm{Se}(\mathrm{IV}),{ }^{38} \mathrm{Te}$ (IV), ${ }^{74} \mathrm{Ce}$ (III), ${ }^{75,76}$ $\mathrm{Gd}(\mathrm{III}),{ }^{77,78}$ and $\mathrm{Tb}(\mathrm{III})^{77,78}$ have no significant absorption bands in the range of interest.

The above arguments apply to the solution conditions existing in the solvent extraction stages of the Purex plant. Changing the acidity, valence states, 
solvents, or solution components (i.e., adding agents that form new complexes) would affect the above discussion.

\subsection{Thermochemistry Relevant to Spectroscopy}

The control of the Purex solution conditions is aimed at optimizing the extraction yields. This means controlling the $\mathrm{U}, \mathrm{Np}$, and $\mathrm{Pu}$ oxidation states, as discussed in section 3.2. For americium, curium, and the rare earths the 3+ oxidation state is invariant under the process conditions.

The complexing of antimony ions and the ions of the platinum metals ( $\mathrm{Ru}$, $\mathrm{Rh}$, and $\mathrm{Pd}$ ) in the process solutions is not simple or stable. The aqueous chemistry of these metal ions is almost exclusively that of mixtures of complexes, so that the precise nature of many of the supposedly simple solutions containing these ions is complicated and often unknown. 66 For the Purex solutions this problem is compounded. The valence states of the ions is not known because of the donation of ligand electrons. 66,80 Since these species have significant absorption bands in the Purex photochemical spectral range, some discussion of the possible mixtures of complexes is warranted.

Radioactive ruthenium, obtained as a result of nuclear reactions, constitutes $\sim 6 \%$ of the total products. 81 Dissolution of uranium rods in nitric acid results in intensive oxidation of ruthenium to produce volatile $\mathrm{RuO}_{4}$, some of which may be carried away with the gaseous products. However, the dissolution process also generates large quantities of nitrogen oxides which react with $\mathrm{RuO}_{4}$ reducing it to $\mathrm{Ru}(\mathrm{II})$ and $\mathrm{Ru}(\mathrm{III}) .81$

Ruthenium forms a number of complexes that coexist and it has a tendency. to form polynuclear chains. ${ }^{81-85}$ It tends to form polynuclear complexes with oxide, nitride, or hydroxyl bridges and forms more nitrosyl (RuNO) complexes than any other metal. $66,80,82$ Table 4.1 lists some of the compounds so far 
Table 4.1. Examples of Possible Mononuclear Six Coordination Complexes Composed of RuNO and the Ligands $\mathrm{NO}_{3}^{-}, \mathrm{NO}_{2}^{-}, \mathrm{OH}^{-}, \mathrm{H}_{2} \mathrm{O}$ (From Fletcher and. Martin ${ }^{82}$ )

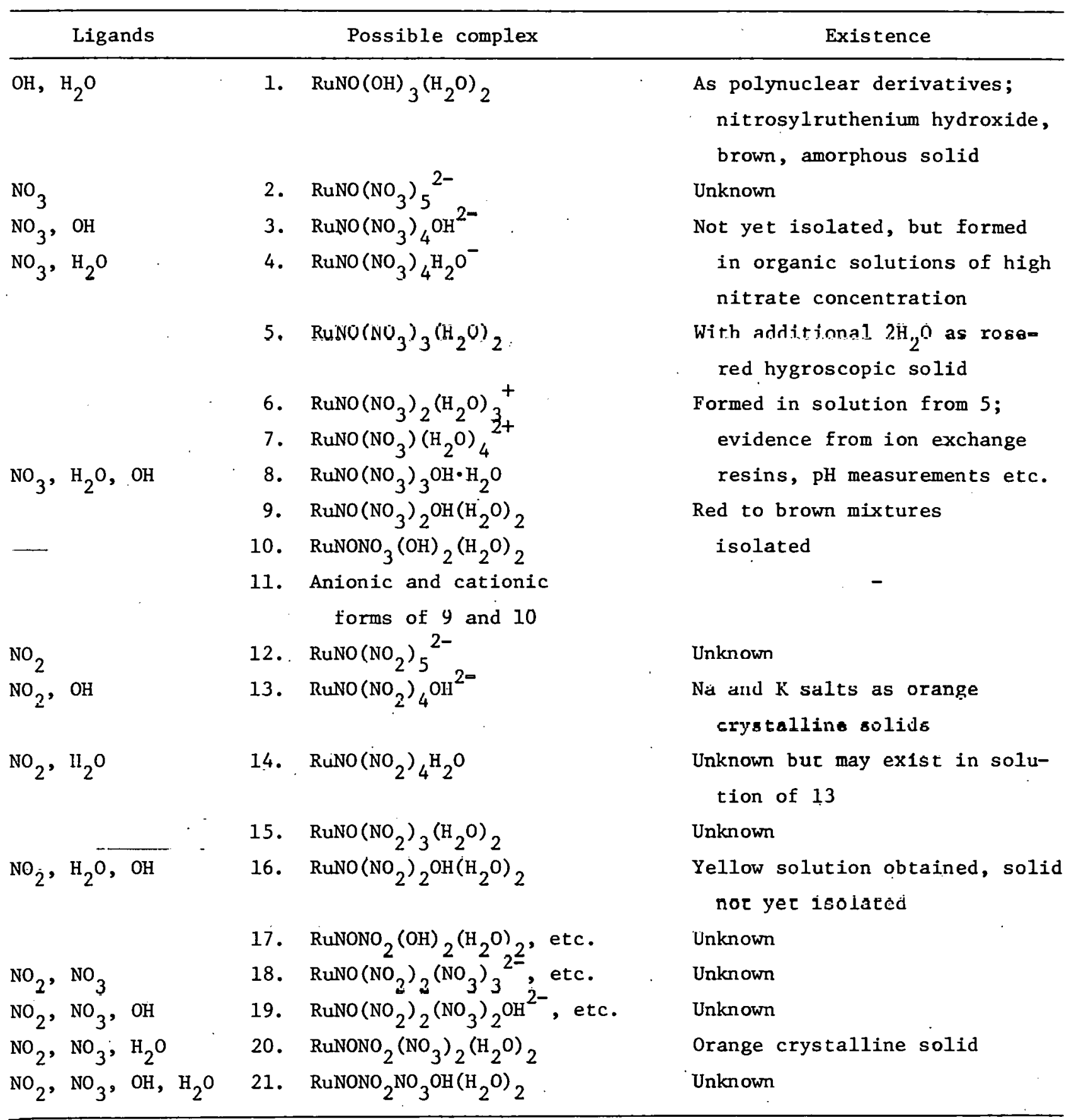


identified. $^{82}$ The most common formal valence states of ruthenium in aqueous solutions are II, III, and IV. A series of aquonitrato nitrosylruthenium complexes of the general formula RuNO $\left(\mathrm{NO}_{3}\right)_{x}(\mathrm{OH})_{3-x}\left(\mathrm{H}_{2} \mathrm{O}\right)_{2}$ has been identified in nitric acid solutions. Nitro and nitrato complexes of nitrosylruthenium are formed from ruthenium tetroxide and ruthenium alloys by the action of oxides of nitrogen and nitric acid. 83,86 A large number of RuNo complexes have been identified. Polynuclear aquonitrato complexes of ruthenium have been observed. These complexes display many colors and therefore absorb in the visible region. 84 The mono-, di-, and trinitrato complexes are in equilibrium in nitric acid solution. 84,86 The nature of the complexed ruthenium in nitric acid solutions has been found to change with the age of the solutions. ${ }^{84}$ Reduction of ruthenium tetroxide in nitric acid has been reported to yield a series of hydroxoaquo-ruthenium complexes of quadrivalent ruthenium of the general formula $\mathrm{Ru}(\mathrm{OH}) \mathrm{x}_{2}^{\left(\mathrm{H}_{2} \mathrm{O}\right)}{ }_{6-\mathrm{x}}\left(\mathrm{NO}_{3}\right)_{4-\mathrm{x}^{\circ}}{ }^{83}$ Nitrato, nitro, and nitrito groups in various complexes of nitrosylruthenium have been identified in preparations derived from aqueous nitric acid. The presence of halide ions in solutions further complicates the picture. Numerous halide complexes are known for all the valence states of ruthenium. A significant number of the above species have extinction . coefficients of several thousand (in units of $\underline{M}^{-1} \mathrm{~cm}^{-1}$ ) in the Purex photochemical spectral range.

The chemistry of rhodium centers mainly around valence states I and III. Thus almost all complexes exist in these two states. 66,80 Rhodium forms oxygenand nitrogen-bridged bi- and trinuclear complexes. The most common valence slate, III, unitike ruthentum, does not form nitrosyl complexes... A large number of octahedral complexes of $\mathrm{Rh}$ (III) are known. Although its cationic and neutral complexes are inert, the anionic complexes of Rh(III) are usually 
labile. The visible spectra of $\mathrm{Rh}$ (III) complexes generally have two bands toward the blue end which are responsible for the colored complexes. $66,87-93$

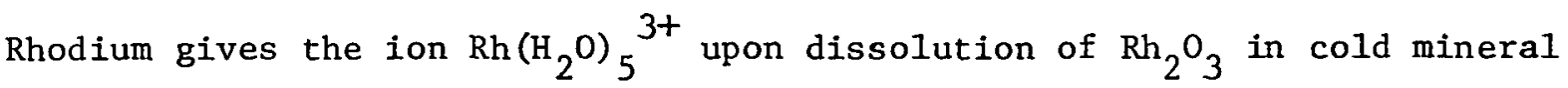
acids.' Numerous halide-aquo complexes have been reported. ${ }^{87-93}$

For palladium the II valence state is readily accessible and numerous complexes are known. 80,94 As a general rule $\mathrm{Pd}(\mathrm{II})$ shows a preference for $\mathrm{NO}_{2}$, halogen, and heavy atom donors such as arsenic and selenium. ${ }^{66}$ It shows a relatively small affinity for oxygen. The aquo ion $\left.\mathrm{Pd}_{\left(\mathrm{H}_{2}\right.} \mathrm{O}\right)_{4}{ }^{2+}$ is obtained when PdO is dissolved in dilute nitric acid. Dissolution of Pd metal in concentrated nitric acid gives nitrite and nitrate complexes. Among the most important compounds of $\operatorname{Pd}(\mathrm{II})$ are the tetrachlorometallates. 94 Besides mononuclear complexes there are a considerable number of binuclear bridged palladium species. Pd(IV) is more stable in complexes than in simple compounds, but only a few complexes are known. In particular the halide complexes have been studied.

Antimony shows a tendency toward cationic behavior in the trivalent state. ${ }^{66}$ Antimony salts readily form complexes with various acids ini wlilch the $\mathrm{sb}^{3+}$ form the nucleus of an anion. $\mathrm{Sb}$ (III) forms oxohalides. The hydrate oxide $\mathrm{Sb}_{2} \mathrm{O}_{3}$ has been reported to exist in aqueous solutions. The trihalides are hydrolyzed in water to mono-oxohalides. The $5+$ oxidation state does nor ex1st in lhe $\Gamma_{1 \text { ete }}$ ion form because of the large ionization energies. $\mathrm{Sb}(\mathrm{V})$ does exist in complexes, where it is bound to ligands of high electronegativity. 4.4 Solution Spectra of Ions Absorbing in the Photochemical Spectral Region It is not possible to treat the spectral data precisely at this time, nor is it necessary. The current requirement is for a general survey of the photochemical spectral region to determine the feasibility of introducing light 
into the complex process mixtures and any specific factors that would interfere. It should be qualitatively determined whether appropriate windows exist at a sufficient number of wavelengths to carry out selective photochemical reactions. The quantitative answer can be obtained only through an experimental program because the complicated mixtures used in reprocessing streams will give unknown mixtures of complex ion species.

Spectra for most of the ions could not be found for the high nitric acid concentrations used in the Purex process. Many of the spectra are presented for $\mathrm{HCl}$ or $\mathrm{HClO}_{4}$ solutions at high acid concentrations, with the, ions complexed with $\mathrm{Cl}^{-}$or uncomplexed, respectively. Other ions are reported as bromides or mixed halide complexes. Comparison between the halide systems should be valid. Comparisons between nitrated, halogenated, and uncomplexed ions, although not as valid, should still serve the present purpose.

\subsubsection{Solvent-Related Absorptions. The absorption spectra of nitric} acid in aqueous solution is shown in Figure 4.1. The two $\mathrm{NO}_{3}^{-}$peaks at 302 and $201 \mathrm{~nm}$ have molar extinction coefficients $(\varepsilon)$ of 7.2 and $9900 \underline{M}^{-1} \mathrm{~cm}^{-1} \mathrm{re}-$ spectively. 95 Previous data on the more intense band showed a $\lambda_{\max }$ at $194 \mathrm{~nm}$ with an $\varepsilon^{96}$ of $12,000 \underline{\mathrm{M}}^{-1} \mathrm{~cm}^{-1}$ and a $\lambda_{\max }$ at $200 \mathrm{~nm}$ with an $\varepsilon^{97}$ of $10,000 \underline{\mathrm{M}}^{-1}$ $\mathrm{cm}^{-1}$. For the weak band previous workers reported $\lambda_{\max }$ of $300 \mathrm{~nm}$ and $\varepsilon$ of 7.3 $\underline{M}^{-1} \mathrm{~cm}^{-1}$. In the 2-molar nitric acid process solutions of a Purex stream the corresponding optical densities would be 14.4 and 19,800 to $24,000 \mathrm{~cm}^{-1}$. Thus, partly because of these two bands, the photochemical spectral range is restricted to wavelengths $>350 \mathrm{~nm}$.

As shown in Figure 4.2, the low energy $\mathrm{NO}_{3}{ }^{-}$band undergoes a hypsochromic (blue) shift to $279 \mathrm{~nm}$ in TBP. ${ }^{63}$ The corresponding $\varepsilon$ for this band is $7.9 \mathrm{M}^{-1}$ $\mathrm{cm}^{-1}$. The same band in tert-butyl alcohol, shown in Figure 4.3(a), has a $\lambda_{\max }$ 


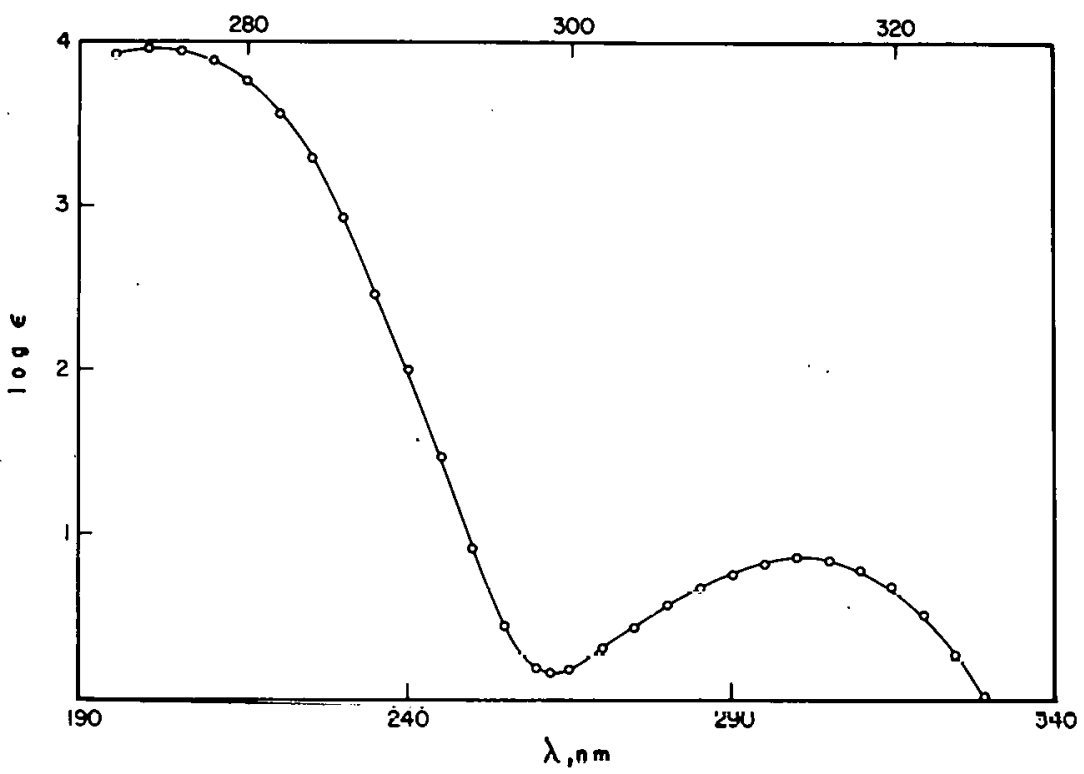

Figurc 4.1. Absorption spertrum of $\mathrm{NO}_{3}^{-}$in aqueous solution. (From Mèyerstein and IreluLı.95)

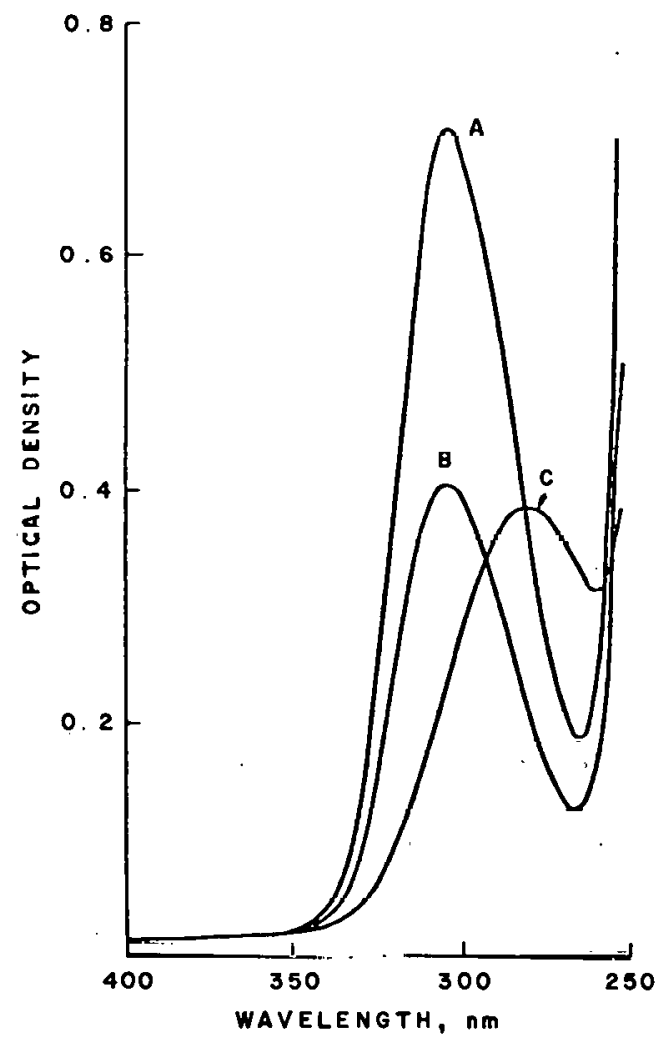

Figure 4.2. Ahsorption spectra for nitric acid in aqueous and In TBF solutions. Curve $\Lambda, 1.0 \mathrm{M}$ nitric acid; curve $B$, aqueous phase containing $0.54 \mathrm{M}$ nitric acid after equilibrating $A$ with an equal volume of $100 \%$ TBP; curve $C$, TBP phase containing $0.46 \mathrm{M}$ nitric acid after equilibration. (From Woodhead.63) 


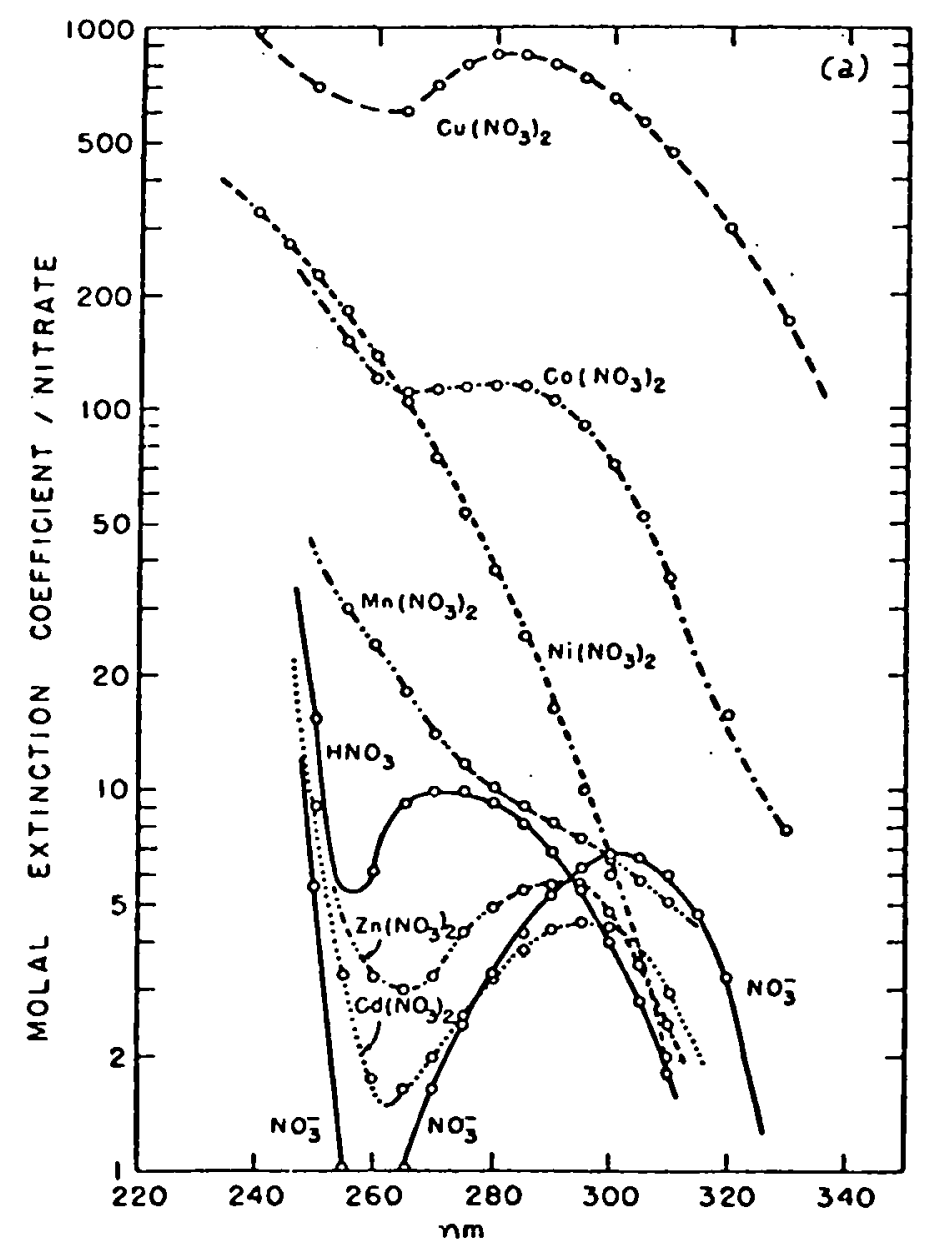

Figure 4.3(a). Absorption spectra of nitrate salts dissolved in tertiary butyl alcohol. The curves have been rorrerted for the absorption of colvent and of cation. (From Katzin. ${ }^{71}$ ) 
at $305 \mathrm{~nm}$ with an $\varepsilon^{71}$ of $6.9 \underline{\mathrm{M}}^{-1} \mathrm{~cm}^{-1}$. For the undissociated species $\mathrm{HNO}_{3}$ the $\lambda_{\max }$ is $270 \mathrm{~nm}$ and $\varepsilon$ is $10 \underline{M}^{-1} \mathrm{~cm}^{-1}$. Complexing of the nitrate ion with various cations results in hypsochromic shifts of the 302-nm nitrate band and, in some cases shown in Figures $4.3(a)$ and (b), increases in $\varepsilon$ by as much as a factor of $100.63,71$ At wavelengths $>350 \mathrm{~nm}$ these nitrate bands do not contribute significantly to the absorption of light.

The nitrite ion $\mathrm{NO}_{2}{ }^{-}$is an additive to the solvent system used to adjust the actinide oxidation states. ${ }^{60}$ The nitrite ion has a band peaking at $\sim 360 \mathrm{~nm}$, as shown in Figure 4.4, curve 1, with an $\varepsilon$ of $\sim 24 \underline{M}^{-1} \mathrm{~cm}^{-1} .98$ Complexing of various metal cations with $\mathrm{NO}_{2}^{-}$causes a blue shift of the peak and could result in a small absorption band in the region of $350 \mathrm{~nm}$. For example, the species $\mathrm{CdNO}_{2}^{+}$has an $\varepsilon$ of $\sim 10 \underline{\mathrm{M}}^{-1} \mathrm{~cm}^{-1}$ at $350 \mathrm{~nm}, 98$ as indicated by curve 2 of Figure 4.4.

Normal tributyl phosphate does not have significant absorptions at wavelengths $>250 \mathrm{~nm} .65$

4.4.2 Solute Ion Absorptions. For the Purex aqueous solutions it is assumed that the majority of the cations exist as complexes containing $\mathrm{H}_{2} \mathrm{O}$, OH $\mathrm{H}^{=}$, $\mathrm{NO}_{3}{ }^{-}, \mathrm{NO}_{2}{ }^{-}$, $\mathrm{NO}^{-}, \mathrm{SO}_{4}{ }^{2-}$, or TBP ligands. Attention is focused on the normal process solutions used in cycles 1, 2, and 3 of Figure 3.1. Consideration of solutions subsequent to this. normal Purex sclieme as discussed by Bond and Leuze 60 would complicate the picture considerably because of the addition of chelating agents and complexing ligands.

The actinide valence states of concern in the Purex scheme are U(VI), $\mathrm{Np}(I V), \mathrm{Np}(\mathrm{V}), \mathrm{Np}(\mathrm{VI}), \mathrm{Pu}(\mathrm{III}), \mathrm{Pu}(\mathrm{IV}), \mathrm{Pu}(\mathrm{V}), \mathrm{Pu}(\mathrm{VI}), \mathrm{Am}(\mathrm{III})$, and $\mathrm{Cm}(\mathrm{III})$. The absorption spectra for these ions in acid solutions are shown 1n F1gures 4.5 to 4.11 . The band wavelength maxima and extinction coefficients are given 


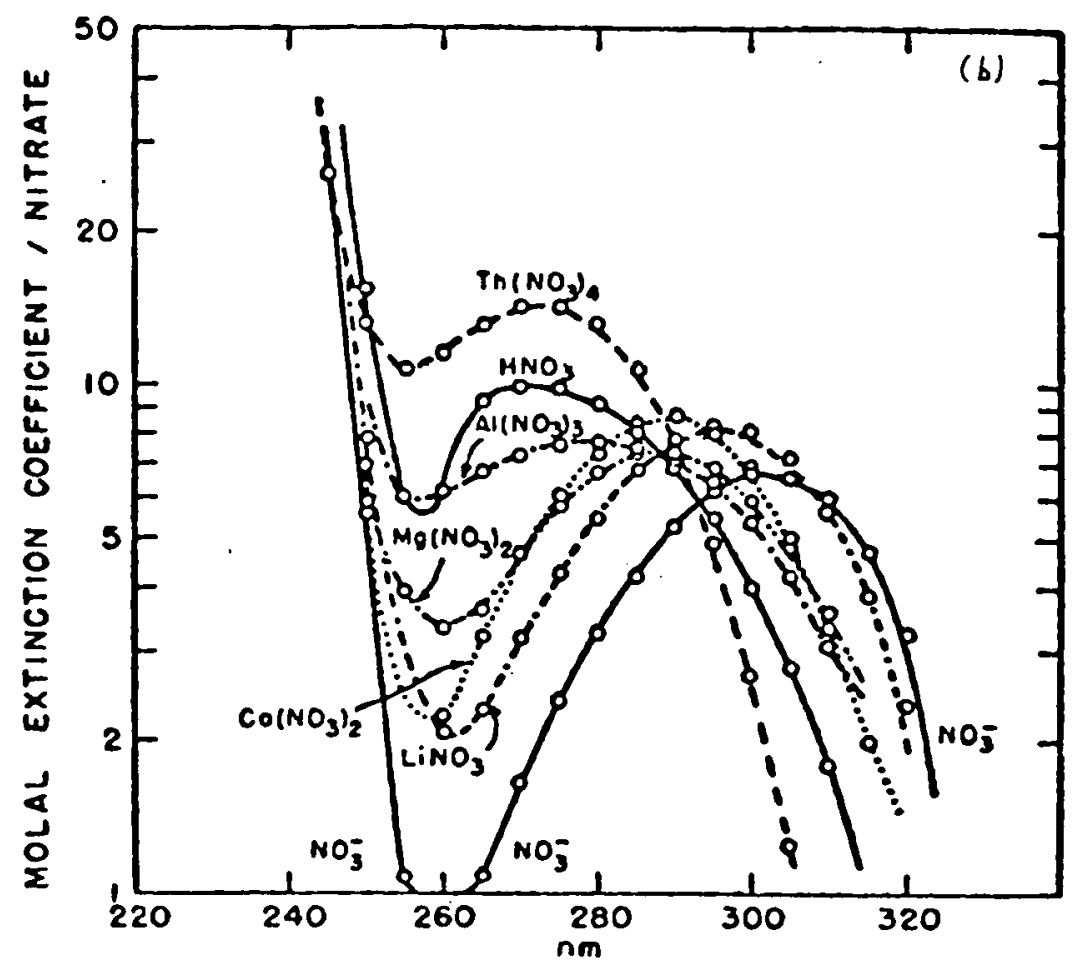

Figure 4.3(b). Absorption spectra of nitrate salts dissolved in tertiary hutyl alcohol. The curves have been corrected for the absorption of solvent and of cation. (From Katzin. ${ }^{71}$ ) 


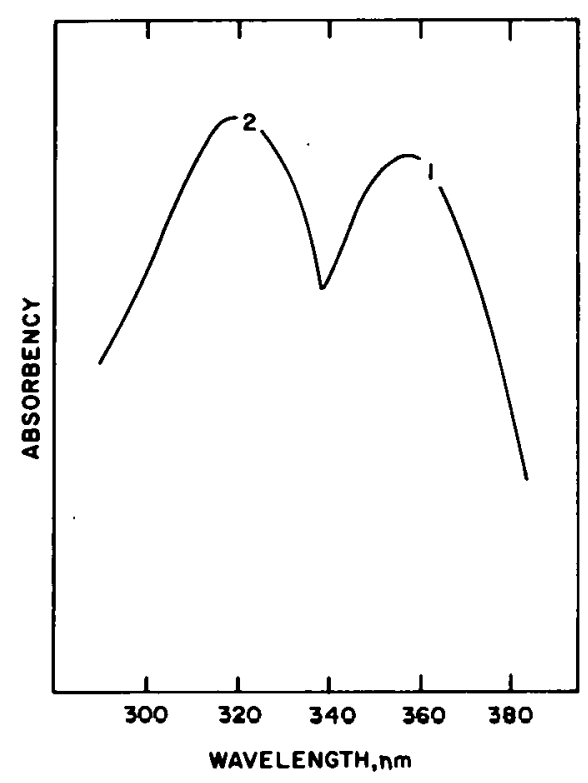

Figure 4.4. Spectra of aqueous solutions of (1) $0.0221 \mathrm{~F} \mathrm{KNO}_{2}$ and (2) $0.0221 \mathrm{~F} \mathrm{KNO}_{2} / 2.00 \mathrm{~F} \mathrm{CdCl}{ }_{2}$. (From Vassian and Eberhardt.98)

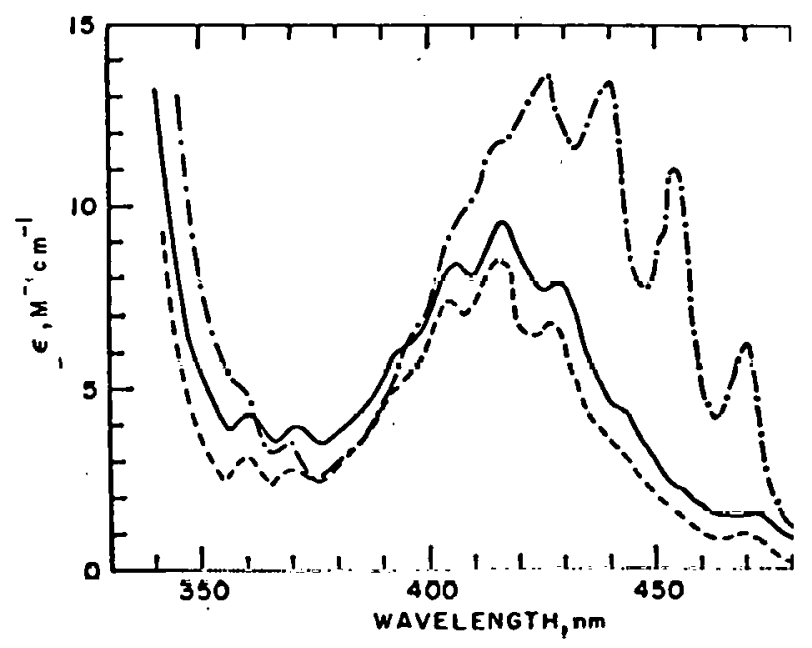

Figure 4.5. Absorption spectra of uranyl nitrate in some aqueous solutions. $0.02 \mathrm{M} \mathrm{UO}_{2}\left(\mathrm{NO}_{3}\right)_{2}$ in $\mathrm{H}_{2} \mathrm{O}_{1}---.0 .00971 \mathrm{M} \mathrm{UO}_{2}\left(\mathrm{MO}_{3}\right)_{2}$ in $0.514 \mathrm{M} \mathrm{HNO}_{3}$; -...., $0.02 \underline{\mathrm{M}} \mathrm{UO}_{2}\left(\mathrm{NO}_{3}\right)_{2}$ in $16 \underline{\mathrm{M} \mathrm{HNO}_{3}}$. (From Rabinowitch and Belford. ${ }^{1}$ ) 


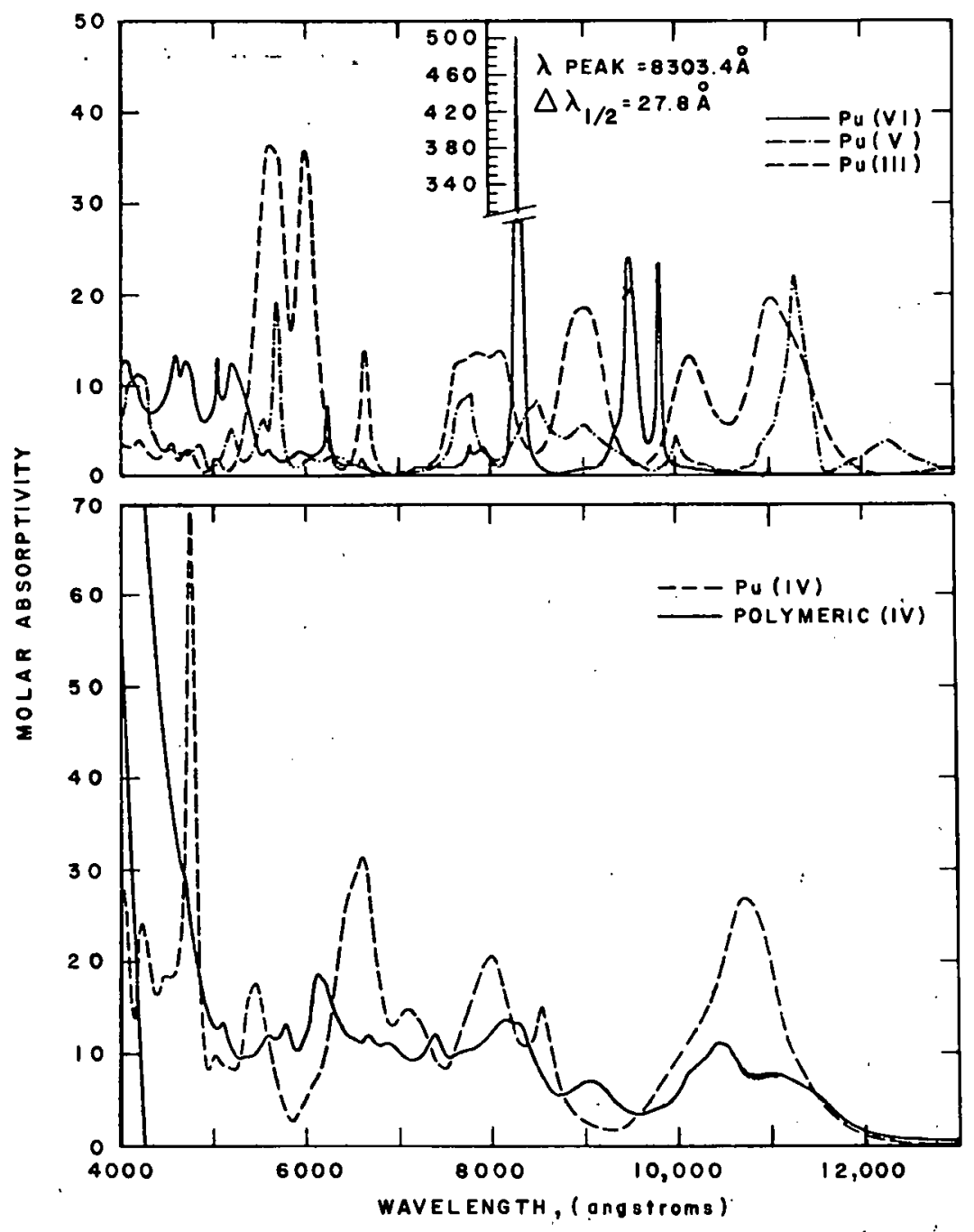

Figure 4.6. Absorption spectra of $\mathrm{Pu}(\mathrm{III})$, (IV), (V), and (VI) and polymeric Pu(IV). Media: Pu(III), (IV), (VI), $1.0 \mathrm{M} \mathrm{HNO}_{3} ; \mathrm{Pu}(\mathrm{V}), 1.0 \mathrm{M} \mathrm{HClO} 4$; poly-

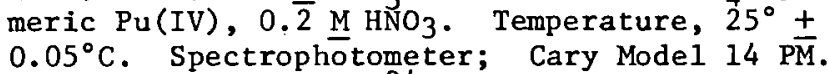
(From Costanyo et al.34) 
(A)

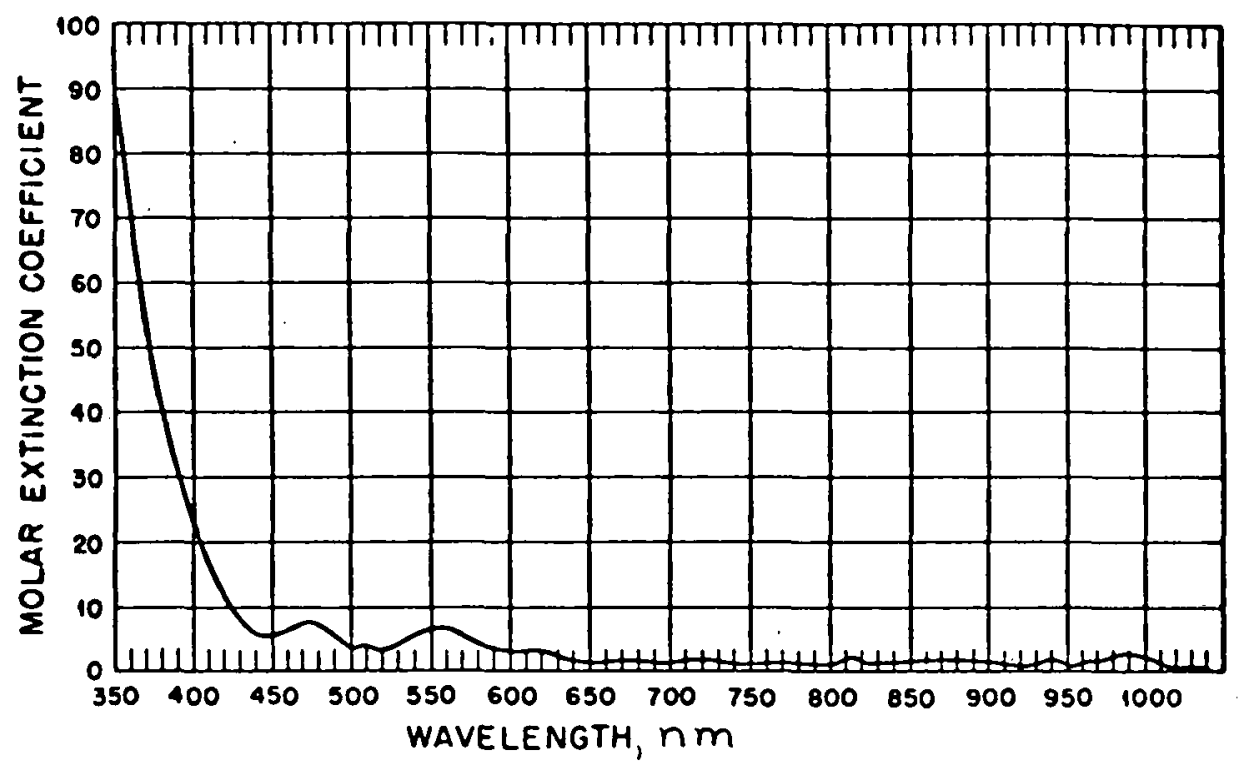

(B)

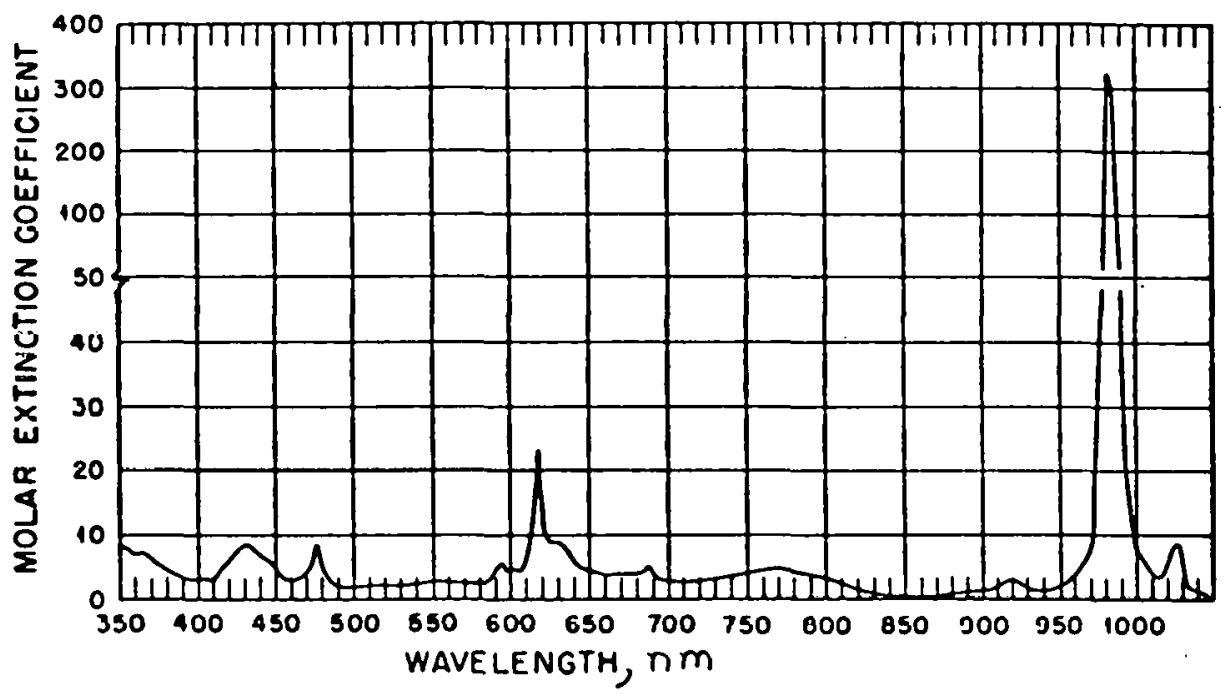

Figure 4.7. Absorption spectra of (a) NP(VI) in 1.0 $\mathrm{M} \mathrm{HClO} 4$; (b) $\mathrm{Np}(\mathrm{V})$ in $1.0 \mathrm{M} \mathrm{HCl}$. (From Hindman et al. 102) 
(c)

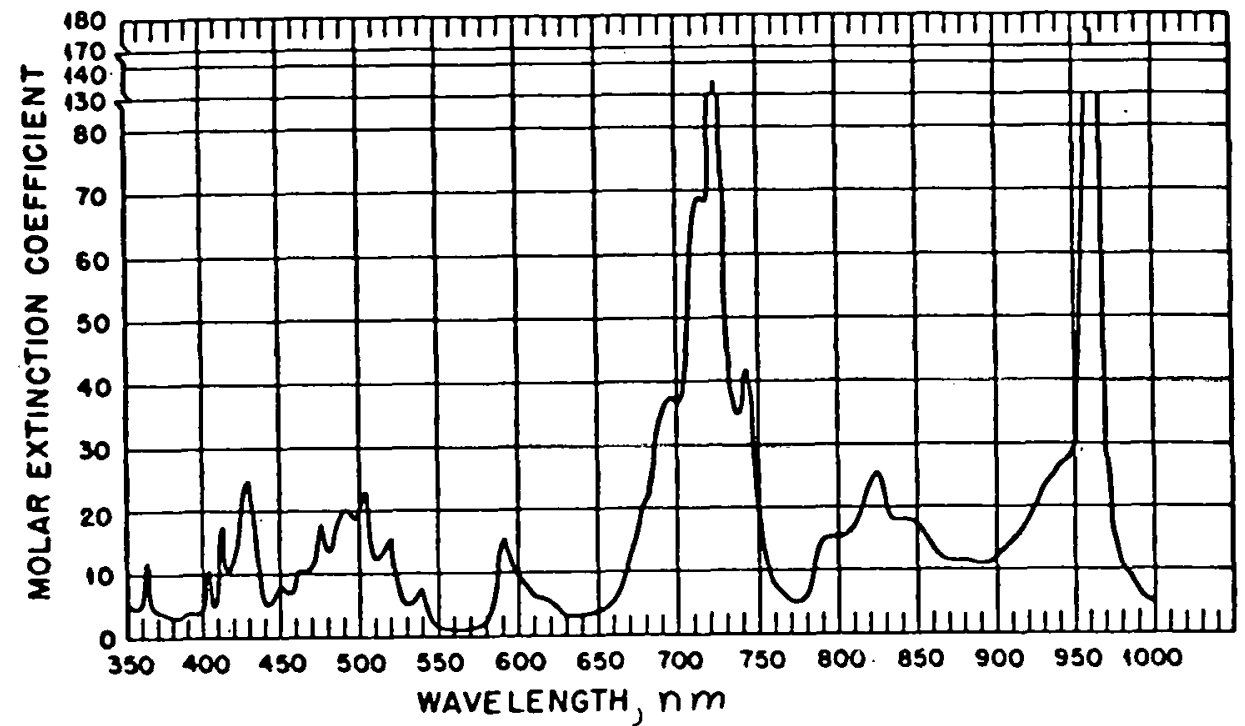

(D)

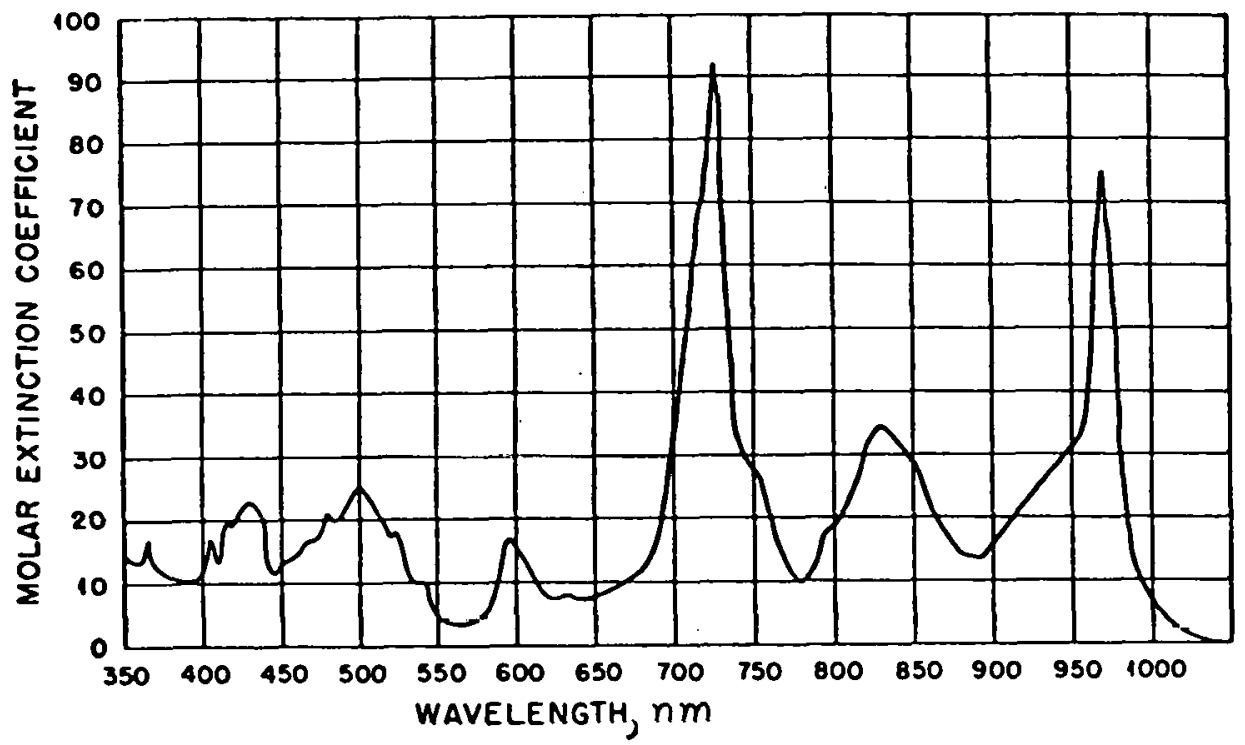

Figure 4.7. Absorption spectra of (c) $\mathrm{Np}$ (IV) in 1.0 $\mathrm{M} \mathrm{HC1}$; (d) $\mathrm{Np}$ (IV) in $1.0 \mathrm{M} \mathrm{H}_{2} \mathrm{SO}_{4}$. (From Hindman et al. 102) 
(a)
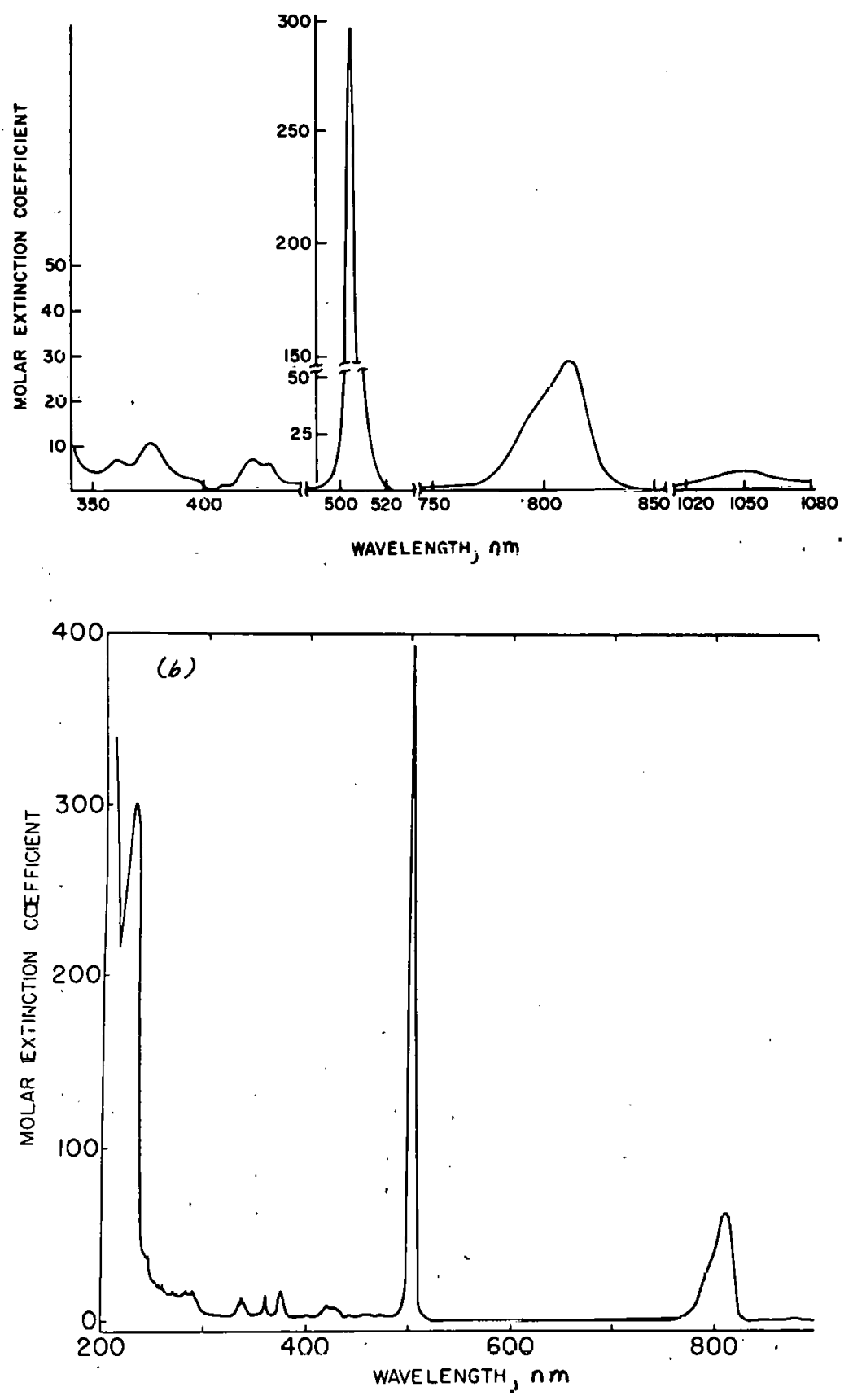

Figure 4.8. Absorption spectrum of $A m$ (III) (a) in $1.00 \mathrm{M} \mathrm{HNO}_{3}$ (from Yakovlev and Kosyakov99); (b) in $1.0 \mathrm{M} \mathrm{HClO}_{4}^{3}$ (from Penneman and Keenan ${ }^{100}$ ). 


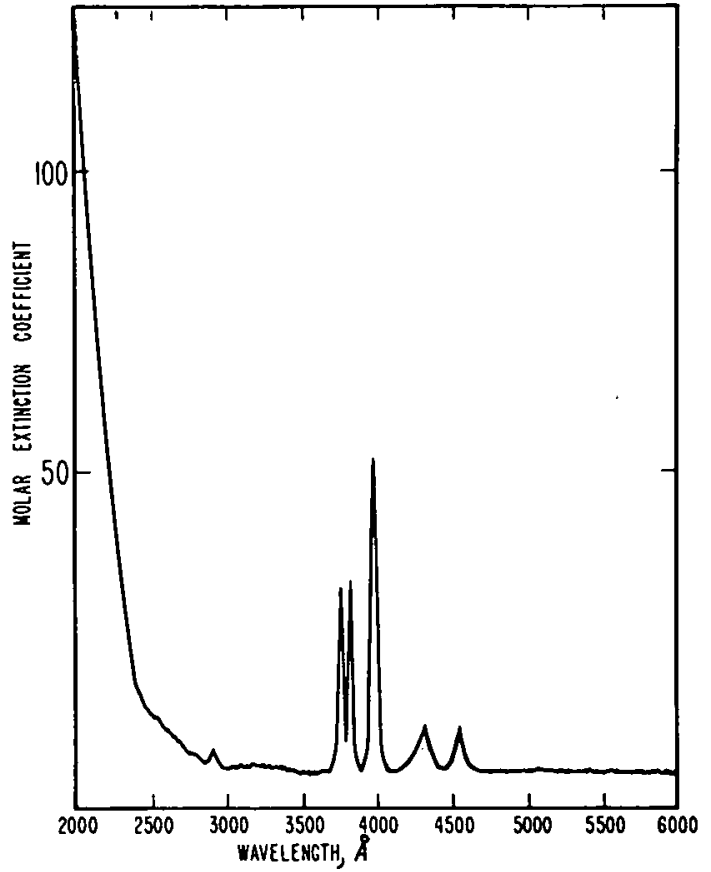

Figure 4.9. Absorption spectrum of aqueous CmIII. (From Penneman and Keenan. 100) 

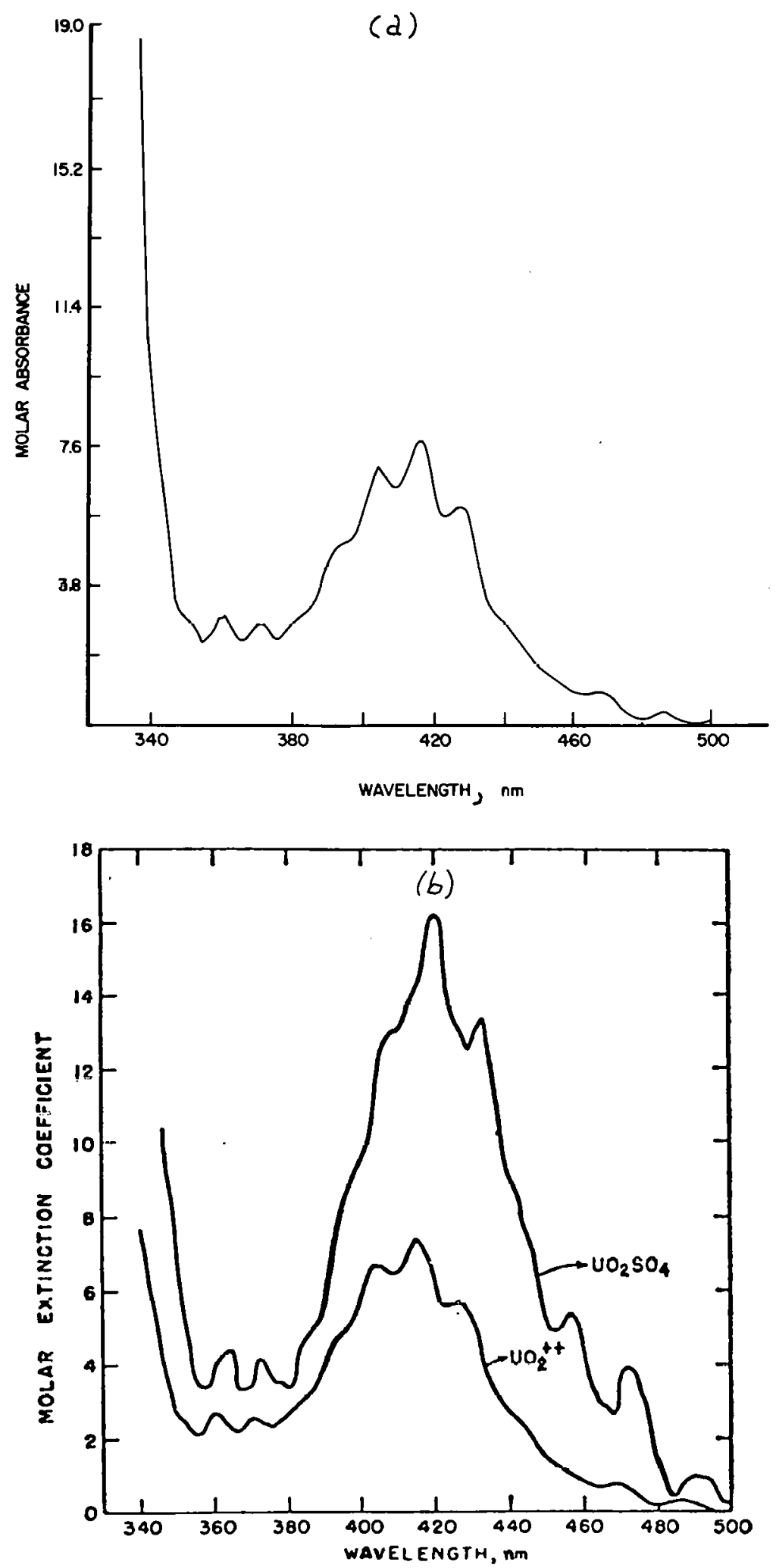

F1gure 4.10. Absurplioll spectrum (a) of the uranyl ion in aqueous $\mathrm{HClO}_{4}$ (from Burrows and Kemp2) and (b) of the complex $\mathrm{UO}_{2} \mathrm{SO}_{4}$ in water (from Rabinowitch and Belford ${ }^{1}$ ). 


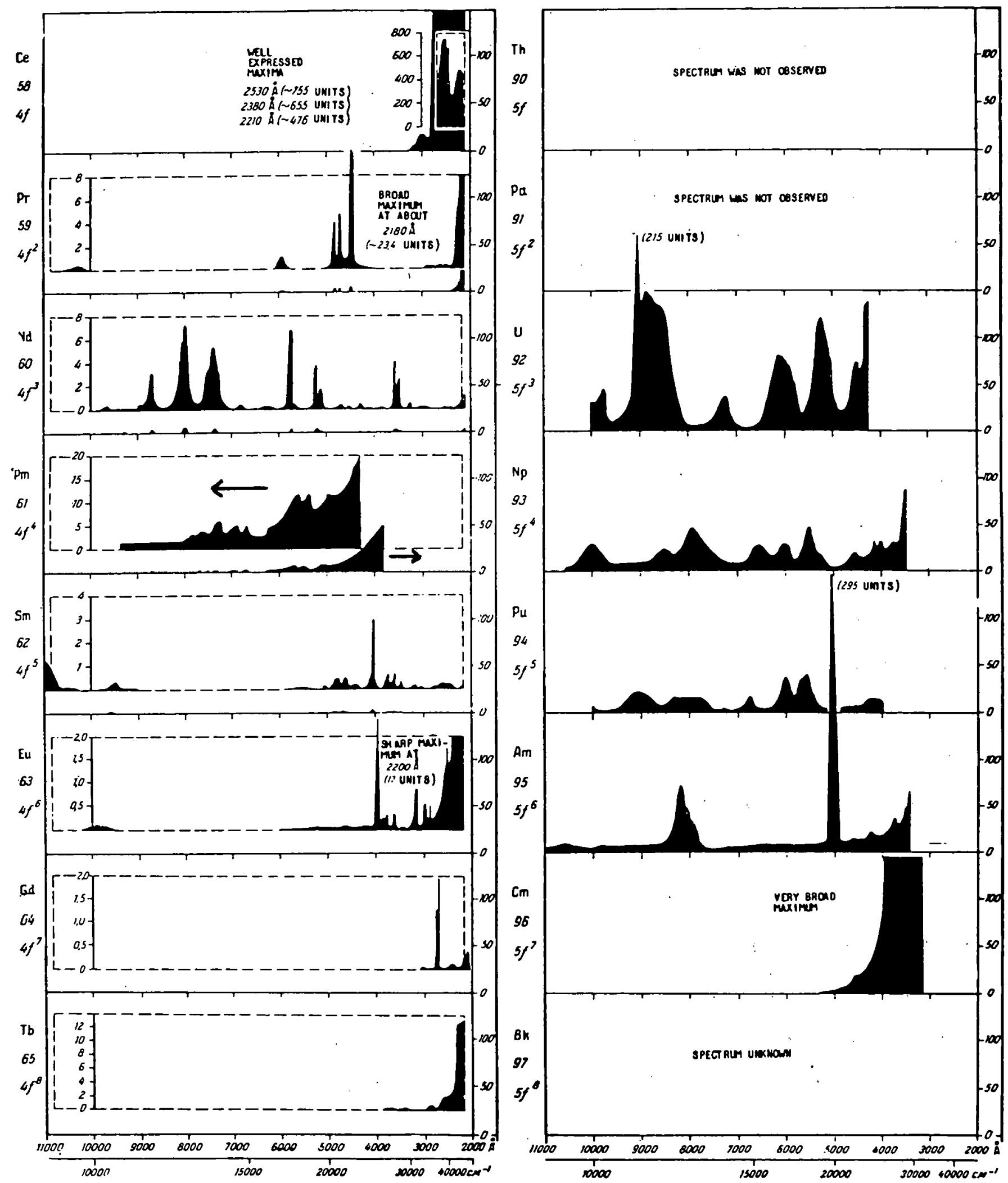

Figure 4.11. Absorption spectra of the 3+ ions of the actinides and of the lanthanides corresponding to them. The extinction coefficients in $\mathrm{M}^{-1} \mathrm{~cm}^{-1}$ units are given on the vertical scales. (From Seaborg. ${ }^{79}$ ) 
in Table 4.2. For $\mathrm{UO}_{2}{ }^{2+}, \mathrm{Pu}^{3+}, \mathrm{Pu}^{4+}$, and $\mathrm{Am}^{3+}$, spectra taken in nitric acid solutions are given. ${ }^{99}$ These spectra consist of a mixture of nitrated species and should be comparable with the corresponding ion absorptions occurring in Purex solutions. The spectra for the remaining actinide ions are not for $\mathrm{HNO}_{3}$ solutions but are based on the behavior of the neptunium and uranyl ions complexed with various anions (Table 4.3 and Figures $4.5,4.7$, and 4.10). The $\varepsilon$ for these ions should be within a factor of roughly 2 or 3 of that for the nitrated species.

As indicated in Figures 4.5 and 4.10 and in Table 4.3, the uranyl ion has a broad, strong band starting at $\sim 350 \mathrm{~nm}$ and extending into the ultraviolet. The $\mathrm{NpO}_{2}{ }^{2+}$ spectra in Figure 4.7 (c) suggests a similar band for this ion. 102 The electronic absorption spectrum of the uranyl ion has been extensively studied but there is still disagreement on the band assignments. In aqueous solutions, the ligands complexing $\mathrm{UO}_{2}{ }^{2+}$ are quite labile and effect only small spectra changes. The visible and near-ultraviolet $\mathrm{UO}_{2}{ }^{2+}$ bands are transitions from bonding orbitals to unfilled $5 f$ or $6 \mathrm{~d}$ uranium orbitals. The generally accepted assignment for the lowest energy transition is the excltation of an eleclivin from the highest filled $\pi$-orbital of the complex to a nonbonding orbital on uranium. 2 The electronic states involved in this transition are believed to be the ground-state singlet and the lowest triplet state. 10.5

The other actinide ions have numerous narrow $(\Delta \lambda \sim 50 \mathrm{~nm})$ or moderately narrow $(\Delta \lambda \sim 100 \mathrm{~nm})$ bands extending from the near-infrared through the visible. Except for $\mathrm{Np}(\mathrm{VI})$ these ions have one or more bands whose extinction coefficients are larger by a factor of 10 or more than that for the uranyl ion band. Although the spectral assignments for these bands have not been studied, the parallel band structure between these actinide ions and the rare earth ions 
Table 4.2

Absorption Band Maxima $\left(\lambda_{\max }\right)$ and Molar Extinction Coefficients $(\varepsilon)$ for the Actinide Ions From 350 to $1100 \mathrm{~nm}$

\begin{tabular}{|c|c|c|c|}
\hline Complex & $\lambda_{\max }(\mathrm{nm})$ & $\varepsilon\left(\underline{M}^{-1} \mathrm{~cm}^{-1}\right)$ & Ref. \\
\hline $\mathrm{UO}_{2}\left(\mathrm{NO}_{3}\right)_{2}$ & 415 & 8 & 1 \\
\hline $\mathrm{NpO}_{2}{ }^{2+}$ & $\begin{array}{l}475 \\
555\end{array}$ & $\begin{array}{l}8 \\
7\end{array}$ & 102 \\
\hline $\mathrm{NpO}_{2} \mathrm{Cl}$ & $\begin{array}{r}365 \\
430 \\
476 \\
618 \\
629 \\
688 \\
770 \\
983 \\
1026\end{array}$ & $\begin{array}{r}7 \\
9 \\
9 \\
24 \\
9 \\
5 \\
5 \\
325 \\
7\end{array}$ & 102 \\
\hline $\mathrm{NpCl}_{4}$ & $\begin{array}{l}363 \\
403 \\
412 \\
429 \\
500 \\
590 \\
700 \\
723 \\
742 \\
820 \\
965\end{array}$ & $\begin{array}{r}10 \\
8 \\
15 \\
24 \\
22 \\
14 \\
38 \\
126 \\
40 \\
26 \\
160\end{array}$ & 102 \\
\hline $\mathrm{PuO}_{2}{ }^{2+}$ & $\begin{array}{l}460 \\
470 \\
505 \\
525 \\
625 \\
830 \\
951 \\
982\end{array}$ & $\begin{array}{r}14 \\
13 \\
14 \\
13 \\
8 \\
503 \\
24 \\
24\end{array}$ & $\cdots$ \\
\hline $\mathrm{PuO}_{2}^{+}$ & $\begin{array}{r}415 \\
569 \\
770 \\
850 \\
900 \\
1000 \\
1130\end{array}$ & $\begin{array}{r}11 \\
19 \\
10 \\
9 \\
6 \\
4 \\
22\end{array}$ & 34 \\
\hline
\end{tabular}


Table 4.2. (Cont'd)

\begin{tabular}{|c|c|c|c|}
\hline Complex & $\lambda_{\max }(\mathrm{nm})$ & $\varepsilon\left(\underline{\mathrm{M}}^{-1} \mathrm{~cm}^{-1}\right)$ & Ref. \\
\hline $\mathrm{Pu}^{4+}$ & $\begin{array}{r}400 \\
425 \\
480 \\
550 \\
650 \\
710 \\
800 \\
855 \\
1070\end{array}$ & $\begin{array}{l}28 \\
24 \\
69 \\
19 \\
31 \\
16 \\
22 \\
16 \\
28\end{array}$ & 34 \\
\hline $\mathrm{Pu}\left(\mathrm{NO}_{3}\right)_{3}$ & $\begin{array}{r}562 \\
601 \\
665 \\
800 \\
900 \\
1010 \\
1105\end{array}$ & $\begin{array}{r}38 \\
\cdot 36 \\
19 \\
14 \\
19 \\
14 \\
20\end{array}$ & 34 \\
\hline $\mathrm{Am}\left(\mathrm{NO}_{3}\right)_{3}$ & $\begin{array}{r}375 \\
440 \\
503 \\
812 \\
1050\end{array}$ & $\begin{array}{r}10 \\
7 \\
300 \\
65 \\
5\end{array}$ & 99,100 \\
\hline $\mathrm{cm}^{3+}$ & $\begin{array}{l}375 \\
381 \\
397 \\
430 \\
455\end{array}$ & $\begin{array}{r}20 \\
31 \\
53 \\
5 \\
5\end{array}$ & 100 \\
\hline
\end{tabular}


Table 4.3

Effect of Different Anions on the Absorption Coefficients

of Uranyl Ions in Ultraviolet

(From Rabinowitch and Belford ${ }^{1}$ )

\begin{tabular}{|c|c|c|c|c|c|c|c|c|c|c|}
\hline \multirow[b]{2}{*}{ Solution cortains } & \multicolumn{10}{|c|}{ Wavelength (nm) } \\
\hline & 236 & 243.5 & 251.0 & 259.2 & . 272.4 & 289.5 & 300.1 & 307.6 & 318.6 & 330.6 \\
\hline $\mathrm{UO}_{2}\left(\mathrm{NO}_{3}\right)_{2}$ & 2020 & 1350 & 675 & 540 & 295 & 160 & 125 & 108 & 65 & 27 \\
\hline $\mathrm{UO}_{2} \mathrm{SO}_{4}$ & 1350 & 1000 & 720 & 545 & 375 & 200 & 108 & 81 & 54 & - \\
\hline $\mathrm{UO}_{2} \mathrm{Cl}_{2}$ & 1050 & 890 & 540 & 490 & 320 & 275 & 170 & - & - & - \\
\hline $\mathrm{UO}_{2}\left(\mathrm{NO}_{3}\right)_{2}+\mathrm{H}_{2} \mathrm{C}_{2} \mathrm{O}_{4}$ & - & - & 2480 & 1950 & 1390 & 780 & 540 & 440 & 300 & - \\
\hline $\mathrm{UO}_{2} \mathrm{SO}_{4}+\mathrm{H}_{2} \mathrm{C}_{2} \mathrm{O}_{4}$ & 3225 & 2850 & 2445 & 2030 & 1440 & 640 & 410 & 280 & 190 & - \\
\hline $\mathrm{UO}_{2} \mathrm{Cl}_{2}+\mathrm{H}_{2} \mathrm{C}_{2} \mathrm{O}_{4}$ & - & - & 1610 & 1380 & 1010 & 585 & 370 & 260 & 180 & - \\
\hline $\mathrm{UO}_{2}\left(\mathrm{CH}_{3} \mathrm{COO}\right)_{2}$ & & & & & . & & & & & \\
\hline$+\mathrm{H}_{2} \mathrm{C}_{2} \mathrm{C}_{4}$ & 3160 & 2670 & 2280 & 1840 & 1230 & - & - & - & - & - \\
\hline $\mathrm{UO}_{2} \mathrm{C}_{2} \mathrm{O}_{4}$ & 2770 & 2380 & 1990 & 1690 & 1230 & 580 & 435 & 290 & 165 & 120 \\
\hline Oxalic acid* & 88 & 64 & 57 & - & 49 & 22 & 5 & 2 & - & - \\
\hline
\end{tabular}

* Numbers show how much light oxalate alone would have absorbed at the different wavelengths. Note that $\varepsilon-$ oxalate added to $\varepsilon-\mathrm{UO}_{2}\left(\mathrm{NO}_{3}\right)_{2}$ is smaller than $\varepsilon$ of the mixture $\mathrm{UO}_{2}\left(\mathrm{NO}_{3}\right)_{2}+$ oxalate, this is interpreted as eviderce $\mathrm{o} \equiv$ complex formation. 
shown in Figure 4.11 suggests that the assignments discussed below for the former pertain also to the latter. 78,79

The data on the absorption spectra of the rare earth ions in solution are extensive. $^{78}$ The triply charged ions in particular have been well studied. The absorption spectra for the trivalent rare earth ions are given in Figures 4.11 and 4.12. The corresponding wavelength maxima and extinction coefficients are given in Table 4.4. The electronic spectrum consists of a number of bands that lie in the infrared, visible, and ultraviolet regions. Two types of bands are observed: narrow bands in the infrared, visible, and near-ultraviolet, and broad bands farther into the ultraviolet. The narrow bands involve electron transitions between the $4 \mathrm{f}$ electronic states. The broad bands involve transitions to higher she11 electronic states. 78

The spectra of the trivalent lanthanides and actinides are similar. Only the extinction coefficients differ, with the actinide $\varepsilon$ 's being larger. 78,79 The narrow bands are due to forbidden transitions between levels of the $f$ shell that take place without a change in principal and azimuthal quantum number ${ }^{78}$ and thus are of low intensity. For f-shell transitions involving ions having electrons in the higher $\mathrm{d}, \mathrm{s}$, and $\mathrm{p}$ electronic levels the influence of the surrounding ligands is reduced (i.e., the $f$ electronic states are protected from external ligand pertubations).

Data from the literature indicate that the oscillator strengths for the narrow bands of the rare earth nitrates and chlorides are practically the same. 77,79 That is, the spectra are independent of these anions for the bands corresponding to electronic transitions between levels of the $4 \mathrm{f}$ shell. Thus the electronic states in this shell are shielded from ligand perturbations and the influence of the complexing ligands on the band characteristics is minimal. 

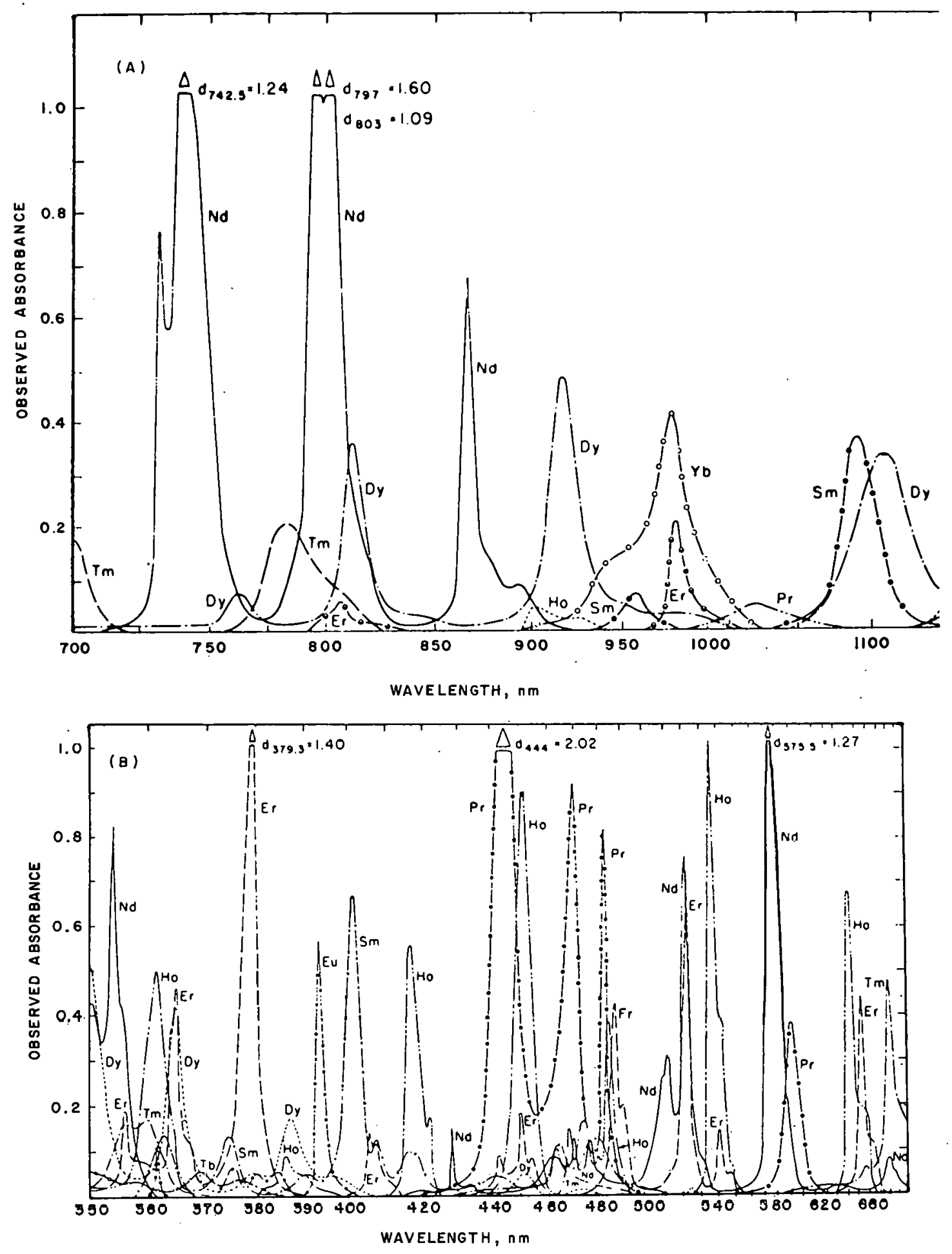

Figure 4.12. Absorption spectra of (a) all rare earths in near-infrared, (b) all rare earths in the visible. Note that the vertical scale is absorbance (optical density), and therefore comparisons between the various ion spectra are not valid for the data as presented. (From Stevenson and Nervik. ${ }^{77}$ ) 

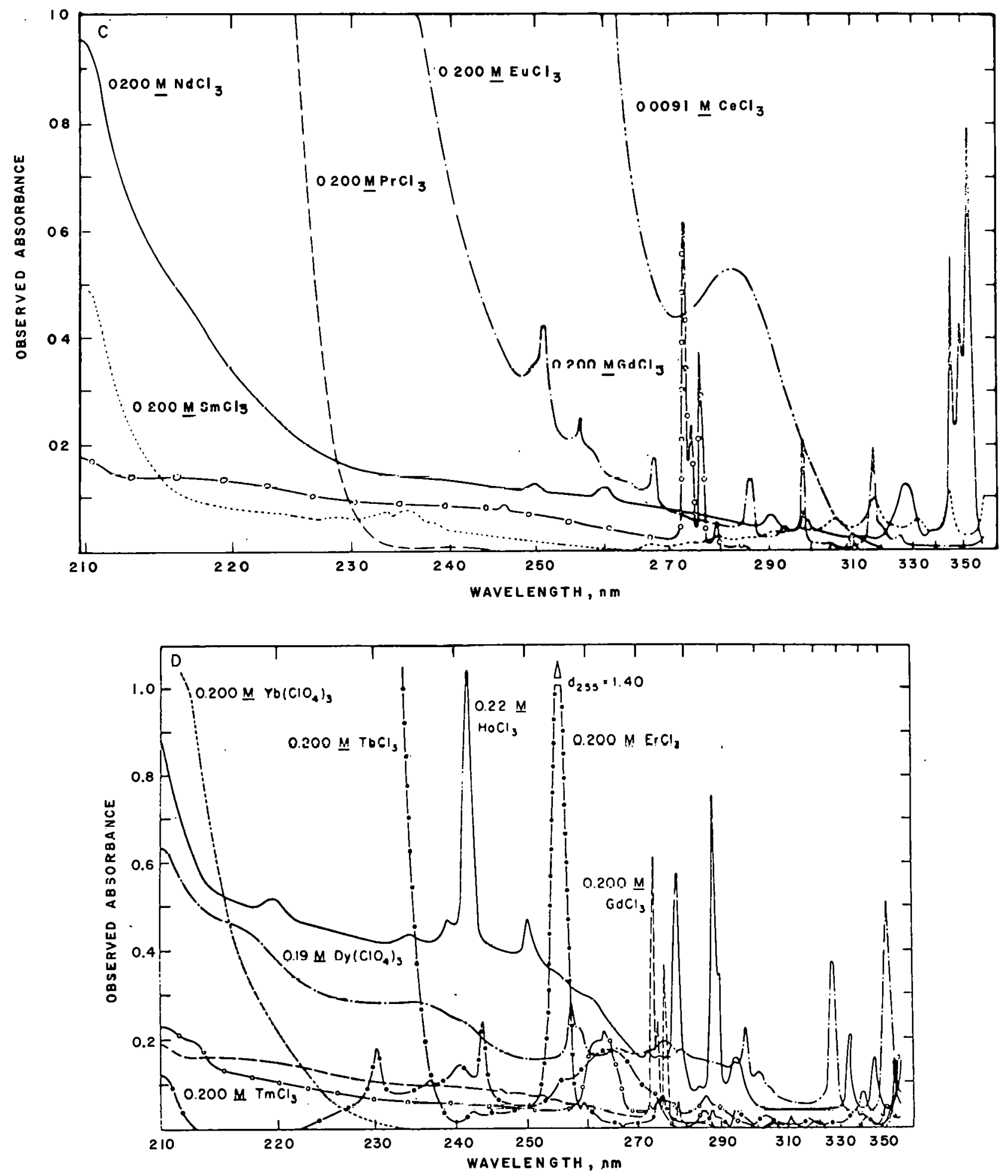

Figure 4.12. Absorption spectra of (c) light rare carth in the ultraviolet, and (d) heavy rare earths in ultraviolet. Note that the vertical scale is absorbance (optical density), and therefore comparisons between the various ion spectra are not valid for the data as presented. (From Stevenson and Nervik.77) 
Table 4.4

Absorption Band Maxima $\left(\lambda_{\max }\right)$ and Molar Extinction Coefficients for the Rare Earth Ions From 350 to $1100 \mathrm{~nm}$

\begin{tabular}{|c|c|c|c|}
\hline Ion & $\lambda_{\max }(\mathrm{nm})$ & $\varepsilon\left(\underline{M}^{-1} \mathrm{~cm}^{-1}\right)$ & Ref. \\
\hline $\mathrm{Pr}^{3+}$ & $\begin{array}{l}444 \\
470 \\
483 \\
590\end{array}$ & $\begin{array}{r}10 \\
5 \\
4 \\
2\end{array}$ & $77-79$ \\
\hline $\mathrm{Nd}^{3+}$ & $\begin{array}{l}522 \\
576 \\
743 \\
800^{a} \\
868\end{array}$ & $\begin{array}{l}3 \\
6 \\
6 \\
7 \\
3\end{array}$ & $77-79$ \\
\hline $\mathrm{Pm}^{3+}$ & $\begin{array}{l}380^{\mathrm{b}} \\
500 \\
540 \\
560 \\
670 \\
700 \\
730\end{array}$ & $\begin{array}{r}50 \\
12 \\
12 \\
12 \\
5 \\
5 \\
7\end{array}$ & 79 \\
\hline $\mathrm{Sm}^{3+}$ & $\begin{array}{r}402 \\
1095\end{array}$ & $\begin{array}{l}3 \\
2\end{array}$ & $77-79$ \\
\hline $\mathrm{Eu}^{3+}$ & 394 & 3 & $77-79$ \\
\hline $\mathrm{Dy}^{3+}$ & $\begin{array}{r}911 \\
1102\end{array}$ & $\begin{array}{l}2 \\
2\end{array}$ & $77-79$ \\
\hline $\mathrm{Ho}^{3+}$ & $\begin{array}{l}416 \\
452 \\
537 \\
641\end{array}$ & $\begin{array}{l}3 \\
5 \\
5 \\
3\end{array}$ & $77-79$ \\
\hline $\mathrm{Er}^{3+}$ & $\begin{array}{l}379 \\
524 \\
654\end{array}$ & $\begin{array}{l}7 \\
4 \\
2\end{array}$ & $77-79$ \\
\hline
\end{tabular}

${ }^{a}$ Peak absent in Figuro 1.1 could be an impurity pcak.

${ }^{b}$ No maximum; spectral scan ended at this $\lambda$, as shown in Figure 4.11. 
The ion spectra in Figures 4.11 and 4.12 are therefore assumed to be representative of the corresponding ion spectra in the Purex solutions.

The affect on the uranyl ion absorption spectrum of going from aqueous to organic solutions is shown in Figures 4.13 to 4.15 . The band maxima do not shift significantly in going from aqueous to TBP or ketonic solvent solutions, but the absorption intensity is increased on the long wavelength side of the band. $^{1}$ The spectra of the $\mathrm{U}(\mathrm{VI})$ and $\mathrm{Pu}(\mathrm{IV})$ nitrate complexes in $19 \%$ TBP diluted in kerosene (the type of solution used in the Purex process) are shown in Figure 4.15. As discussed in section 3.2, the species giving rise to these bands are the neutral complexes $\mathrm{UO}_{2}\left(\mathrm{NO}_{3}\right)_{2}$ and $\mathrm{Pu}\left(\mathrm{NO}_{3}\right)_{4}$ solvated by 'l'BY. Comparison of the $U(V I)$ ion in the two solvent systems (Figures 4.13 and 4.15 ) indicates little shift in band maxima and long wavelength intensity enhancement for the uranyi ion. For plutonium the spectrum in Figure 4.15 correlates with the aqueous spectrum in Figure 4.6 Inote the absence of the peaks at 600 , 683, and $893 \mathrm{~nm}$ that are characteristic of the species $\mathrm{H}_{2} \mathrm{Pu}\left(\mathrm{NO}_{3}\right)_{6}$ or its anion]. The band intensities correspond to the intensities observed in $5 \underline{M}$ nitric acid solutions. This is as expected since the predominant spectes ts the neutral nitrate. Similar behavior would be expected for the other actinide ion complexes. Thus the $\lambda_{\max }$ for the actinide complexes should not change when they are extracted from the aqueous nitric acid to the IBP-kerosene phase, But the net light absorbance by the neutral nitrated species should increase (i.e., the concentration of this species should increase).

The electronic absorption bands of the ions belonging to the second and third transition metal series involve three types of electron transitions. The absorption spectra of the fission product metal complexes having $4 \mathrm{~d}$ and $5 \mathrm{~d}$ electrons display ligand field, charge transfer, and internal ligand transitions. 


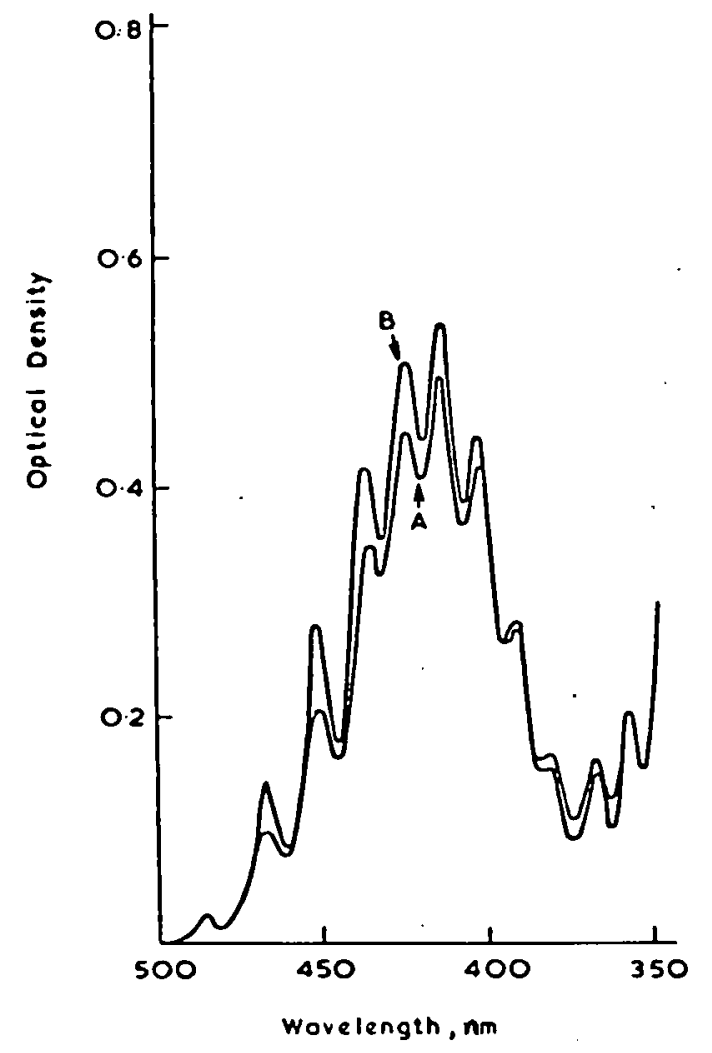

Figure 4.13. Absorption spectra for $0.05 \mathrm{M} \mathrm{U}(\mathrm{VI})$ solutions in hydrated TBP. Curve A, neutral solution; curve $\mathrm{B}$, with $1.4 \mathrm{M}$ nitric acid. (From Woodhead.63) 


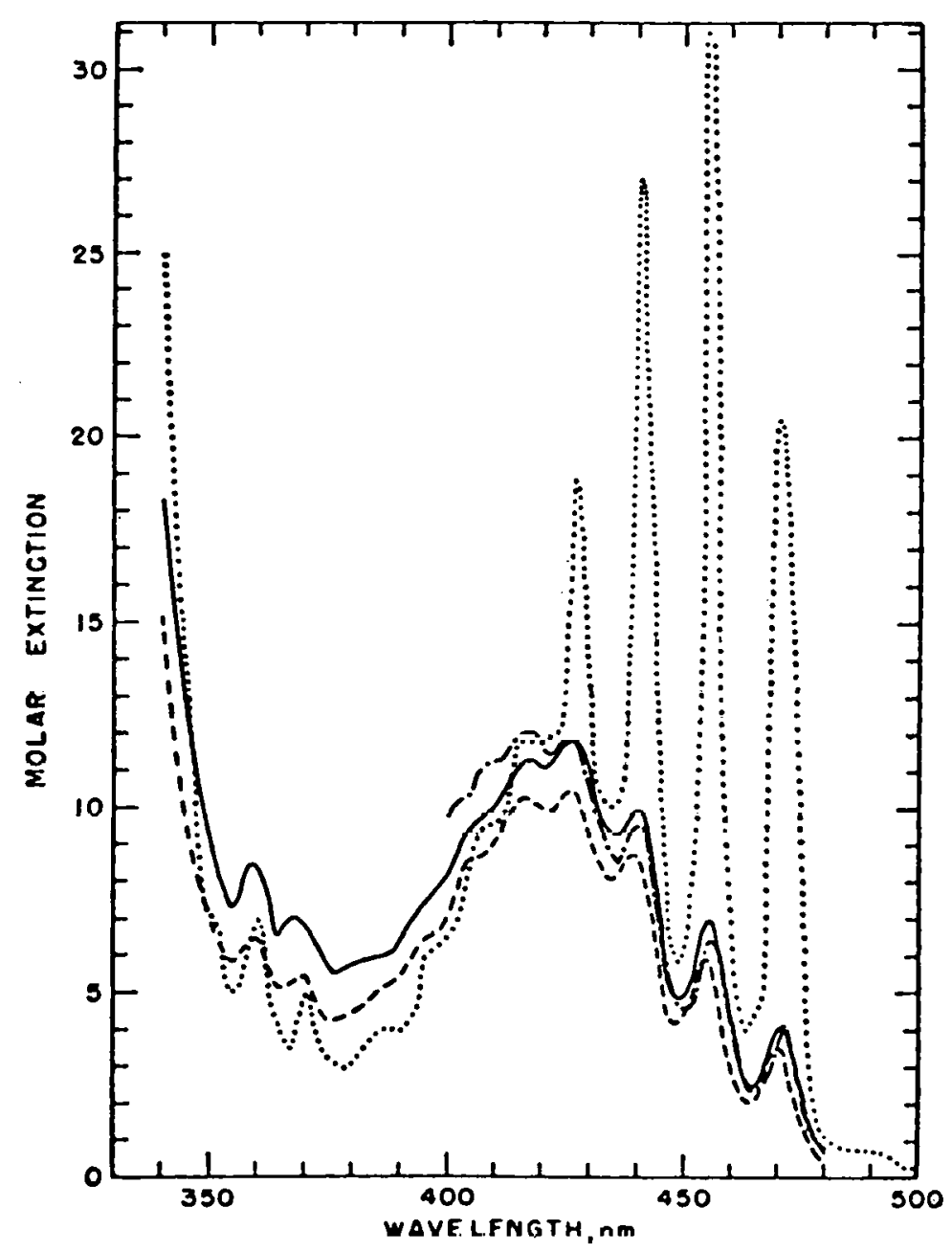

Figure 4.14. Absorption spectra of uranyl nitrate in some ketonic solvents. - 0.02 M uranyl nitrate in acetone; - $\ldots+, 0.02 \mathrm{M}$ uranyl nitrate in methyl isobutyl ketone; - - - $0.02 \mathrm{M}$ uranyl nitrate in cyclohexanone;....., $0.02 \mathrm{M}$ urany 1 nitrate, $0.02 \mathrm{M}$ tetrabutylammonium nitrate in acetone. (From Rabinowitch and Belford.1)

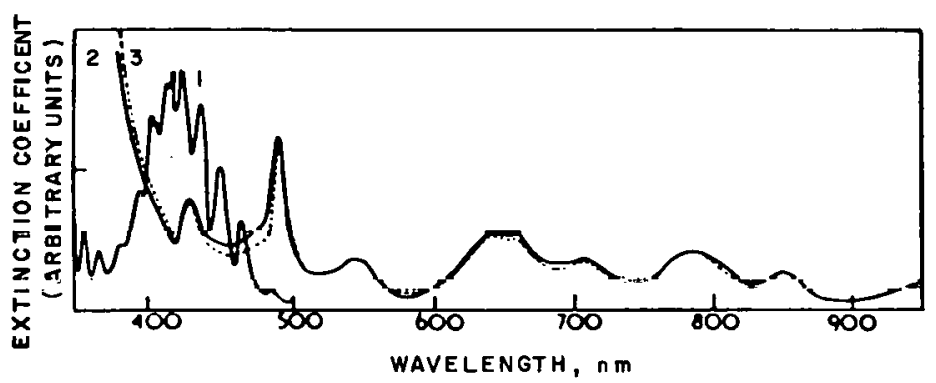

Figure 4.15. Spectra of uranyl and plutonium $\mathrm{Pu}(\mathrm{IV})$ nitrates in TBP. Curve $1, \mathrm{UO}_{2}\left(\mathrm{NO}_{3}\right)_{2}$; curve 2, $\mathrm{Pu}\left(\mathrm{NO}_{3}\right) 4$, ca. $0.05 \mathrm{M} \mathrm{HNO}_{3}$; curve 3 (dotted), $\mathrm{Pu}\left(\mathrm{NO}_{3}\right)_{4}$, ca. $0.9 \overline{\mathrm{M}} \mathrm{HNO}_{3}$. (From Healy and McKay. 62) 
Observation of any or all of these bands is a function of the metal, its oxidation state, and the coordinating 1igands. Identification of electronic transitions is difficult because of absorption overlap and lack of distinct excitedstate character. The spectra for these complexed metal ions are quite sensitive to the coordinating ligand environment. Both the position and intensity of the absorption bands are a function of the ligand-metal complexation. The composition of the transition metal complexes existing in the Purex process solutions is not known and probably, for a given solution, is continually changing. The ions in these multicomponent solutions are probably present as more than one type of complex. For such complicated solution chemistry, the degree of absorption due to each fission product ion can be evaluated at present only by making rough estimations based on the spectra of known complexes. For our purposes the extinction coefficients will be based on data from the literature.

Among the potentially strongest light absorbing species in the Purex process solutions are the ruthenium ion complexes. Because of the number of complexes that coexist and the tendency toward formation of polynuclear chain complexes the assignment of the ruthenium ion absorptions in such solutions is not feasible. The fact that the Purex solutions change color with time, going from very dark amber brown to very light rose color, ${ }^{106}$ further complicates the problem. This color change has been correlated with various ruthenium complexes known to undergo slow ligand exchange. To carry out photochemistry on these solutions the rose-colored phase is most suitable. The various ruthenium ion absorption band intensities and wavelength maxima are a function of the complexIng 11gand and therefore the solution compostition. In general, as shown in Figure 4.16, one or two absorption band maxima are observed from $2550 \mathrm{~nm}$ to $300 \mathrm{~nm}$ for the ruthenium complexes. The molar extinction coefficients of the band peaks 

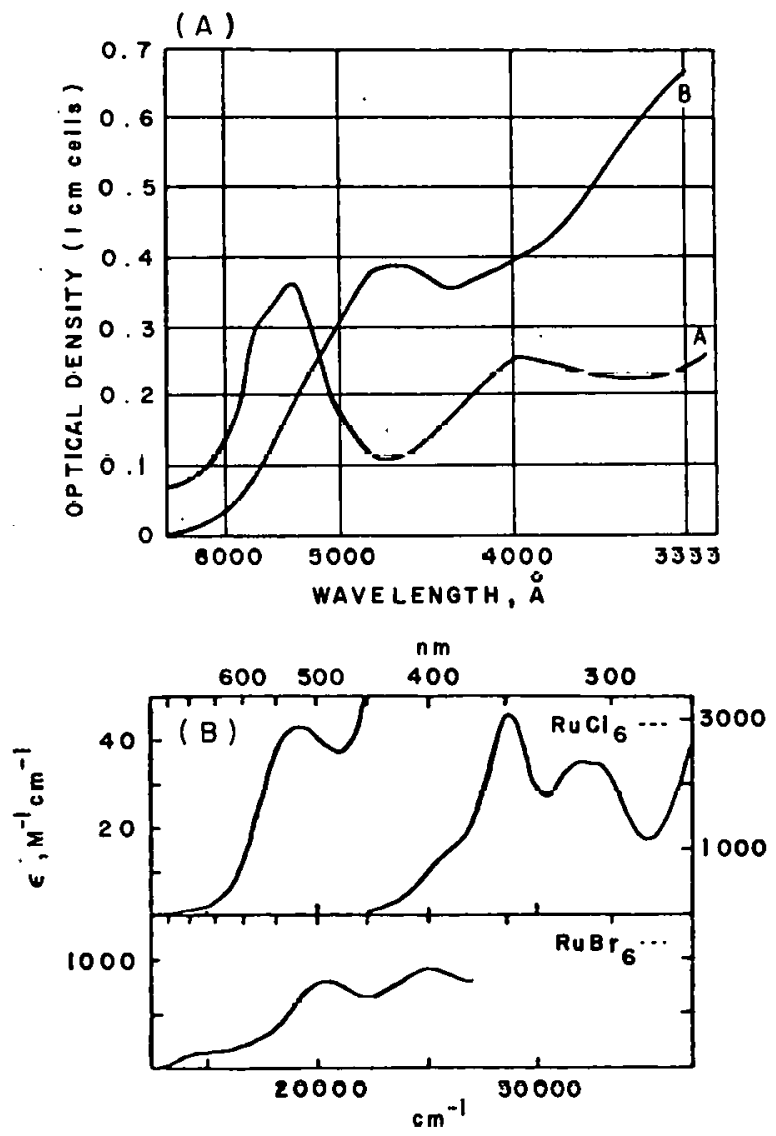

Figure 1.16. Abeorption spectra of various ruthenium complexes. (a) Spectrophotometric curves of nitrosy1ruthenium complexes in nitric acid: $A$, purple complex $\left([\mathrm{Ru}]=1.5 \times 10^{-4} \mathrm{M}\right)$ in $16 \mathrm{M} \mathrm{HNO} ; \mathrm{B}$, trinitratonitrogylruthonium ([Ru] $=5 . \overline{7} \times 10^{-3} \mathrm{M}$ ) in $8 \mathrm{M}$ HNOJ, aged for $3.3 \mathrm{~h}$ at $20^{\circ} \mathrm{C}$ (From Fletcher et al. $8 \overline{4}$ ). (b) Speclra of cliluru alld biumu cumplexes of Ru(III): upper curve in $10 \mathrm{M} \mathrm{HCl}$; lower curve in $6 \mathrm{M} \mathrm{HBr}$ (from Jorgensen 110). 

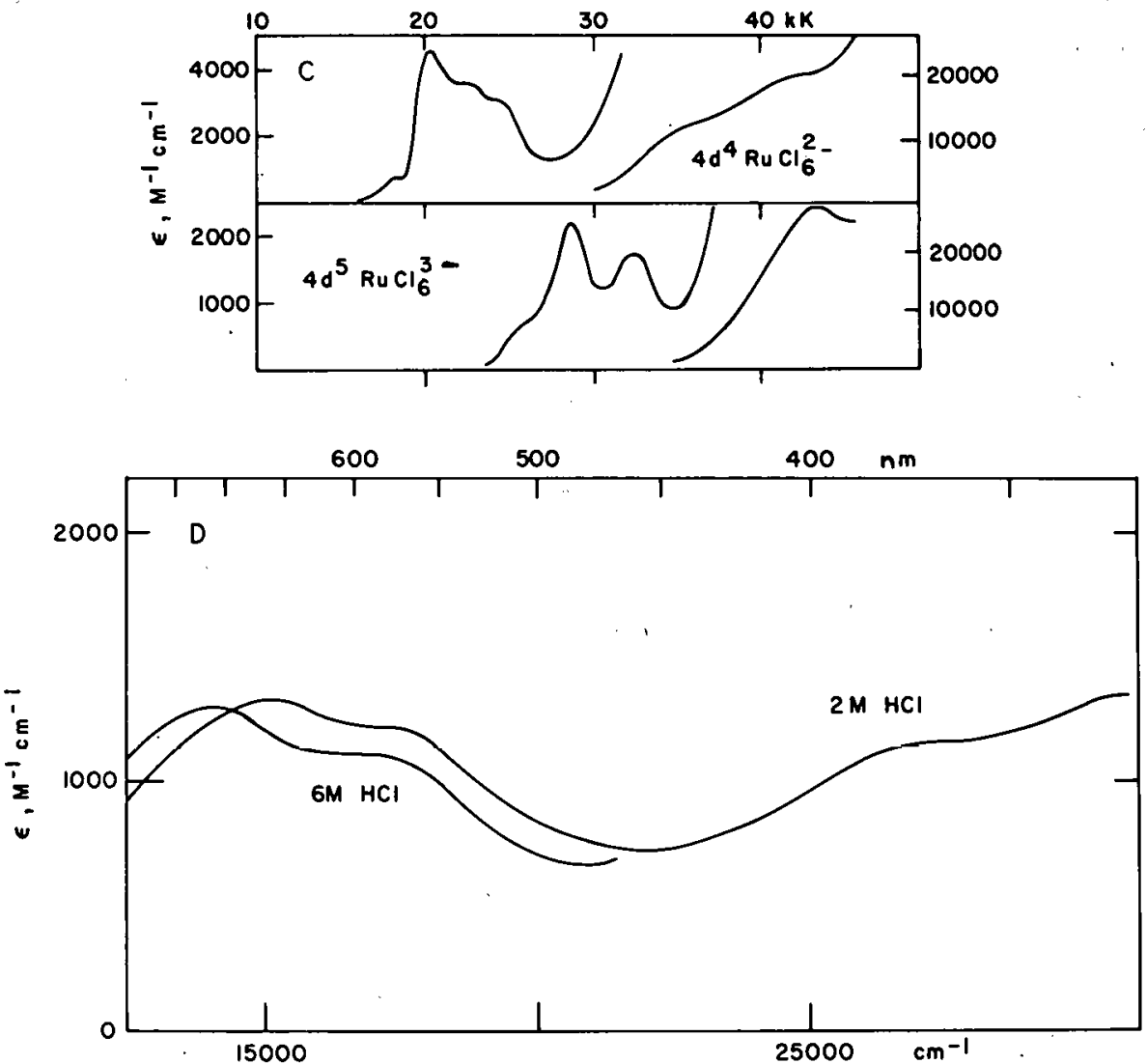

Figure 4.16. Absorption spectra of various ruthenium complexes. (c) $d^{4}$ and $d^{5}$ hexachloro complexes (from Jorgensen 93). (d) $0.001 \mathrm{M}$ ruthenium in $2 \mathrm{M}$ and $6 \mathrm{M}$ $\mathrm{HCl}$ (from Jorgensen 110 ). 

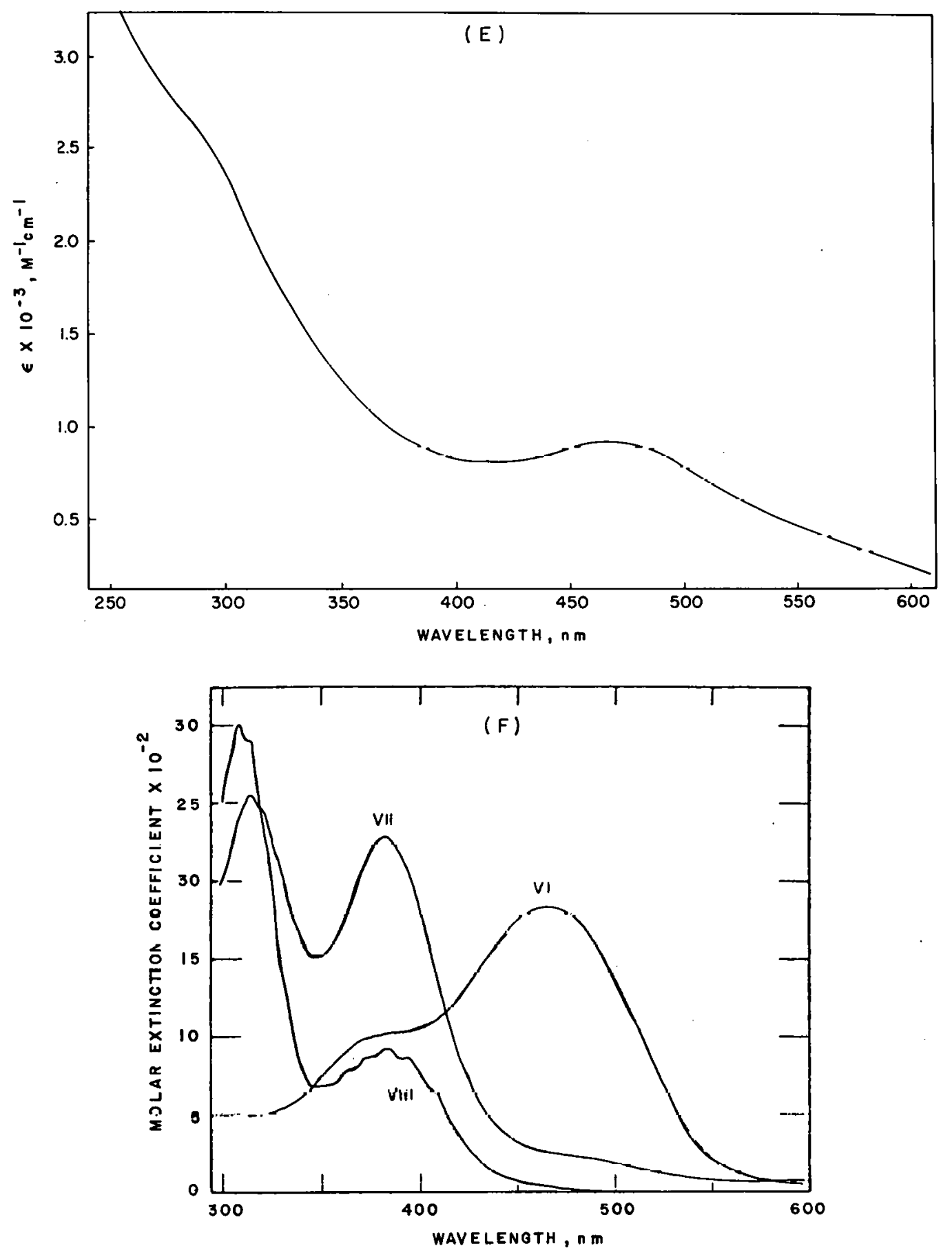

Figure 4.16. Absorption spectra of various ruthenium complexes. (e) Effect of the perchloric acid concentration on the absorption spectrum of Ru(IV) perchlorate in 12 M HC104 (all spectra taken on freshly prepared solutions with a Cary 14 recording spectrophotometer using $1-\mathrm{cm}$ cells) (from Gortsema and Cobble $\left.e^{88}\right)$. (f) Molar extinction coefficients of $\mathrm{Ru}(\mathrm{VIII}),(\mathrm{VII})$, and (VI) as a function of wavelength (from Connick and Hurley 107). 
generally vary between $\sim 130$ and $2300 \underline{\mathrm{M}}^{-1} \mathrm{~cm}^{-1}$; as shown in Figure 4.16 and Table 4.5. The spectra in Figure 4.16(a) are the most relevant to the Purex solutions. The trinitrate species [spectrum B in Figure 4.16(a)] show a broad band between 435 and $590 \mathrm{~nm}$, with an $\varepsilon$ of $\sim 133 \underline{\mathrm{M}}^{-1} \mathrm{~cm}^{-1}$, while at the 333-nm scan cutoff point ${ }^{84}$ the $\varepsilon$ is $2240 \underline{M}^{-1} \mathrm{~cm}^{-1}$. The $\varepsilon$ for the peaks in spectrum $A$ of Figure 4.16(a) cannot be estimated because the data are insufficient. The absorption spectrum of the tetranitro complex of ruthenium shows no prominent peaks in the visible. ${ }^{82}$ Because of the importance of ruthenium to the spectral characteristics of the Purex solutions an $\varepsilon$ range, based on maximum and minimum extinction coefficients from the literature, will be used in the optical window evaluations of section 4.5 .

For the rhodium ion in aqueous solutions, the absorption band intensities are somewhat lower than for ruthenium systems. Rhodium complexes have two or three band maxima in the 550 to $350-\mathrm{nm}$ region of the Purex photochemical spectral range (Figure 4.17). The molar extinction coefficients vary from $\sim 50$ to $\sim 200 \underline{\mathrm{M}}^{-1} \mathrm{~cm}^{-1}$, as shown in Figure 4.17 and Table 4.6. The band positions are sensitive to the ligand system but the extinction coefficients do not vary by more than a factor of 4 .

Palladium ions have one or two intense bands in the 500 to $350-\mathrm{nm}$ region (Figure 4.18). The $\varepsilon^{\prime}$ 's vary from $\sim 5000$ to $\sim 12,000 \underline{M}^{-1} \mathrm{~cm}^{-1}$, as shown in Table 4.7. Such large extinction coefficients coupled with the palladium process concentrations point out the important role of the $\mathrm{Pd}$ (II) complexes in determining the spectral properties of the Purex solutions. More relevant data are needed on the absorptivities of the nitrate and related complexes of Pd(II) which must exist in the process solutions. To date no literature exists on the complexes 
Table 4.5

Absorption Band Maxima $\left(\lambda_{\max }\right)$ and Molar Extinction Coefficients $(\varepsilon)$ for Ruthenium Complexes From 350 to $1100 \mathrm{~nm}$

\begin{tabular}{|c|c|c|c|}
\hline Ion complex & $\lambda_{\max }(\mathrm{nm})$ & $\varepsilon\left(\underline{M}^{-1} \mathrm{~cm}^{-1}\right)$ & Ref. \\
\hline $\operatorname{RuNO}\left(\mathrm{NO}_{3}\right)_{3}$ & $\begin{array}{l}333^{*} \\
470\end{array}$ & $\begin{array}{l}240 \\
133\end{array}$ & 84 \\
\hline$R u(V I)$ & $\begin{array}{l}380 \\
465\end{array}$ & $\begin{array}{l}1000 \\
1800\end{array}$ & 107 \\
\hline $\operatorname{Ru}(V I I)$ & $\begin{array}{l}380 \\
485\end{array}$ & $\begin{array}{r}2300 \\
200\end{array}$ & 107 \\
\hline $\mathrm{Ru}(\mathrm{VIII})$ & 380 & 900 & 107 \\
\hline $\operatorname{RuCl}_{6}{ }^{3-}$ & $\begin{array}{l}349 \\
521\end{array}$ & $\begin{array}{r}2160 \\
43\end{array}$ & 100,93 \\
\hline $\operatorname{RuBr}_{6}{ }^{3-}$ & $\begin{array}{l}400 \\
485 \\
655\end{array}$ & $\begin{array}{l}900 \\
770 \\
130\end{array}$ & 110 \\
\hline $\mathrm{Ku}(11)$ & $\begin{array}{l}570 \\
660\end{array}$ & $\begin{array}{l}1130 \\
1250\end{array}$ & 110 \\
\hline
\end{tabular}

*No maximum; spectral scan ended at this $\lambda$, as shown in Figure $4.16(\mathrm{a})$. 

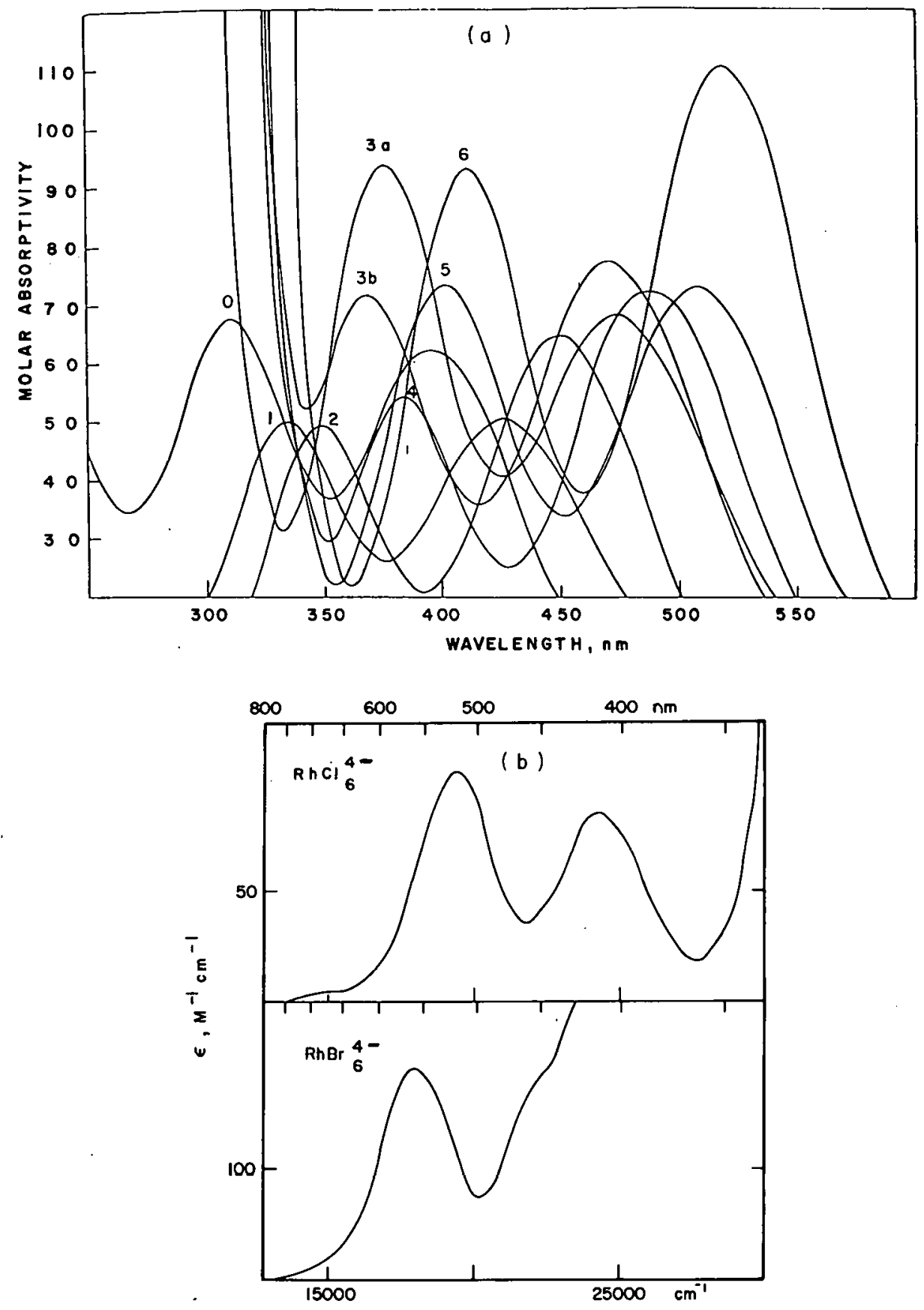

Figure 4.17. Absorption spectra of various rhodium complexes. (a) molar absorptivities of $\mathrm{Rb}$ (III)chloride speçies in $6 \mathrm{M}$ acid $\left(\mathrm{HCl}+\mathrm{HClO}_{4}\right):(0)$ $\mathrm{Rh}$ (aquated) ${ }^{3+}$; (1) $\mathrm{RhCl}{ }^{2+} ;\left(2, \mathrm{RhCl}_{2}{ }^{+} ;(3 \mathrm{a})\right.$, cis$\mathrm{RhCl}_{3}$; (3b) trano-RhCl 3 , (4) $\mathrm{RhCl}_{4}^{-}$, (5) $\mathrm{RhCl}_{5}{ }^{2-}$, (6) $\mathrm{RhCl}_{4}{ }^{3-}$ (From Wolsey et al. 89); (b) spectra of hexachloro- and hexabromo-Rh (III) ions $(0.01 \mathrm{M}$ to $0.3 \mathrm{M} \mathrm{Na}_{3} \mathrm{RhCl}_{6}$ in $4 \mathrm{M} \mathrm{HCl}$ and $\mathrm{H}_{2} \mathrm{O}$, immediately

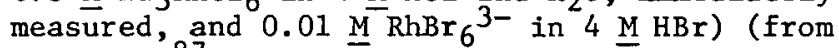
Jorgensen 87 ). 
Table 4.6

Absorption Band Maxima $\left(\lambda_{\max }\right.$ ) and Molar Extinction Coefficients $(\varepsilon)$ for Rhodium Complexes From 350 to $1100 \mathrm{~nm}$

\begin{tabular}{|c|c|c|c|}
\hline Ion complex & $\lambda_{\max }(\mathrm{nm})$ & $\varepsilon\left(\underline{M}^{-1} \mathrm{~cm}^{-1}\right)$ & Ref. \\
\hline $\mathrm{Rh}^{3+}$ & 396 & $47-62$ & 87,109 \\
\hline $\mathrm{RhCl}^{2+}$ & 426 & 50 & 109 \\
\hline $\mathrm{RhCl}_{2}^{+}$ & $\begin{array}{l}349 \\
450\end{array}$ & $\begin{array}{l}50 \\
65\end{array}$ & 1119 \\
\hline cis $-\mathrm{RhCl}_{3}$ & $\begin{array}{l}376 \\
474\end{array}$ & $\begin{array}{l}94 \\
68\end{array}$ & 109 \\
\hline trans $-\mathrm{RhCl}_{3}$ & $\begin{array}{l}370 \\
471\end{array}$ & $\begin{array}{l}72 \\
77\end{array}$ & 109 \\
\hline $\mathrm{RhCl}_{4}^{-}$ & $\begin{array}{l}385 \\
488\end{array}$ & $\begin{array}{l}54 \\
72\end{array}$ & 109 \\
\hline $\mathrm{RhCl}_{5}{ }^{2}$ & $\begin{array}{l}402 \\
507\end{array}$ & $\begin{array}{l}73 \\
73\end{array}$ & 109 \\
\hline $\mathrm{RhCl}_{6}^{3-}$ & $\begin{array}{l}411 \\
518 \\
680\end{array}$ & $\begin{array}{r}82-94 \\
102-112 \\
3\end{array}$ & 87,109 \\
\hline $\mathrm{RhBr}_{6}^{3-}$ & 553 & 190 & 87 \\
\hline
\end{tabular}




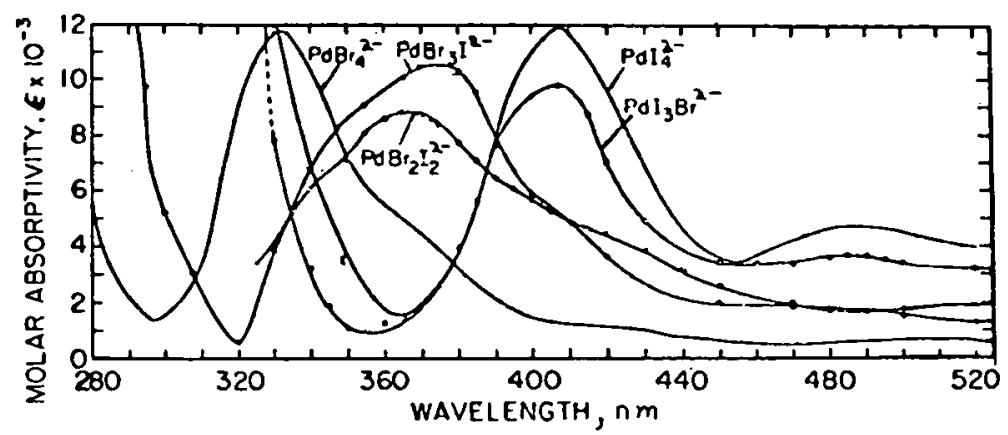

Figure 4.18. Spectra of palladium-bromide-iodide mixed complexes. (From Srivastava and Newman.94)

Table 4.7

Absorption Band Maxima $\left(\lambda_{\max }\right)$ and Molar Extinction Coefficients $(\varepsilon)$ for Palladium Complexes From 350 to $1100 \mathrm{~nm}$

\begin{tabular}{lccc}
\hline Ion complex & $\lambda_{\max }(\mathrm{nm})$ & $\varepsilon\left(\underline{M}^{-1} \mathrm{~cm}^{-1}\right)$ & Ref. \\
\hline $\mathrm{PdBr}_{4}^{2-}$ & $350 *$ & 7,000 & 94 \\
$\mathrm{PdBr}_{3}{ }^{2-}$ & 375 & 11,800 & 94 \\
$\mathrm{PdBr}_{2}{ }^{2-}{ }^{2-}$ & 370 & 8,700 & 94 \\
$\mathrm{PdBrI}_{3}^{2-}$ & 407 & 9,800 & 94 \\
$\mathrm{PdI}_{4}{ }^{2-}$ & 407 & 11,800 & 94 \\
\hline
\end{tabular}

*No maximum; spectral scan ended at this $\lambda$, as shown in Figure 4.18 . 
and spectral properties of $\mathrm{Pd}(\mathrm{II})$ dissolved in aqueous nitric acid. Thus detailed studies analogous to those on the ruthenium system 82,84 are needed.

Antimony(V) complexes have a large absorption in the ultraviolet. The tail of this band extends into the Purex photochemical spectral range, as shown in Figure 4.19. The molar extinction coefficients drop off rapidly from $ح 200$ $\underline{M}^{-1} \mathrm{~cm}^{-1}$ at $350 \mathrm{~nm}$ until they are negligible at wavelengths greater than $\sim 400$ $\mathrm{nm}$. The molybdenum(VI) ion has a similar ultraviolet absorption band; its tail appears to extend beyond $350 \mathrm{~nm} .^{37,109}$ The molar extinction coefficient at 350 $\mathrm{nm}$ is $\sim 100 \underline{\mathrm{M}}^{-1} \mathrm{~cm}^{-1}$.

\subsection{Spertral Windóws}

To carry out photoshemistry on an ion in solution, the solution must be of sufficient transparency that reasonable product yields can be obtained; i.e., the major fraction of the exciting light must be absorbed by the ion and not by solvent or other solution components. In this section an attempt is made to characterize in a general manner the spectral properties of the Purex process solutions pertinent to the photochemistry. Because of the complexity of these solutions, only a preliminary evaluation can be made.

The Purex photochemical spectral range, as shown in Figure 4.20, extends from $\sim 350$ to $\sim 1100 \mathrm{~nm}$ and is subdivided into three regions. The first covers the $\sim 350$ to $\sim 480-\mathrm{nm}$ region, the second goes from $\sim 480$ to $660 \mathrm{~nm}$, and the third extends from $\sim 660$ to $1100 \mathrm{~nm}$. The first two regions contain the bands of the $\mathrm{Ru}, \mathrm{Pd}$, and $\mathrm{Rh}$ complexes, which are the ștrongest nonactinide interfering absorptions over the entire photochemical spectral range. The first region, in addition, contains the uranyl band which, because of the high uranyl ion concentrations, will dominate the light absorption in this reglon for the Purex solutions used in the process shown in Figure 3.1. The third region contains 


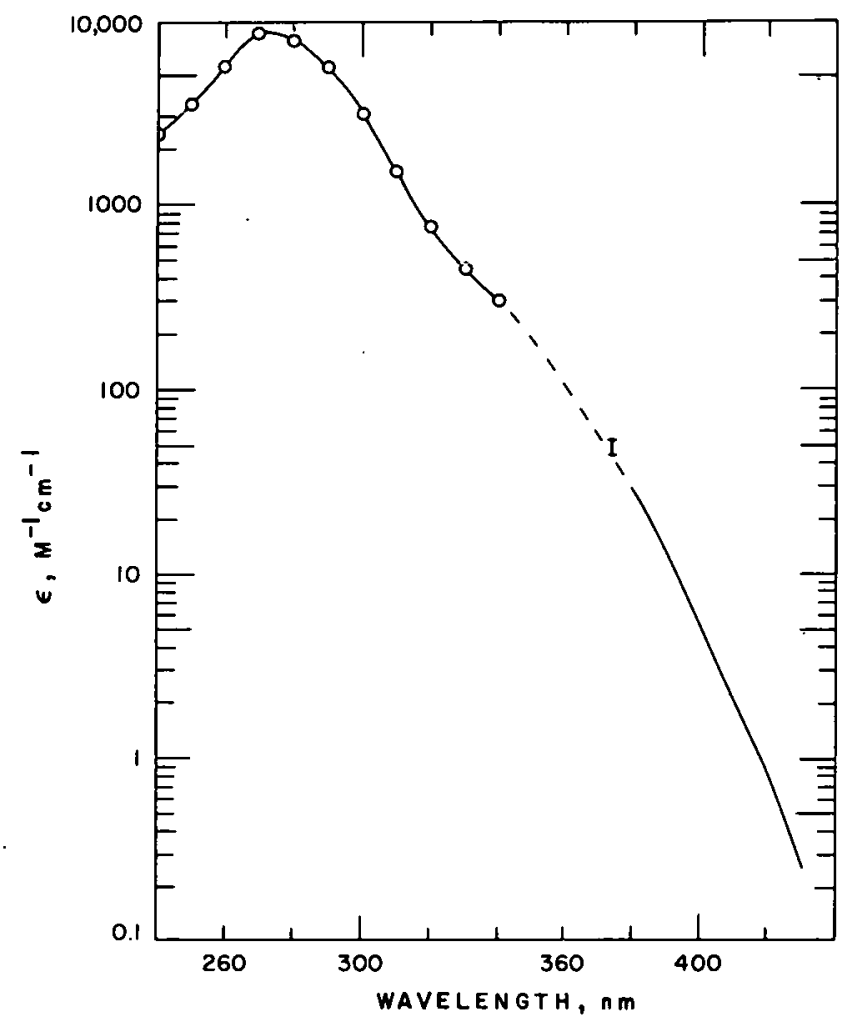

Figure 4.19. Spectrum of $\mathrm{Sb}(\mathrm{V})$ in concentrated HCl. (From Whitney and Davidson. ${ }^{68}$ )

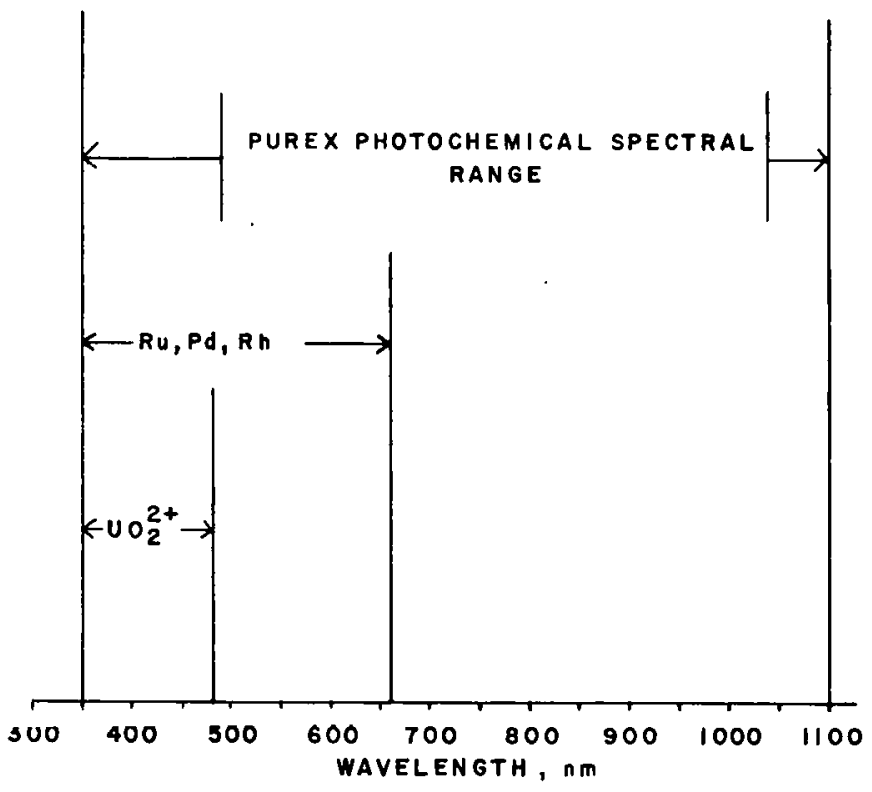

Figure 4.20. Purex photochemical spectral range and subregions. 
absorption bands that, with selection of the appropriate wavelength of the exciting light, allow the various actinide ions to be photolyzed using the unaltered Purex solutions.

Since the $\mathrm{Ru}, \mathrm{Pd}$, and $\mathrm{Rh}$ complexes have bands in the 350 to 660-nm region, it is necessary to evaluate the extent to which the light absorption due to these complexes must be reduced (via extinction coefficient or concentration changes) to attain Purex solutions in which the actinide bands can be practically photolyzed. For this evaluation use is made of a reduction factor RF, defined by

$$
\begin{aligned}
\mathrm{RF}=\frac{\text { Sum of modified stream interfering absorbances }}{\text { Sum of original stream interfering absorbances }} \\
\qquad \begin{array}{c}
\sum \mathrm{C}_{i}^{\prime} \varepsilon_{i}^{-} \\
=\frac{i}{i} C_{i} \varepsilon_{i}
\end{array}
\end{aligned}
$$

where $C_{i}$ and $\varepsilon_{i}$ are the concentration and extinction coefficients for those ions in the original (unprimed) and modified (primed) waste reprocessing streams which absorb the exciting light needed to carry out a given acrinide photochemical reaction. The fraction of exciting light absorbed by the interfering complexes in the original and modified streams is given by the light loss factors

$$
\begin{aligned}
\text { LLF } & =\frac{\sum_{i} C_{i} \varepsilon_{i}}{C_{a} \varepsilon_{a}+\sum_{i} C_{i} \varepsilon_{i}}, \\
L L F^{\prime} & =\frac{\sum C_{i}^{\prime} \varepsilon_{i}^{\prime}}{C_{a} \varepsilon_{a}+\sum_{i} C_{i}^{\prime} \varepsilon_{i}^{\prime}} .
\end{aligned}
$$

The reduction factor can be expressed in terms of these light loss factors as 


$$
R F=\frac{L L F^{\prime}(1-L L F)}{L L F\left(1-L L F^{\prime}\right)}
$$

In the following sections the parameters for the above equations are extracted from Tables 4.2 and 4.4 to 4.7.

As is evident from the above equation, the $R F$ value is a function of the exciting light loss level. The required reductions can therefore be flexible or stringent and large or small, depending on the fraction of light to be lost through interfering absorptions. The $R F$ values will generally be given as a range encompassing the extinction coefficient extremes. To attain the light loss conditions specified by the $R F$ values, two variables can be adjusted: concentration and extinction coefficient. For interfering ions, therefore, two methods can be used to minimize the absorptions: (1) reduction of the concentration of the ion, and/or (2) reduction of the extinction coefficient by changing the metal valence state and/or the composition of the complex.

4.5.1 The Urany1 Window. For the urany1 ion $\mathrm{UO}_{2}{ }^{2+}$ the $\sim 380$ to $\sim 480-\mathrm{nm}$ excitation band peaks at $\sim 415 \mathrm{~nm}$, as shown in Figure 4.5. The nitrate ion (complex with a metal or solvent) and solvents do not have a significant absorption in the uranyl region. The nitrite ion has an absorption infringing on the high energy side of the band, as shown in Figure 4.4, with an $\varepsilon$ of $\sim 10 \underline{M}^{-1} \mathrm{~cm}^{-1}$ at $380 \mathrm{~nm}$. Figure 4.6 shows that the $\mathrm{Pu}(\mathrm{IV})$ species has two maxima, at 400 and 425 $\mathrm{nm}$, with $\varepsilon$ of 28 and $24 \underline{\mathrm{M}}^{-1} \mathrm{~cm}^{-1}$, respectively, and a prominent peak at $480 \mathrm{~nm}$, with $\varepsilon$ of $69 \underline{M}^{-1} \mathrm{~cm}^{-1}$. A general background absorption of $\varepsilon \sim 20 \underline{M}^{-1} \mathrm{~cm}^{-1}$ due to this ion extends over the uranyl band, but at the $\mathrm{UO}_{2}{ }^{2+}$ maximum at $415 \mathrm{~nm} \varepsilon$ is $\sim 14 \underline{\mathrm{M}}^{-1} \mathrm{~cm}^{-1}$. The $\mathrm{Pu}(\mathrm{V})$ ions in Figure 4.6 have an average $\varepsilon$ of $\sim 3 \underline{\mathrm{M}}^{-1} \mathrm{~cm}^{-1}$, with a peak at $415 \mathrm{~nm}$ whose $\varepsilon$ is $\sim 11 \underline{\mathrm{M}}^{-1} \mathrm{~cm}^{-1}$. The $\mathrm{Pu}$ (III) complex in Figure 4.6 has a low background absorption with an $\varepsilon$ of $\sim 3 \underline{M}^{-1} \mathrm{~cm}^{-1}$. In Figure 4.7 
Np (VI) shows the beginning of an ultraviolet band whose $\varepsilon$ increases from 7 to $38 \underline{\mathrm{M}}^{-1} \mathrm{~cm}^{-1}$ on going from 480 to $380 \mathrm{~nm}$, with a value of $14 \underline{\mathrm{M}}^{-1} \mathrm{~cm}^{-1}$ at $415 \mathrm{~nm}$. The $N_{p}(\nabla)$ spectra in Figure 4.7 have two peaks, at 430 and $476 \mathrm{~nm}$, with the same $\varepsilon$ of $\underline{9} \underline{M}^{-1} \mathrm{~cm}^{-1}$, while a dip occurs at $415 \mathrm{~nm}$ to give an $\varepsilon$ of $5 \underline{M}^{-1} \mathrm{~cm}^{-1}$. The three peaks of $\mathrm{Np}(\mathrm{IV})$ at 403,412 , and $429 \mathrm{~nm}$ have $\varepsilon^{\prime} \mathrm{s}$ of 8,15 , and $24 \underline{\mathrm{M}}^{-1} \mathrm{~cm}^{-1}$, respectively, while at $415 \mathrm{~nm} \varepsilon$ is $10 \underline{M}^{-1} \mathrm{~cm}^{-1}$. For $A m$ (III) and $\mathrm{Cm}$ (III) there is no absorption at the uranyl ion maxima of $415 \mathrm{~nm}$, as shown in Figures 4.8 and 4.9. However, $A m$ (III) has two and $\operatorname{Cm}$ (III) has four peaks over the 380 to $480-\mathrm{nm}$ range, with $\varepsilon$ 's varying from 5 to $53 \underline{M}^{-1} \mathrm{~cm}^{-1}$.

The rare earth ions $\mathrm{Nd}^{3+}, \mathrm{Pm}^{3+}, \mathrm{Dy}^{3+}$, and $\mathrm{Er}^{3+}$ do not have significant absorption bands in the 380 to $480-\mathrm{nm}$ region. As shown in Figure 4.12, $\mathrm{Eu}^{3+}$ and $\mathrm{Sm}^{3+}$ have respective peaks at 394 and $402 \mathrm{~nm}$, with $\varepsilon$ equal to $3 \underline{\mathrm{M}}^{-1}$ $\mathrm{cm}^{-1}$. The $\mathrm{Ho}^{3+}$ species has two peaks, at 416 and $452 \mathrm{~nm}$, with $\varepsilon^{\prime} s$ of 3 and 5 $\underline{M}^{-1}-\mathrm{cm}^{-1}$. The $\mathrm{Pr}^{3+}$ peaks at 444 and $470 \mathrm{~nm}$ have $\varepsilon$ 's of 10 and $5 \underline{\mathrm{M}}^{-1} \mathrm{~cm}^{-1}$. As shown in Figure 4.11 the $\mathrm{Pm}^{3+}$ ultraviolet band tail extends into the $\mathrm{UO}_{2}{ }^{2+}$ region, with $\varepsilon$ going from $50 \underline{M}^{-1} \mathrm{~cm}^{-1}$ at $380 \mathrm{~nm}$ to $10 \underline{M}^{-1} \mathrm{~cm}^{-1}$ at $480 \mathrm{~nm}$. The $\mathrm{Sb}^{5+}$ ion (Figure 4.19) shows similar behavior, with its ultraviolet tail having an $\varepsilon$ of $30 \underline{\mathrm{M}}^{-1} \mathrm{~cm}^{-1}$ at $380 \mathrm{~nm}$. The rhodium ions (Figure 4.17) have one or two peaks in this region, with $\varepsilon$ in the range of 50 to $100 \underline{\mathrm{M}}^{-1} \mathrm{~cm}^{-1}$.

For the uranyl oyotem the above interfering aboorptiono have c's somewhat comparable with that for the $U_{2}^{2+}$, which is $\gamma \underline{M}^{-1} \mathrm{~cm}^{-1}$. 'l'heretore the absorption of light by these ions will not be significant until their concentration is roughly comparable with that of the $\mathrm{UO}_{2}{ }^{2+}$ ion. By selection of the appropriate wavelength of the exciting light it should be possible to avoid the interfering maxima of these ions and thereby have only absorption by a general background. For $99.9 \%$ recovery of the uranium such general-background absorp- 
tion light. losses would be significant only for solutions in which the last $0.1 \%$ of the $\mathrm{UO}_{2}{ }^{2+}$ was being photolyzed. The amount of light utilized to photolyze $\mathrm{UO}_{2}{ }^{2+}$ at the $10^{-3} \mathrm{M}$ level should be $25 \%$ for solutions from which $99 \%$ of the fission products have been removed.

This is not the case, however, for the ruthenium and palladium ions, which have strong absorptions in the uranyl ion band region. The Pd(II) complexes have very large absorptions in the 380 to $480-\mathrm{nm}$ region, with $\varepsilon$ ranging from 11,800 to $4700 \mathrm{M}^{-1} \mathrm{~cm}^{-1}$ (Figure 4.18). Similarly, as is apparent in Figure 4.16, the ruthenium ion complexes show strong bands in this region, with a maximum $\varepsilon$ of $2300 \underline{\mathrm{M}}^{-1} \mathrm{~cm}^{-1}$. The perhaps more relevant spectra in Figure 4.16 (a) have $\varepsilon^{\prime}$ 's in the range of 133 to $470 \underline{M}^{-1} \mathrm{~cm}^{-1}$.

The strong band case for these two ion systems represents the most serious constraint on introducing 380 to $480-\mathrm{nm}$ exciting 1ight into Purex process solutions. Assume that the $\mathrm{Pd}$ and $\mathrm{Ru}$ ions have $\varepsilon$ 's of 11,800 and $2300 \underline{\mathrm{M}}^{-1}$ $\mathrm{cm}^{-1}$ respectively. Since the ruthenium and palladium complexes are major solution components, as shown in Table 3.3, urany1 photochemistry cannot be carried out in the 380 to $480-\mathrm{nm}$ region until the absorption of light by these two ion systems is significantly reduced. For the concentrations given in Table 3.3, the reduction factor (defined in section 4.5) of $2 \times 10^{-2}$ gives a solution in which $90 \%$ of the exciting light is absorbed by $\mathrm{UO}_{2}{ }^{2+}$ and $10 \%$ by palladium and ruthenium.

In the weak band case, the $\mathrm{Pd}$ and $\mathrm{Ru}$ species have $\varepsilon^{\prime} \mathrm{s}$ of 4700 and $133 \underline{\mathrm{M}}^{-1} \mathrm{~cm}^{-1}$ respectively. The reduction factor for $1 \mathrm{M} \mathrm{UO}_{2}{ }^{2+}$ solutions is $6 \mathrm{x}$ $10^{-2}$ for $10 \%$ light luss. To remove $99.9 \%$ of the uranium requires working with $\sim 10^{-3} \mathrm{M} \mathrm{UO}_{2}{ }^{2+}$ solutions, which in turn requires, for $1.0 \%$ light absorbed by $\mathrm{UO}_{2}{ }^{2+}$, a reduction factor of $5 \times 10^{-2}$. This same reduction factor increases 
the light utilization by uranyl ion to $50 \%$ for solutions from which $99 \%$ of the fission products have been removed. Thus the reduction factor for a given level of interfering species is a function of actinide concentration, extinction coefficient, and light loss criteria. The severity of the constraints set by the $\mathrm{Ru}$ and $\mathrm{Pd}$ complexes on the 480 to $660-\mathrm{nm}$ photochemical spectral region is determined by the light loss level used for a given $\mathrm{UO}_{2}{ }^{2+}$ concentration.

Ruthenium presents difficulties in chemical processes and effluent disposal systems that make its removal from the process stream advaintageous. By optimizing the light loss versus the extent of Ku and Pd light absurpliul, it should be possible to obtain reasonable reduction factors at usable light loss levels. One way of attaining the reduction factor conditions is to decrease the concentrations of $\mathrm{Ru}$ and $\mathrm{Pd}$ in the process stream. The alternative to physically removing these two elements is to change their complexes so that they are transparent to the 380 to $480-\mathrm{nm}$ light. The tetranitratonitrosyl ruthenium complex, for example, has no prominent peaks in this region. 82

The above results show that the primary light absorbers in the 380 to $480-\mathrm{nm}$ uranyl photochemical spectral range are palladium and ruthenium complexes. The low $\varepsilon\left(133 \underline{\mathrm{M}}^{-1} \mathrm{~cm}^{-1}\right)$ used for the ruthenium system is probably close to the real $\lambda_{\max }$ solution value. This may not be the case for the palladium system, since the reported values are for halide and not nitrate complexes. A more reasonable $\varepsilon$ for palladium complexes in the Purex solutions may be similar to that for the ruthenium system, i.e., $\varepsilon=\sim 100$ to $200 \underline{M}^{-1} \mathrm{~cm}^{-1}$. If this is the case the reduction factor for these two interfering metals would be 20.4 for $1.0 \%$ light utilization at the $10^{-3} \underline{\mathrm{M}}$ urany 1 level.

The conclusion drawn from these arguments is that palladium and ruthenium ion complexes in the Purex process solutions are the major species 
that absorb light in the 380 to $480-\mathrm{nm}$ photochemical range. Experimental work on these ion systems under Purex solution conditions is required to quantify the extent of this problem area.

4.5.2 The Plutonium Windows. For the absorption peaks of the plutonium complexes shown in Figure 4.6 no significant solvent-related absorptions occur. Because of the $\mathrm{UO}_{2}{ }^{2+}$ coupled with the ruthenium and palladium complex absorptions, the region below $\sim 480 \mathrm{~nm}$ is too opaque to utilize any plutonium peaks for photolysis at shorter wavelengths. The $\mathrm{Ru}, \mathrm{Pd}$, and $\mathrm{Rh}$ complexes have absorption bands extending to $\sim 660 \mathrm{~nm}$ whose maxima have $\varepsilon$ varying from 1250 to 43 , 5000 to 500, and 190 to $72 \mathrm{M}^{-1} \mathrm{~cm}^{-1}$ respectively. The plutonium peaks in this 480 to $660-\mathrm{nm}$ range vary from 19 to $500 \mathrm{M}^{-1} \mathrm{~cm}^{-1}$. Considering the broad interfering bands shown in Figures 4.16 to 4.18 and the relative concentrations given in Table 3.3, utilization of the region from 480 to $v 660-\mathrm{nm}$ to photolyze plutonium species would be more advantageous if the $\mathrm{Ru}, \mathrm{Pd}$, and $\mathrm{Rh}$ ion absorptions for the Purex solutions were appropriately reduced. For $10 \%$ light 10 ss at the $\sim 10^{-2}$ $\mathrm{M}$ plutonium concentrations the $\mathrm{Ru}, \mathrm{Pd}$, and $\mathrm{Rh}$ reduction factor ranges from 0.3 to $9 \times 10^{-4}$. With $90 \%$ light utilization for excitation of the $10^{-5} \underline{\mathrm{M}}$ plutonium solutions (99.9\% recovery leve1), with $99 \%$ of the fission products removed, the reduction factor ranges from $3 \times 10^{-2}$ to $8 \times 10^{-4}$. These ranges represent the difference between the maximum and minimum $\varepsilon$ cases.

In the plutonium 480 to $660-\mathrm{nm}$ range there is only one strong interfering actinide peak, due to americium at $503 \mathrm{~nm}$ with an $\varepsilon$ of $300 \underline{\mathrm{M}}^{-1} \mathrm{~cm}^{-1}$. As shown in Figure 4.8, this is a sharp peak $\sim 50 \mathrm{~nm}$ wide at the base. Any plutonium peak that the americium band might interfere with can be avoided by selecting an appropriate wavelength. The remaining actinide ion absorptions in this region are due to neptunium ions whose $\varepsilon^{\prime}$ 's ranging from 3 to $25 \underline{\mathrm{M}}^{-1} \mathrm{~cm}^{-1}$ 
and therefore are comparable with or weaker than the corresponding plutonium absorptions. Examination of Figures 4.6 and 4.7 and Table 3.3 leads to the conclusion that selection of an appropriate wavelength should lead to excitation of a given plutonium ion band in the 480 to $660-\mathrm{nm}$ photochemical spectral range, with minimal light loss due to neptunium absorption.

The rare earth ions $\mathrm{Pr}^{3+}, \mathrm{Eu}^{3+}, \mathrm{Ho}^{3+}$, and $\mathrm{Nd}^{3+}$ each have several sharp bands in the 480 to $600-\mathrm{nm}$ range, with $\varepsilon^{\prime}$ s below $6 \underline{M}^{-1} \mathrm{~cm}^{-1}$ (Figure 4.12). The $\mathrm{Pm}^{3+}$ ion (Figure 4.11) has three sharp bands at 500, 540, and $560 \mathrm{~nm}$ that are of equal intensity and have an $\varepsilon$ value of $12 \underline{M}^{-1} \mathrm{~cm}^{-1}$. The lanthanide bands do not cause significant light losses and can readily be minimized by selecting appropriate excitation wavelengths. Thus, as far as Purex process solutions are concerned, the plutonium bands in the 480 to $660-\mathrm{nm}$ photochemical spectral range can be utilized without removal of the other actinides or lanthanides.

For the plutonium photochemical spectral range from 660 to 1100 nm the only interfering absorbing species are the actinides and lanthanides. Figure 4.7 shows that $N p(V)$ has an $\sim 50-n m-w i d e$ band (at the base) at $983 \mathrm{~nm}$, with an $\varepsilon$ of $325 \underline{\mathrm{M}}^{-1} \mathrm{~cm}^{-1}$. The $\mathrm{Np}$ (IV) ion has two strong bands at 723 and 965 $\mathrm{nm}$, with $\varepsilon^{\prime} \mathrm{s}$ of 126 and $160 \underline{\mathrm{M}}^{-1} \mathrm{~cm}^{-1}$ and base widths of $\sim 120$ and $\sim 100 \mathrm{~nm}$ respectively. Several small absorptions occur over this range, with $\varepsilon$ 's from 24 to $5 \underline{\mathrm{M}}^{-1} \mathrm{~cm}^{-1}$ (Table 4.2). Americium has a band at $812 \mathrm{~nm}$ with an $\varepsilon$ of $65 \underline{\mathrm{M}}^{-1} \mathrm{~cm}^{-1}$ and a small peak at $1050 \mathrm{~nm}$ with an $\varepsilon$ of $5 \underline{M}^{-1} \mathrm{~cm}^{-1}$. As shown in Figure 4.12 and Table 4.4; the lanthanides have numerous bands over this 660 to 1100-nm photochemical spectral range but the $\varepsilon^{\prime} s$ are $\leq 7 \underline{M}^{-1} \mathrm{~cm}^{-1}$. Comparison of Figures 4.6 to 4.8 for this photochemical spectral range leads to the conclusion that the flexibility in wavelength selection, due to the number, position, and width of the plutonium ion bands, is more than adequate to excite a given plutonium 
ion, with little light loss due to interfering actinide or lanthanide absorption.

It is concluded that over the usable 480 to $1100-\mathrm{nm}$ plutonium photochemical spectral range the interfering absorptions due to the actinides and lanthanides can be circumvented by selecting appropriate exciting light wavelengths for the unaltered Purex solutions. The region from 480 to $660-\mathrm{nm}$ is not accessible for photolysis of the Purex solutions until the absorption of light by the $\mathrm{Pd}, \mathrm{Ru}$, and $\mathrm{Rh}$ ions has been reduced. The extent of depletion depends on the light loss level criteria.

4.5.3 The Neptunium Windows. The neptunium ions have three strong bands, 723, 965, and $983 \mathrm{~nm}$, and four moderate-intensity bands, 500, 590, 618, and 820 $\mathrm{nm}$, over the usable 480 to $1100-\mathrm{nm}$ photochemical spectral region, as can be seen from Figure 4.7 and Table 4.2 .

As discussed in section 4.5.2, the 480-nm limit is due to $U, P d$, $R u$, and $\mathrm{Rh}$ complexes making the Purex solutions opaque to light of shorter wavelength. Furthermore, the photochemical spectral range of the unaltered Purex solutions is from 660 to $1100 \mathrm{~nm}$ because of these three complexes. The reduction factor for the $\mathrm{Pd}, \mathrm{Ru}$, and $\mathrm{Rh}$ ions required to carry out photolysis of the $8 \times 10^{-4} \underline{\mathrm{M}} \mathrm{Np}$ (IV) solutions at $10 \%$ light loss ranges from $9 \times 10^{-2}$ to $7 \times 10^{-3}$ for the 480 to $660-\mathrm{nm}$ photochemical spectral range when $99 \%$ of the fission products are absent. As in the case of plutonium, by selecting appropriate exciting-light wavelengths it should be possible to photolyze a given Np(IV) band in the 480 to 660-nm region with minimal light loss due to $\mathrm{Am}$, $\mathrm{Pu}$, or lanthanide absorptions. The $\mathrm{Np}(\mathrm{V})$ band in the 660 to $1100-\mathrm{nm}$ range is at $983 \mathrm{~nm}$, with an $\varepsilon$ of $325 \underline{M}^{-1} \mathrm{~cm}^{-1}$. The $\mathrm{Np}(\mathrm{IV})$ ion has two strong bands at 723 and $965 \mathrm{~nm}$ with $\varepsilon^{\prime} \mathrm{s}$ of 126 and $160 \underline{M}^{-1} \mathrm{~cm}^{-1}$ respectively which sandwich a sma11 band at $820 \mathrm{~nm}$ whose 
$\varepsilon$ is $26 \underline{\mathrm{M}}^{-1} \mathrm{~cm}^{-1}$. Both the plutonium and rare earth ions have numerous bands throughout this region, as can be seen in Figures 4.6 and 4.12. Americium has a band at $812 \mathrm{~nm}$ with an $\varepsilon$ of $65 \underline{\mathrm{M}}^{-1} \mathrm{~cm}^{-1}$ that would interfere with the $\mathrm{Np}$ (IV) peak at $820 \mathrm{~nm}$. Comparison of band intensities and positions. leads to the conclusion that the 723 and $965-\mathrm{nm}$ bands can be used to excite the Np(IV) ion, with minimal light losses due to absorption by the plutonium and lanthanide complexes. Thus, over the usable 480 to $1100-\mathrm{nm}$ neptunium photochemical spectral range the interfering bands due to lanthanide and actinide complexes can be avoided by selecting appropriate exciting light wavelengths for the unaltered Purex solutions. 'l'he most usetul Np(IV) peaks tor carrying out photochemistry are at 723 and $965 \mathrm{~nm}$. The region from 480 to $660 \mathrm{~nm}$ cannot be used for photolysis until the light absorption of the $\mathrm{Pd}, \mathrm{Ru}$, and $\mathrm{Rh}$ ions has been reduced to the levels required by the light loss criteria.

4.5.4 The Americium Window. The Am(III) ion has one intense peak at 503 $\mathrm{nm}$, with an $\varepsilon$ of $300 \mathrm{M}^{-1} \mathrm{~cm}^{-1}$. A second peak at $812 \mathrm{~nm}$ has an $\varepsilon$ of $65 \underline{\mathrm{M}}^{-1} \mathrm{~cm}^{-1}$. As shown in Figure 3.1, americium and curium stay with the aqueous phase after step one of the Purex scheme and are thus separated from the U, Np, and Pu. The americium window is therefore concerned with the light losses due to ions in the aqueous fraction, which contains $99 \%$ of the fission products, $\sim 1.5 \%$ of the uranium and plutonium, and $5 \%$ of the neptunium. The intense Am(III) peak at $503 \mathrm{~nm}$ somewhat relaxes the requirements of the 480 to $660-\mathrm{nm} \mathrm{Pd}, \mathrm{Ru}$, and $\mathrm{Rh}$ reduction factor. Thus, for $10 \%$ light loss at $2 \times 10^{-3} \underline{M} \mathrm{Am}$ (III) excited at $503 \mathrm{~nm}$, the reduction factor ranges from $3 \times 10^{-2}$ to $3 \times 10^{-3}$ for the aqueous raffinate solution conditions. For solutions from which $99 \%$ of the $\mathrm{Pd}, \mathrm{Ru}$, and $\mathrm{Rh}$ have been removed and the Am(III) concentration is $2 \times 10^{-6} \underline{\mathrm{M}}$ (99.9\% recovery leve1), a $10 \%$ 1ight loss factor means a reduction factor in the $10^{-1}$ to $3 \times 10^{-3}$ range. 
The band at $812 \mathrm{~nm}$ will have interfering bands from $\mathrm{Np}(\mathrm{IV})$ and the plutonium ions having $\varepsilon^{\prime} \mathrm{s}<20 \underline{\mathrm{M}}^{-1} \mathrm{~cm}^{-1}$. The $\mathrm{Nd}^{3+}, \mathrm{Tm}^{3+}$, and $\mathrm{Dy}{ }^{3+}$ peaks in this region have $\varepsilon^{\prime} s \leq 7 \underline{M}^{-1} \mathrm{~cm}^{-1}$. Thus the $812-\mathrm{nm} \mathrm{Am}{ }^{3+}$ band has no large interfering absorptions, and it should be possible to excite $\mathrm{Am}^{3+}$ in unaltered aqueous raffinate solutions.

4.5.5 The Curium Windows. After the first wash step of the Purex cycle, $299 \%$ of the curium is in the aqueous raffinate, which contains $99 \%$ of the other fission products, $\sim 1.5 \%$ of the uranium and plutonium, and $\sim 5 \%$ of the neptunium. As shown in Figure 4.9, the $\mathrm{Cm}^{3+}$ ion has three sharp, usable bands at 375,381 , and $397 \mathrm{~nm}$. The peaks lie in the $\mathrm{UO}_{2}{ }^{2+}$ valley, where $\varepsilon$ is 6 to 3 $\underline{\mathrm{M}}^{-1} \mathrm{~cm}^{-1}$ and the solutions contain $\sim 10^{-2} \underline{\mathrm{M}} \mathrm{UO}_{2}{ }^{2+}$.

The palladium and rhodium complexes could also have absorption minima in this region, as shown in Figures 4.17 and 4.18 , with $\varepsilon$ 's of $\sim 2000$ and $25 \underline{\mathrm{M}}^{-1} \mathrm{~cm}^{-1}$ respectively. The lowest $\varepsilon$ for ruthenium ions found for this region is $21000 \underline{\mathrm{M}}^{-1} \mathrm{~cm}^{-1}$. The lanthanide bands in the region of the $\mathrm{Cm}$ (III) 375,381 , and 397-nm peaks are quite weak except for $\mathrm{Pm}^{3+}$, whose ultraviolet tail has an $\varepsilon$ of $50 \underline{\mathrm{M}}^{-1} \mathrm{~cm}^{-1}$ at $380 \mathrm{~nm}$.

The plutonium ions ${ }^{103,104}$ have ultraviolet absorption band tails extending above $350 \mathrm{~nm}$, as do the antimony ${ }^{68}$ and molybdenum ${ }^{37,109}$ complexes. The $\varepsilon^{\prime} \mathrm{s}$ at $350 \mathrm{~nm}$ for these ions range from 100 to $200 \underline{\mathrm{M}}^{-1} \mathrm{~cm}^{-1}$. Thus for 6.11 $\mathrm{x} 10^{-4} \underline{\mathrm{M}} \mathrm{Cm}(\mathrm{III})$ solutions with $1 \%$ light utilization, the reduction factor is w0.2 for the aqueous raffinate solutions in which the $397-\mathrm{nm}$ band is excited. At the other extreme the $\mathrm{Ru}, \mathrm{Pd}$, and $\mathrm{Rh} \varepsilon^{\prime} \mathrm{s}$ could be $3000,10,000$, and $95 \underline{M}^{-1}$ $\mathrm{cm}^{-1}$ respectively, yielding a reduction factor of $\sim 3 \times 10^{-2}$ for excitation of the 375 or $381-\mathrm{nm} \mathrm{Cm}$ (III) bands. 


\subsection{PHOTOCHEMICAL SEPARATION SCHEMES}

On the basis of the actinide photochemistry covered in section 2 , some photochemical process schemes are tentatively proposed. Emphasis is placed on photochemical reactions that either can be carried out on existing Purex solutions or involve additives that do not introduce process-interfering by-products. Schemes involving other types of additives are not ruled out, but keeping the chemical problems to a minimum seems the most sensible approach, given the limitations of existing actinide data.

The following photochemical schemes are speculative. There are important chemical differences between the Purex solutions and those in the literature. Thus several adjustable parameters in these acid systems need to be studied. The $\mathrm{pH}$, temperature, and ionic strength, for example, can significantly affect rates and yields.

- Since uranium is a major solution component (see Tables 3.1 and 3.2), actinide fractionating is accomplished, as shown in Figures 3.1 and 5.1 , by chemical procedures that remove the neptunium and plutonium ions from the process stream and leave $\mathrm{UU}_{2}{ }^{2+}$. However, the uranium photochemistry. could be used to carry out the plutonium reduction in step 2 of the Purex process as an alternative to the scheme presented in Figure 5.1. As discussed in section 3, Pu(IV) to (III) reduction was previous $\perp$ y carried out by using ferrous sulphamate, which leads to processing problems. The AGNS plant at Barnwell, S.C., will use an electrolytic procedure for this step: $U(V I)$ is reduced to $U(I V)$, which then thermochemically reduces $\mathrm{Pu}(\mathrm{IV})$ to $\mathrm{Pu}(\mathrm{III})$ and regenerates $\mathrm{U}(\mathrm{VI})$. . This reaction scheme can also be accomplished photochemically:

$$
\mathrm{U}(\mathrm{VI}) \frac{\mathrm{hv}}{\text { reductant }} \rightarrow \mathrm{U}(\mathrm{IV})
$$




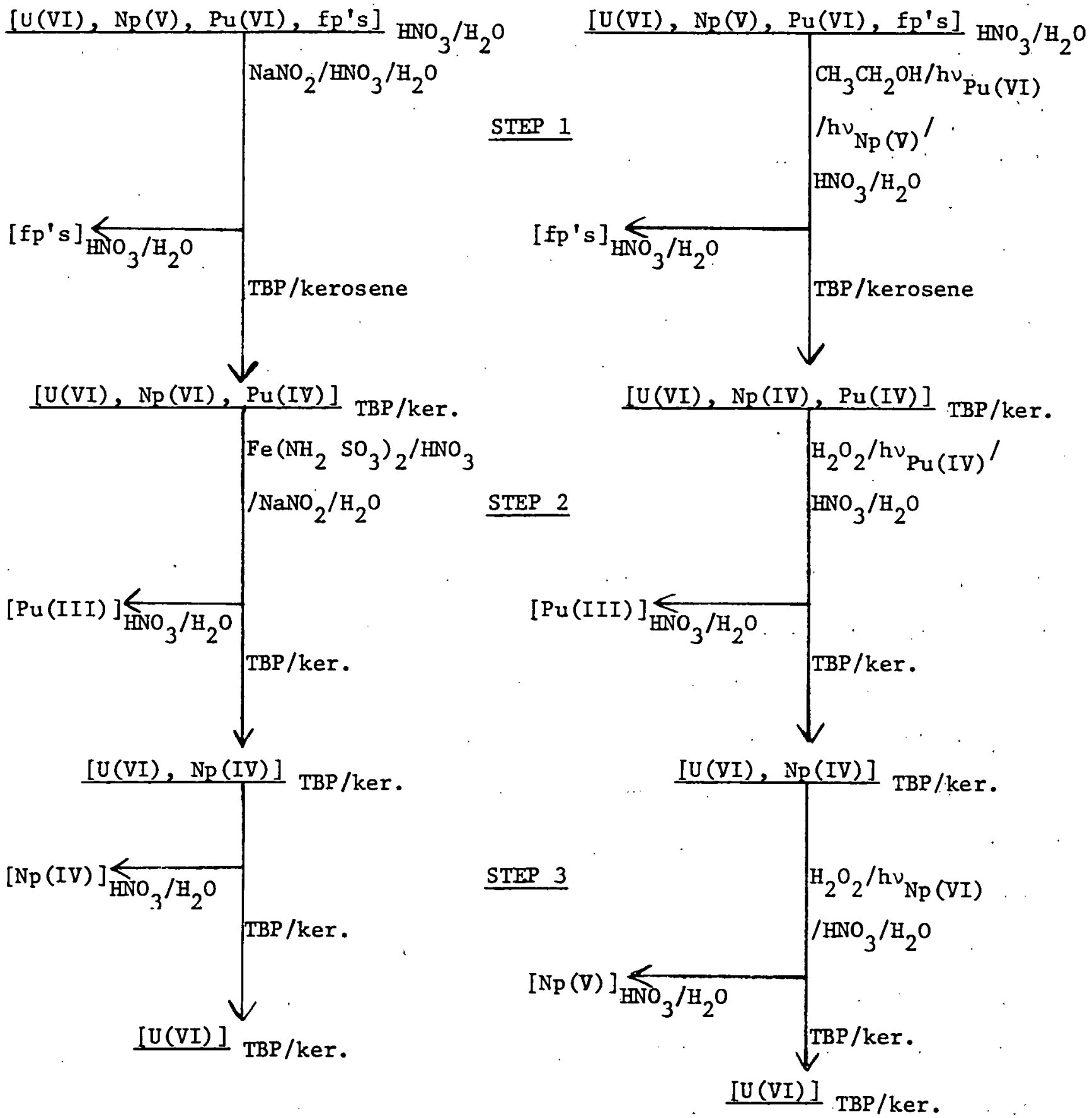

Figure 5.1. Comparison of a Purex and a proposed photochemical flow sheet. 


$$
\mathrm{U}(\mathrm{IV})+2 \mathrm{Pu}(\mathrm{IV}) \rightarrow \mathrm{U}(\mathrm{VI})+2 \mathrm{Pu}(\mathrm{III}),
$$

where the reductant can be an alcohol, carboxylic acid, or one of the other solutes discussed in section 2.1. The photochemical scheme has the advantage of not working with electrode systems in which mixing, contamination, and other operating problems arise.

On the basis of reactions 22 through 25 of section 2.2, a photochemical reaction scheme can be envisioned in which light is used to rapidly and quantitatively convert any mixture of $\mathrm{Np}(\mathrm{IV}), \mathrm{Np}(\mathrm{V})$, and $\mathrm{Np}(\mathrm{VI})$ to $\mathrm{Np}(\mathrm{IV})$ :

$$
\mathrm{Np}(\mathrm{IV})+\mathrm{Np}(\mathrm{V})+\mathrm{Np}(\mathrm{VI}) \frac{\mathrm{h \nu}}{1.5 \underline{\mathrm{M} \mathrm{HClO}}_{4} / 8.3 \% \mathrm{CH}_{3} \mathrm{CH}_{2} \mathrm{OH}} 33 \mathrm{~Np}(\mathrm{IV})
$$

This selective oxidation-state generation scheme could be incorporated into the Purex separation process. As "shown in Figure 5.1, photochemical generation of' Np (IV) would be incorporated in Purex step 1, where Np(IV) is partitioned to tributyl phosphate from high acid solutions. Having neptunium in the 4t oxidation state before Purex step. 2 reduces the amount of ferrous sulfamate required in this step; $\mathrm{i} . \mathrm{e}$. , only the $\mathrm{Pu}(\mathrm{IV})$ to $\mathrm{Pu}(\mathrm{III})$ reduction will occur, since the neptunium already exists as $\mathrm{Np}(\mathrm{IV})$.

Step 3 of the Purex process involves partitioning Np(IV) to the aqueous phase by washing the tributyl phosphate phase with low acidity solutions, while keeping the organic phase U(VI) concentration high. By utilizing the hydrogen peroxide photooxidation reaction 26 in Purex step 3 one can generate Np(V), which is insoluble in the tributyl phosphate and will therefore extract into the aqueous phase. This separation via $\mathrm{Np}(\mathrm{V})$ generation might negate the Purex processing requirement of high $U(V I)$ concentration. 
For molar or higher nitric acid solutions containing urea, according to photochemical reactions 29 and 30, a mixture of neptunium valence states can be quantitatively converted to $N p(V I)$. Quantitative extraction into tributyl phosphate of neptunium as $\mathrm{Np}(\mathrm{VI})$ from this photochemical reaction mixture should be possible. ${ }^{31}$ Such a reaction scheme could have value in step 1 of the Purex process.

In nitric acid solutions, $\mathrm{Np}(\mathrm{V})$ appears to be photochemically stable when subjected to irradiation by a mercury-quartz lamp. Using such a light source and combining reactions 27,28 and/or $31, \mathrm{~Np}(\mathrm{~V})$ can be rapidly and selectively generated in step 3 of the Purex process for extraction into the aqueous phase. This process modification, shown in Figure 5.1, where $1.5 \mathrm{M}$ nitric acid solutions containing $\geq 0.1 \%$ hydrogen peroxide are used, has the advantage of utilizing unmodified Purex solutions.

The plutonium photochemical reactions in section 2.3 suggest several schemes that selectively generate a given plutonium ion. The present thermochemical Purex extraction has difficulties with nitric acid and sodium nitrate losses, $\mathrm{pH}$ and $\mathrm{NO}_{2}{ }^{-}$ion control, and loss of plutonium to the aqueous fission product fraction. The following photochemical alternatives, it is hoped, will eliminate the nitrite problems, lessen the $\mathrm{pH}$ control problem, and lower the loss of plutonium.

By adding ethanol, $\mathrm{Pu}(\mathrm{VI})$ can be photoreduced to $\mathrm{Pu}(\mathrm{IV}) \cdot$ in aqueous $\mathrm{ni}-$ tric acid (reaction 33), which suggests that the existing Purex process might be improved by adding a photochemical step. Introducing $\mathrm{Pu}(\mathrm{VI})$ exciting light Into the first step of the Purex process, to which ethanol has been added, might improve the efficiency of $\mathrm{Pu}(\mathrm{IV})$ extraction into the TBP phase and thereby decrease the.plutonium contamination of the fission product fraction. Alter- 
natively, as shown in Figure 5.1, the addition of sodium nitrate could be eliminated by adding alcohol and carrying out the $\mathrm{Pu}(\mathrm{VI})$ to $\mathrm{Pu}(\mathrm{IV})$, and $\mathrm{Np}(\mathrm{V})$ to Np(IV) photochemistry suggested by reactions 33 and 25 respectively:

$$
\begin{aligned}
& \mathrm{Pu}(\mathrm{VI}) \underset{\mathrm{CH}_{3} \mathrm{CH}_{2} \mathrm{OH}}{\stackrel{\mathrm{hu}}{\mathrm{OIV}}),} \\
& \mathrm{Np}(\mathrm{V}) \underset{\mathrm{CH}_{3} \mathrm{CH}_{2} \mathrm{OH}}{\stackrel{\mathrm{hv}}{\mathrm{Np}}(\mathrm{IV})} .
\end{aligned}
$$

In the second step of the Purex process shown in Figure 5.1, plutonium is the first actinide extracted from the tributyl phosphate solution. This is accomplished by thermochemical reduction of $\mathrm{Pu}(\mathrm{IV})$ to $\mathrm{Pu(III)}$ by ferrous sulfamate, which results in byproducts that introduce solid waste and recycling problems. By carrying out the photochemical $\mathrm{H}_{2} \dot{U}_{2}$ reduction of $\mathrm{Pu}$ (IV) shown in Figure 5.1, these problems can be avoided.

The mechanism of the perchloric acid - plutonium system has been studied in detail. The results show that the photochemistry holds promise for selective plutonium ion generation but involves complex sets of reactions. Thus, in the Purex process shown in Figure 5.1, photochemical Pu(III) generating schemes based on known photoreactions 36 and 37 can be envisioned. However, the desired optimal reaction conditions are not known and cannot be readily extrapolated from present data because of the complexity of the photochemistry. The plutonium photochemical reactions should be studied further and in more detail in the various acid media, since the known photochemistry shows potential for separating actinides by selective adjustment of valences.

The nitric acid photochemistry oyotcmo are morc directly related to the Purex.scheme, since the process aqueous solvent is a nitric acid solution. As 
shown in Figure 5.1, by carrying out the hydrogen peroxide photoreduction of $\mathrm{Pu}(\mathrm{IV})$ to $\mathrm{Pu}(\mathrm{III})$ (reaction 40 ), the Purex byproducts and recycling problems might be eliminated. Ihe addition of hydrogen peroxide to $\mathrm{Pu}$ (IV) solutions results in a bonus. Complexing by $\mathrm{H}_{2} \mathrm{O}_{2}$ leads to plutonium species having moderately strong absorption peaks in the 490-nm region, with $\varepsilon^{\prime}$ s in the 300 to 500 range. ${ }^{103}$ Thus another important parameter of the actinide photochemistry is the extent to which added photochemical reagents alter the absorption spectra. The uranyl ion shows only minor changes upon altering the complexing ligands. ${ }^{1}$ Plutonium ions, on the other hand, show significant spectral changes for some complexes. 103

The above photochemical schemes pertain to modifications of the existing Purex process. The use of photochemistry to separate the last fraction of actinides from the high and low-level waste streams should also be explored. In any commercial separation scheme the ideal thermodynamic reaction conditions cannot be attained because of the finite process time requirements. In fact, one problem in the Purex thermochemical schemes is that the rates of reaction tend to be slow. 23,52 The much faster photochemical reaction rates should lead to improved redox yields and thereby increase the extraction efficiencies. Thus, 99. $9 \%$ actinide recovery levels might be attained by photochemically processing the aqueous raffinate solutions having low actinide concentrations. That is, by taking advantage of the faster approach to equilibrium for photochemical systems, it may be possible to meet the actinide recovery requirements for 1000-year waste discussed in section 3 .

In more general terms the use of photochemistry to fractionate the actinides could reduce the solvent requirements and thermochemical limitations. At present, Purex processing is limited by solution parameters such as $\mathrm{pH}$, solute 
shown in Figure 5.1, by carrying out the hydrogen peroxide photoreduction of $\mathrm{Pu}(\mathrm{IV})$ to $\mathrm{Pu}($ III) (reaction 40), the Purex byproducts and recycling problems might be eliminated. The addition of hydrogen peroxide to $\mathrm{Pu(IV)}$ solutions results in a bonus. Complexing by $\mathrm{H}_{2} \mathrm{O}_{2}$ leads to plutonium species having moderately strong absorption peaks in the 490-nm region, with $\varepsilon^{\prime}$ 's in the 300 to 500 range. ${ }^{103}$ Thus another important parameter of the actinide photochemistry is the extent to which added photochemical reagents alter the absorption spectra. The uranyl ion shows only minor changes upon altering the complexing 1igands. ${ }^{1}$ Plutonium ions, on the other hand, show significant spectral changes for some complexes. 103

The above photochemical schemes pertain to modifications of the existing Purex process. The use of photochemistry to separate the last fraction of actinides from the high and low-level waste streams should also be explored. In any commercial separation scheme the ideal thermodynamic reaction conditions cannot be attained because of the finite process time requirements. In fact, one problem in the Purex thermochemical schemes is that the rates of reaction . tend to be slow. 23,52 The much faster photochemical reaction rates should lead to improved redox yields and thereby increase the extraction efficiencies. Thus, 99.9\% actinide recovery levels by photochemically processing the aqueous raffinate solutions having low actinide concentrations. That is, by taking advantage of the taster approach to equilibrium for photochemlcal syscems, It may be possible to meet the actinide recovery requirements for 1000-year waste discussed in section 3 .

In more general terms the use of photochemistry to fractionate the actinides could reduce the solvent requirements and thermochemical limitations. At present, Purex processing is limited by solution parameters such as $\mathrm{pH}$, solute 
concentration, and extractant concentration as we11 as by kinetic and equilibrium constraints. The photochemical systems either require no solute or have solute thresholds above which the photochemistry yields are constant. Similarly, the quantum yields also display $\mathrm{pH}$ thresholds. Thus a range is replaced by a lower limit, which should relax process control requirements. The loss of the TBP extractant to the aqueous phase can be decreased if the photochemistry can be carried out at lower acid concentrations. Furthermore, it may be possible to substitute a different organic extractant for the tributyl phosphate by adding organic complexing ligands to the aqueous phase which would not interfere with the photochemical redox reactions but would improve actinide extraction. This new extractant could then be less polar, would therefore extract less nitric acid than the tributyl phosphate, and thus would alleviate the acid loss problems.

Before any actinide photochemical processing scheme can be practically evaluated, experimental work must be done on solutions under conditions relevant to those existing in Purex process streams. The aim of the above discussion has been to point out that, on the basis of the data in the literature, potentially useful photoredox reactions exist and should be invest1gated further.

\subsection{CONCLUSIONS AND FUTURE RESEARCH}

The net results of this feasibility study are the defining of the known photochemistry and the identification of problems that might limit the usefulness of photochemical processing of nuclear waste solutions.

The extent to which the various ions found in the process stream quench excited actinfde cuinplexes must be determined. 
The spectral composition and properties of the processing solutions must be evaluated quantitatively in order to evaluate the actinide photochemical excitation windows.

The known actinide.photochemistry must be studied and quantified for solution conditions existing in reprocessing streams. The yields and any interfering thermochemistry must be studied.

In the present program the feasibility of using photochemistry in fractionating nuclear wastes has been qualitatively evaluated and it has been concluded that the approach has sufficient potential to warrant further study. Results from the experimental investigations propused above should makc it possible to quantitatively define the potential utility of photochemical processing in nuclear waste partitioning. 
REFERENCES

1. E. Rabinowitch and R. L. Belford, Spectroscopy and Photochemistry of Urany 1 Compounds, Pergamon Press, Oxford, 1964, and references therein.

2. H. D. Burrows and T. J. Kemp, Chem. Soc. Rev 3 , 139 (1974), and references therein.

3. R. J. Hill, T. J. Kemp, D. M. Allen, and A. Cox, J. Chem. Soc. Faraday Trans. I. $\underline{70}, 847$ (1974).

4. B. Sahoo and D. Patnaik, J. Indian Chem. Soc. 36, 483 (1959).

5. U. K. Das, S. K. Pujari, B. Sahoo, and D. Patnaik, Curr. Sci. 30, 380 (1961).

6. U. K. Das, B. Sahoo, and D. Patnaik, J. Indian Chem. Soc. 38, 843 (1961).

7. B. Sahoo and D. Patnaik, J. Indian Chem. Soc. 36, 135 (1959).

8. B. Sahoo and D. Patnaik, Curr. Sci. 27, 243 (1958).

9. K. K. Tripathy, B. Sahoo, and D. Patnaik, J. Indian Chem. Soc. 36, 739 (1959).

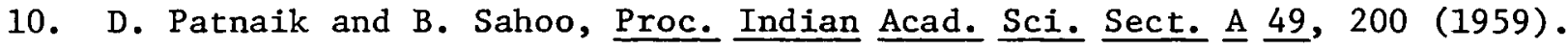

11. B. Sahoo and D. Patnaik, Curr. Sci. 28, 195 (1959).

12. B. Sahoo and D. Patnaik, Curr. Sci. 28, 16 (1959).

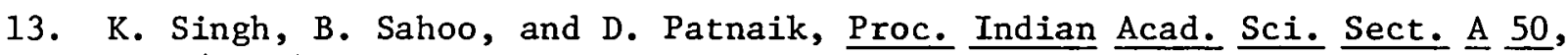
129 (1959).

14. B. Sahoo, Curr. Sci. 29, 16 (1960).

15. K. C. Satapathy and B. Sahoo, Curr. Sci. 36, 320 (1967).

16. U. K. Das and D. Patnaik, Chem. Ind. London, No. 14, 699 (1973).

17. W. M. Riggs, Ana. Chem. 44, 390 (1972).

18. J. T. Bell and S. R. Buxton, J. Inorg. Nucl. Chem. 36, 1575 (1974).

19. J. T. Bell and L. R. Buxton, J. Inorg. Nucl. Chem. 37, 1469 (1975).

20. J. T. Bel1 and M. R. Billings, J. Inorg. Nuc1. Chem. 38, 831 (1976).

21. D. M. Allen, H. D. Burrows, A. Cox, R. J. Hill, T. J. Kemp, and.T. J. Stone J. Chem. Soc. Chem. Commun., 59, (1973). 
22. J. T. Bell, H. A. Friedman, and M. R. Billings, J. Inorg. Nucl. Chem. 36, $2563(74)$.

23. T. W. Newton, The Kinetics of the Oxidation-Reduction Reactions of Uranium, Neptunium, Plutonium and Americium in Aqueous Solutions, ERDA Critical Review Series, TID-26506, 1975.

24. Y. LeDuigou and W. Leidert, Z. Anal. Chem. 278, 29 (1976).

25. S. Sakuraba and R. Matsushima, Bul1. Chem. Soc. Jpn 43, 2359 (1970).

26. R. Matsushima and S. Sakuraba, J. Am. Chem. Soc. 93, 5421 (1971).

27. R. Matsushima and S. Sakuraba, J. Am. Chem. Soc. 93, 7143 (1971).

28. R. Matsushima, J. Am. Chem. Soc. 94, 6010 (1972).

29. J. L. Kropp, J. Chem. Phys. 46, 843 (1967).

30. A. A. Nemodruck, E. V. Bezrogova, S. A. Ivanova, and Yu P. Novikov, Zh. Ana1. Khim. 27, 73 (1972).

31. A. A. Nemodruck, E. V. Bezrogova, S. A. Ivanova, and Yu P. Novikov, Zh. Anal. Khim. 27, 2414 (1972).

32. P. F. Palei, A. A. Femodruk, and E. V. Bezrogava, Radiochimiya 11, 300 (1969).

33. A. S. Ghosh Mazumdar and C. K. Sivaramakrishnan, J. Inorg. Nuc1. Chem. 27, 2423 (1965).

34. D. A. Costanyo, R. E. Biggers, and J. T. Bell, J. Inorg. Nuc1. Chem. 35, 609 (1973).

35. J. T. Bel1 and H. A. Friedman, J. Inorg. Nucl. Chem. 38, 831 (1976).

36. L. L. Burger, I. M. Rehn, and C. M. Slansky, Properties of the System Urany1 Nitrate-Aluminium Nitrate-Nitric Acid-Water-Hexone, Part VII, HW-19949, 1952.

37. A. W. Adamson, W. L. Waltz, E. Zinato, D. W. Watts, P. D. Fleischauer, and R. D. Lindholm, Chem. Rev. 68, 541 (1968).

38. A. W. Adamson and P. D. Fleischauer, Concepts of Inorganic Photochemistry, Wiley, New York, 1975.

39.. M. Koyama, Y. Kanchiku, and T. Fujenaga, Coord. Chem. Rev. $\underline{3}$, 285 (1968).

40. P. C. Ford, J. D. Petersen, and A. E. Hintzc, Coord. Chem. Rev. 14, 67 (1974).

41. R. P. Craig and N. Davidson, J. Am. Chem. Soc. $\underline{73}, 1951$ (1951). 
42. V. Balzani and V. Carassiti, Photochemistry of Coordination Compounds, Academic Press, New York, 1970.

43. T. W. Martin, A. Henshall, and R. C. Gross, J. Am. Chem. Soc. 85, 113 (1963).

44. T. W. Martin, R. E. Rummel, and R. C. Gross, J. Am. Chem. Soc. 86, 2595 (1964).

45. W. B. Kay, Chem. Rev. 60, 185 (1960).

46. E. Hayon and E. Sarto, J. Chem. Phys. 43, 4314. (1965).

47. M. Daniels, R. V. Meyers, and E. V. Belardo, J. Phys. Chem. 72, 389 (1968).

48. U. Shuali, M. Ottolenghi, J. Rabani, and V. Yelin, J. Phys. Chem. 73, 3445 (1969).

49. F. Barat, L. Gilles, B. Hickel, and J. Sutton, J. Chem. Soc. A, Pt. 2, 1982 (1970).

50. L. L. Burger and M. D. Money, Nitrous Acid Behavior in Purex Systems, HW-60278, 1959.

51. V. Balzani, L. Moggi, M. F. Manfrin, and F. Bolletta, Coord. Chem. Rev. 15, 321 (1975).

52. J. K. Thomas, Advances in Radiation Chemistry, Vol. 1, pp. 103-98, M. Burton and J. Magee, Editors, Wiley, New York, 1969.

53. A. 0. Allen, The Radiation Chemistry of Water and Aqueous Solutions, Van Nostrand, Princeton, N. J., 1961.

54. W. G. Burns and R. Barker, Progress in Reaction Kinetics, G. Porter, Vol. 3, pp. 303-68, Editor, Pergamon, New York, 1965.

55. E. J. Hart, Editor, Radiation Chemistry-I, Advances in Chemistry Series 81, 1968 .

56. G. Stein, in Radiatlun Cliemistry of Aqueous Systems, pp. 83-9, G. Stein, Editor, Wiley, New York, 1968.

57. C. Gopinathan, G. Stevens, and E. J. Hart, J. Phys. Chem. 76, 3698 (1972).

58. E. J. Hart, J. Am. Chem. Soc. $\underline{81}, 6085$ (1959).

59. G. Stein and M. Tomkiewicz, Trans. Faraday Soc. 67, 1678 (1971).

60. W. D. Bond and G. E. Leuze, Feasibility Studies of the Partitioning of Commercial High-Level Wastes Generated in Spent Nuclear Fuel Reprocessing: Annual Progress Report for FY-1974, ORNL-5012, 1975. 
61. Staff of Oak Ridge National Laboratory, Siting of Fuel Reprocessing Plants and Waste Management Facilities, ORNL-4451, 1970.

62. T. V. Healy and H. A. C. McKay, Trans. Faraday Soc. 52, 633 (1956).

63. J. L. Woodhead, J. Inorg. Nucl. Chem. 27, 1111 (1965).

64. W. E. Schuler, Nitric Acid Species in Tri-n-buty1 Phosphate Solutions, DP-513, 1960.

65. T. J. Collopy and J. F. Blum, J. Phys. Chem. 64, 1324 (1960).

66. F. A. Cotton and G. Wilkinson, Advanced Inorganic Chemistry, Interscience, New York, 1967.

6.7. R. S. Drago, Physical Methods in Inorganic Chemistry, Reinhold, New York, 1.967 .

68. .T. E. Whitney and N. Davidsoí, J. Am. Chem. Soc. ⒈, 3809 (1949).

69. G. E. Boyd, J. W. Cobble, C. M. Nelson, and W. T. Smith Jr., J. Am. Chem. Soc. 74, 556 (1952).

70. K. V. Kotegov, O. N. Pavlov, and V. P. Shvedov, in Advances in Inorganic Chemistry and Radiochemistry, Vol. 2, pp. 1-72, Editors H. J. Emeleus and A. G. Sharpe, Academic Press, N. Y., 1968.

71. L. J. Katzin, J. Chem. Phys. 18, 789 (1950).

72. C. I. Browne, R. P. Craig, and N. Davidson, J. Am. Chem. Soc. $\underline{73}, 1946$ (1951).

73. R. P. Craig and F. Davidson, J. Am. Chem. Soc. 73, 1951 (1951).

74. B. Z. Iofa, V. Van-sin, and M. Ridvan, Radiokhimiya $\underline{8}, 14$ (1966).

75. C. J. Hochanade1 and J. A. Ghormley, J. Chem. Phys. 21, 880 (195.3).

76. T. J. Sworski, Radiat. Res. 4, 483 (1956).

77. P. C. Stevenson and W. E. Nervik, The Radiochemistry of the Rare Earths, Scandium, Yttrium and Actinium, NAS-NS-3020, 1961.

78. M. A. E1'yashevich, Spertra of the Rare Earth3, AEC-tr-4403, 1961.

79. G. T. Seaborg, in The Transuranium Elements, p. 1492, G. T. Seaborg et a1., Editors, McGraw-Hi11, New York, 1949.

80. W. C. Griffith, The Chemistry of the Rarer Platinium Metals, Wiley (Interscience), New York, 1967. 
81. 0. E. Zvyagintsev, in Proc. Int. Conf. Peaceful Uses of Atomic Energy, Vol. 7, p. 169, UN, New York, 1956.

82. J. M. Fletcher and F. S. Martin, in Proc. Int. Conf. Peaceful Uses of Atomic Energy, Vo1. 7, p. 141, UN, New York, 1956.

83. J. S. Anderson and J. D. M. McConnel, J. Inorg. Nuclear Chem. 1, 371 (1955).

84. J. M. Fletcher, J. L. Jenkins, F. M. Lever, F. S. Martin, A. R. Powe11, and R. Todd, J. Inorg. Nuc1. Chem. 1, 378 (1955).

85. F. P. Gortsema and J. W. Cobble, J. Am. Chem. Soc. 83, 4317 (1961).

86. J. M. Fletcher, J. Inorg. Nucl. Chem. 8 , 277 (1958).

87. C. K. Jorgensen, Acta Chem. Scand. 10, 500 (1956).

88. W. Robb and G. M. Harris, J. Am. Chem. Soc. 87, 4472 (1965).

89. W. C. Wolsey, C. A. Reynolds and J. Kleinberg, Inorg. Chem. 2, 463 (1963).

90. C. K. Jorgensen, Acta Chem. Scand. 11, 151 (1957).

91. C. K. Jorgensen, Acta Chem. Scand. 11, 166 (1957).

92. R. D. Gillard and G. Wilkenson, J. Chem. Soc. 870 (1964).

93. C. K. Jorgensen, Mol. Phys. 2, 309 (1959).

94. S. C. Srivastava and L. Newman, Inorg. Chem. 6, 762 (1967).

95. D. Meyerstein and A. Treinin, Trans. Faraday Soc. 57, 2104 (1961).

96. K. L. McEwen, J. Chcm. Phys. 34, 547 (1961).

97. J. A. Friend and L. E. Lyons, J. Chem. Soc. 1572 (1959).

98. E. G. Vassian and W. II. Eberhardt, J. Phys. Chem. 62, 84 (1958),

99. G. N. Yakovlev and V. N. Kosyakov, in Proc. Int. Conf. Peaceful Uses of Atomic Energy, Vo1. 7, p. 363, UN, New York, 1956.

100. R. A. Penneman and T. K. Keenan, The Radiochemistry of Americium and Curium, NAS-NS-3006, 1960.

101. D. A. Costanzo, R. E. Biggers, and J. T. Bell, J. Inorg. Nucl. Chem. 35, 609 (1973).

102. J. C. Hindman, L. B. Magnnusson and T. J. La Chapelle, in The Transuranium Elements, p. 1039, G. T. Seaborg et al., Editors, McGraw-Hi11, New York, 1949. 
103. J. M. Cleveland, Coord. Chem: Rev. 5, 101 (1970).

104. M. Shiloh and Y. Marcus, The Chemistry of Trivalent Neptunium, Plutonium and Americium in Halide Solutions, IA-924, 1964.

105. J. T. Bell and R. E. Biggers, J. Mol. Spectros. 18, 247 (1965).

106. D. Campbe11, ORNL, Private communication. March, 1976.

107. R. E. Connick and C. R. Hurley, J. Am. Chem. Soc. 74, 5012 (1952).

108. J. L. Woodhead and J. M. Fletcher, J. Chem. Soc., 5039 (1961).

109. W. C. Wolsey, C. A. Reynolds, and J. Kleinberg, Inorg. Chem. 2, 463 (1963).

110. C. K. Jorgensen, Acta Chem. Scand. 10, 518 (1956). 